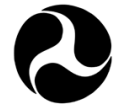

U.S. Department of Transportation

Federal Railroad Administration

\section{Improving Collision Post Crashworthiness of} Legacy Locomotives

Office of Research,

Development

and Technology

Washington, DC 20590

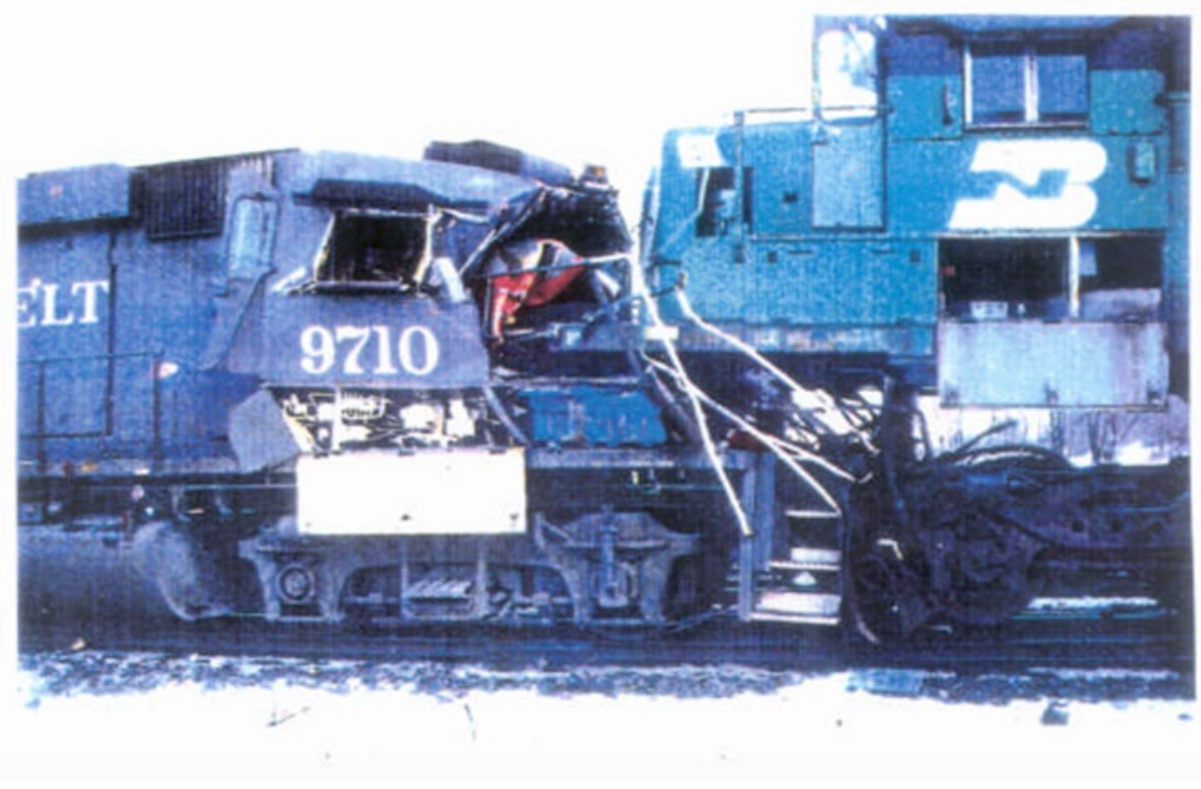

DOT/FRA/ORD-19/40

Final Report

October 2019 


\section{NOTICE}

This document is disseminated under the sponsorship of the Department of Transportation in the interest of information exchange. The United States Government assumes no liability for its contents or use thereof. Any opinions, findings and conclusions, or recommendations expressed in this material do not necessarily reflect the views or policies of the United States Government, nor does mention of trade names, commercial products, or organizations imply endorsement by the United States Government. The United States Government assumes no liability for the content or use of the material contained in this document.

\section{NOTICE}

The United States Government does not endorse products or manufacturers. Trade or manufacturers' names appear herein solely because they are considered essential to the objective of this report. 


\section{REPORT DOCUMENTATION PAGE}

\section{Form Approved OMB No. 0704-0188}

Public reporting burden for this collection of information is estimated to average 1 hour per response, including the time for reviewing instructions, searching existing data sources, gathering and maintaining the data needed, and completing and reviewing the collection of information. Send comments regarding this burden estimate or any other aspect of this collection of information, including suggestions for reducing this burden, to Washington Headquarters Services, Directorate for Information Operations and Reports, 1215 Jefferson Davis Highway, Suite 1204, Arlington, VA 22202-4302, and to the Office of Management and Budget, Paperwork Reduction Project (0704-0188), Washington, DC 20503.

\begin{tabular}{|l|c|c|}
\hline 1. AGENCY USE ONLY (Leave blank) & 2. REPORT DATE & October 2019 \\
\hline
\end{tabular}

3. REPORT TYPE AND DATES COVERED

Technical Report

April 2, 2015 to December 31, 2017

\section{TITLE AND SUBTITLE}

Improving Collision Post Crashworthiness of Legacy Locomotives

\section{AUTHOR(S)}

Sharma \& Associates, Inc.

\section{PERFORMING ORGANIZATION NAME(S) AND ADDRESS(ES)}

Sharma \& Associates, Inc.

100 W. Plainfield Road

Countryside, IL 60525

\section{SPONSORING/MONITORING AGENCY NAME(S) AND ADDRESS(ES)}

U.S. Department of Transportation Federal Railroad Administration

Office of Railroad Policy and Development

Office of Research, Development and Technology

Washington, DC 20590

11. SUPPLEMENTARY NOTES

COR: Jeffrey Gordon

\section{2a. DISTRIBUTION/AVAILABILITY STATEMENT}

This document is available to the public through the FRA website.

12b. DISTRIBUTION CODE

13. ABSTRACT (Maximum 200 words)

Modern locomotives are built to crashworthiness standards defined in Subpart D of Title 49 Code of Federal Regulations (CFR) Part 229 as well as the Association of American Railroads'(AAR) S-580 standards. Older locomotives, specifically the narrownose locomotives, were not designed to these crashworthiness standards and lack the crew protection offered by modern locomotives in case of train collisions. While these older locomotives have generally been relegated to non-lead locomotive service on several Class I railroads, it is not uncommon to see these units in mainline service. Though the number of these locomotives is decreasing, the fleet evolution trend for the next 13 years shows that a significant number of them will remain in service for the foreseeable future. Therefore, there remains a risk of injuries and fatalities for the crew.

This report analyzes the historical locomotive fleet evolution and accident data to estimate the residual risk of injuries and fatalities over the next 13 years from the legacy locomotives in service. Further, a typical legacy narrow-nose locomotive hood structure is analyzed to understand its behavior under the S-580 requirements. This analysis has led to the development of multiple concepts of collision post design for retrofit within the existing short hood space to provide crashworthiness protection which meets and exceeds the $2001 \mathrm{~S}-580$ requirements. The proposed designs are amenable to a retrofit with no impact on locomotive functionalities, bringing the legacy locomotives in compliance with crashworthiness requirements and minimizing the injury and fatality risk to the crew in a collision.

\begin{tabular}{|c|c|c|c|}
\hline & $\begin{array}{l}\text { 15. NUMBER OF PAGES } \\
58\end{array}$ \\
\hline \multicolumn{3}{|c|}{$\begin{array}{l}\text { 14. SUBJECT TERMS } \\
\text { Accidents, crashworthiness, collision-posts, crash protection, S-580, narrow- nose, fatalities }\end{array}$} & 16. PRICE CODE \\
\hline 17. SECURITY CLASSIFICATION & 18. SECURITY CLASSIFICATION & 19. SECURITY CLASSIFICATION & 20. LIMITATION OF ABSTRACT \\
\hline OF REPORT & OF THIS PAGE & OF ABSTRACT & \\
\hline Unclassified & Unclassified & Unclassified & \\
\hline JSN 7540-01-280-5500 & & & $\begin{array}{l}\text { Standard Form } 298(\text { Rev. } 2-89) \\
\text { scribed by ANSI Std. 239-18 } \\
-102\end{array}$ \\
\hline
\end{tabular}




\section{METRIC/ENGLISH CONVERSION FACTORS}

\begin{tabular}{|c|c|c|c|}
\hline \multicolumn{2}{|c|}{ ENGLISH TO METRIC } & \multicolumn{2}{|c|}{ METRIC TO ENGLISH } \\
\hline \multicolumn{2}{|c|}{ LENGTH (APPROXIMATE) } & \multicolumn{2}{|c|}{ LENGTH (APPROXIMATE) } \\
\hline 1 inch (in) & 2.5 centimeters $(\mathrm{cm})$ & 1 millimeter $(\mathrm{mm})$ & $=0.04$ inch (in) \\
\hline 1 foot (ft) & 30 centimeters $(\mathrm{cm})$ & 1 centimeter $(\mathrm{cm})$ & $=0.4$ inch (in) \\
\hline 1 yard (yd) & $=0.9$ meter $(\mathrm{m})$ & 1 meter $(\mathrm{m})$ & $=3.3$ feet $(\mathrm{ft})$ \\
\hline 1 mile (mi) & 1.6 kilometers $(\mathrm{km})$ & 1 meter $(m)$ & $=1.1$ yards $(y d)$ \\
\hline & & 1 kilometer $(\mathrm{km})$ & $=0.6 \mathrm{mile}(\mathrm{mi})$ \\
\hline AREA (APPROXIMATE) & & AREA (APPROXIMATE) & \\
\hline 1 square inch (sq in, in $\left.{ }^{2}\right)$ & 6.5 square centimeters $\left(\mathrm{cm}^{2}\right)$ & 1 square centimeter $\left(\mathrm{cm}^{2}\right)$ & $=0.16$ square inch $\left(\mathrm{sq} i n, \mathrm{in}^{2}\right)$ \\
\hline 1 square foot $\left(\mathrm{sq} \mathrm{ft}, \mathrm{ft}^{2}\right)$ & $=0.09$ square meter $\left(\mathrm{m}^{2}\right)$ & 1 square meter $\left(\mathrm{m}^{2}\right)$ & $=1.2$ square yards $\left(\mathrm{sq} y d, \mathrm{yd}^{2}\right)$ \\
\hline 1 square yard (sq yd, $\left.y^{2}{ }^{2}\right)$ & 0.8 square meter $\left(\mathrm{m}^{2}\right)$ & 1 square kilometer $\left(\mathrm{km}^{2}\right)$ & $=0.4$ square mile $\left(\mathrm{sq} \mathrm{mi}, \mathrm{mi}^{2}\right)$ \\
\hline 1 square mile (sq mi, mi²) & 2.6 square kilometers $\left(\mathrm{km}^{2}\right)$ & 10,000 square meters $\left(\mathrm{m}^{2}\right)$ & $=1$ hectare $(\mathrm{ha})=2.5$ acres \\
\hline 1 acre = 0.4 hectare (he) & 4,000 square meters $\left(m^{2}\right)$ & & \\
\hline \multicolumn{2}{|c|}{ MASS - WEIGHT (APPROXIMATE) } & \multicolumn{2}{|c|}{ MASS - WEIGHT (APPROXIMATE) } \\
\hline 1 ounce $(o z)$ & $=28$ grams $(\mathrm{gm})$ & 1 gram (gm) & $=0.036$ ounce $(\mathrm{oz})$ \\
\hline 1 pound (Ib) & 0.45 kilogram $(\mathrm{kg})$ & 1 kilogram (kg) & $=2.2$ pounds $(\mathrm{lb})$ \\
\hline $\begin{array}{l}1 \text { short ton }=2,000 \text { pounds } \\
\text { (lb) }\end{array}$ & 0.9 tonne $(t)$ & 1 tonne $(t)$ & $\begin{array}{l}=1,000 \text { kilograms }(\mathrm{kg}) \\
=1.1 \text { short tons }\end{array}$ \\
\hline \multicolumn{2}{|l|}{ VOLUME (APPROXIMATE) } & \multicolumn{2}{|c|}{ VOLUME (APPROXIMATE) } \\
\hline 1 teaspoon $(\mathrm{tsp})$ & 5 milliliters (ml) & 1 milliliter $(\mathrm{ml})$ & $=0.03$ fluid ounce $(\mathrm{fl} \mathrm{oz})$ \\
\hline 1 tablespoon (tbsp) & 15 milliliters (ml) & 1 liter (I) & $=2.1$ pints $(p t)$ \\
\hline 1 fluid ounce (fl oz) & 30 milliliters ( $\mathrm{ml}$ ) & 1 liter (I) & $=1.06$ quarts (qt) \\
\hline 1 cup $(c)$ & 0.24 liter (I) & 1 liter (I) & $=0.26$ gallon (gal) \\
\hline 1 pint (pt) & 0.47 liter (I) & & \\
\hline 1 quart (qt) & $=0.96$ liter $(\mathrm{I})$ & & \\
\hline 1 gallon (gal) & 3.8 liters (I) & & \\
\hline 1 cubic foot $\left(\mathrm{cu} \mathrm{ft}, \mathrm{ft}^{3}\right)$ & 0.03 cubic meter $\left(\mathrm{m}^{3}\right)$ & 1 cubic meter $\left(m^{3}\right)$ & $=36$ cubic feet $\left(\mathrm{cu} \mathrm{ft}, \mathrm{ft}^{3}\right)$ \\
\hline 1 cubic yard (cu yd, yd $\left.{ }^{3}\right)$ & 0.76 cubic meter $\left(\mathrm{m}^{3}\right)$ & 1 cubic meter $\left(m^{3}\right)$ & $=1.3$ cubic yards $\left(\mathrm{cu} y \mathrm{yd}, \mathrm{yd}^{3}\right)$ \\
\hline \multicolumn{2}{|c|}{ TEMPERATURE (EXACT) } & \multicolumn{2}{|c|}{ TEMPERATURE (EXACT) } \\
\hline$[(x-32)(5 / 9)]^{\circ} \mathrm{F}$ & $=\mathrm{y}^{\circ} \mathrm{C}$ & {$[(9 / 5) y+32]^{\circ} \mathrm{C}$} & $=x^{\circ} \mathrm{F}$ \\
\hline
\end{tabular}

\section{QUICK INCH - CENTIMETER LENGTH CONVERSION}

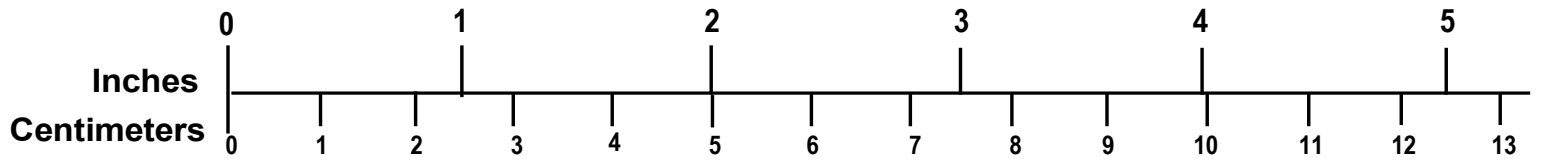

\section{QUICK FAHRENHEIT - CELSIUS TEMPERATURE CONVERSIO}

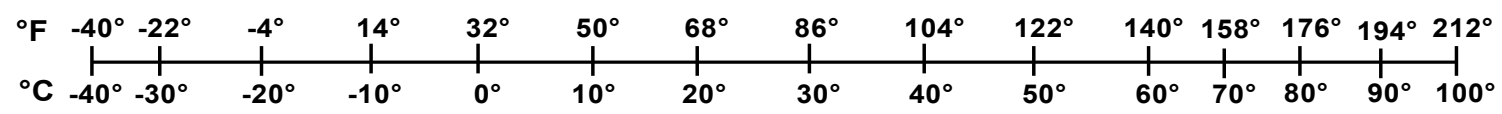

For more exact and or other conversion factors, see NIST Miscellaneous Publication 286, Units of Weights and Measures. Price \$2.50 SD Catalog No. C13 10286 


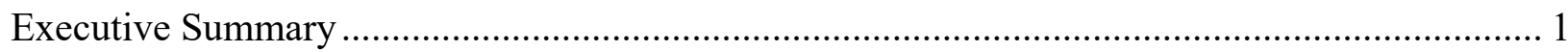

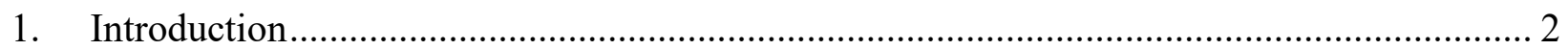

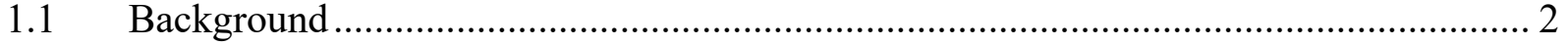

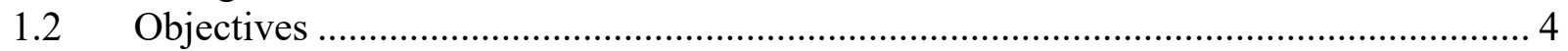

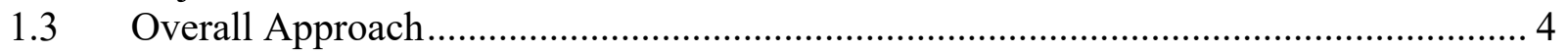

$1.4 \quad$ Scope

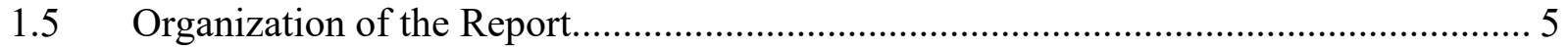

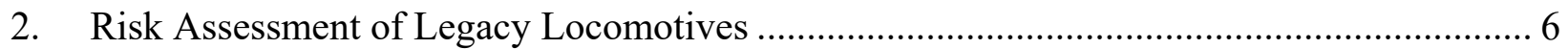

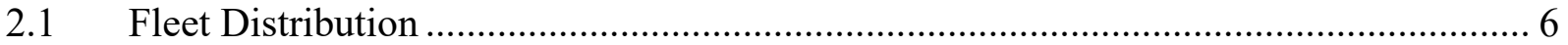

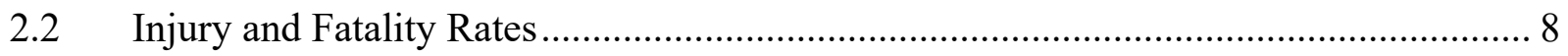

3. Evaluation of Baseline and Alternative Collision Post Designs ............................................ 14

3.1 Baseline Collision Post Crashworthiness Evaluation ................................................. 16

3.2 Evaluation of the Proposed Collision Post Designs to Meet 2001 Version of AAR S-

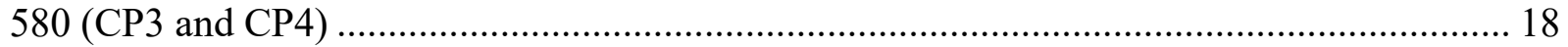

3.3 Evaluation of the Proposed Collision Post Design to Meet 2016 Version of AAR S-580

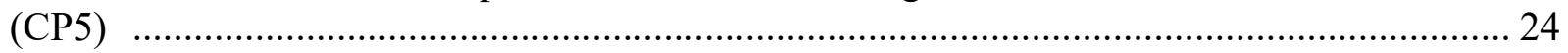

3.4 Weight Impact of Collision Post Design Alternatives ................................................... 28

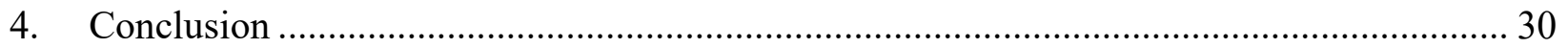

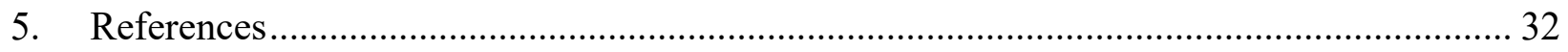

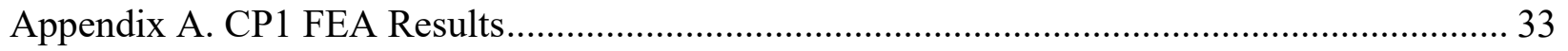

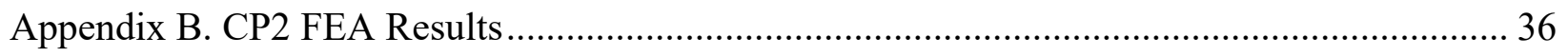

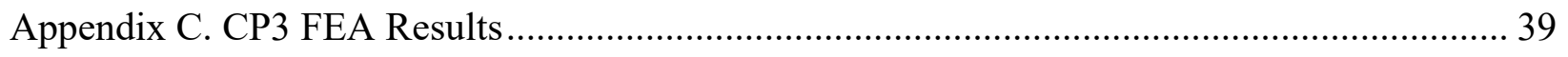

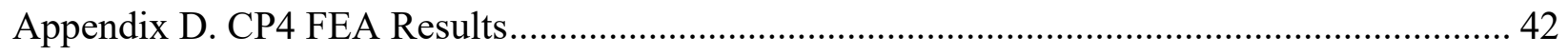

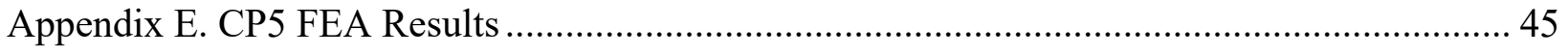

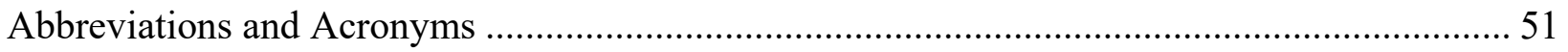




\section{Illustrations}

Figure 1. S-580 Evolution - Wide Nose Locomotives............................................................ 3

Figure 2. S-580 Evolution of Narrow-Nose Locomotives.......................................................... 4

Figure 3. Head-on Collisions and Fatalities, 2000-2014 ..................................................... 5

Figure 4. Legacy and S-580 locomotive Fleet in Class-I and Other Railroads ............................... 6

Figure 5. Mix of Legacy and S-580 Locomotives - Past Trend and Projected Growth................. 7

Figure 6. Revenue Trains and Collision Data-1990-2016 Class I and Non-Class-I Trains ........ 9

Figure 7. Fatalities Data-Legacy and Pre-2009 S-580 Locomotive Equipped Trains ................ 10

Figure 8. Injuries Data - Legacy and Pre-2009 S-580 Locomotive Equipped Trains................... 11

Figure 9. Fatalities and Injuries Data - Post 2008 S-580 Locomotive Equipped Trains............... 12

Figure 10. Estimated Fatalities and Injuries for 2017-2030 for Legacy Fleet .............................. 13

Figure 11. Narrow-Nose Locomotive used for FEA Model ...................................................... 14

Figure 12. FEA Model and Constraints for Baseline Locomotive Operator Cab......................... 15

Figure 13. Baseline Collision Post Designs................................................................................ 17

Figure 14. Baseline CP1 Stress Contour for LC01 ............................................................... 17

Figure 15. Baseline CP2 Stress Contour for LC01 .............................................................. 18

Figure 16. Collision Post CP3 (Tapered Steel Plate).................................................................... 19

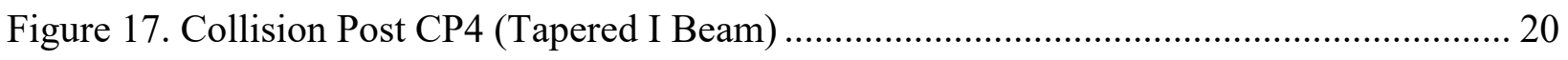

Figure 18. CP3 Stress Contour for LC01 ........................................................................ 21

Figure 19. CP4 Stress Contour for LC01 ………………..................................................... 21

Figure 20. CP3 Displacement Plot for LC04 (5X Magnification) ............................................... 22

Figure 21. CP4 Displacement Plot for LC04 (5X Magnification) .............................................. 22

Figure 22. Stiffness Comparison of Collision Posts for Load Case LC04 .................................. 23

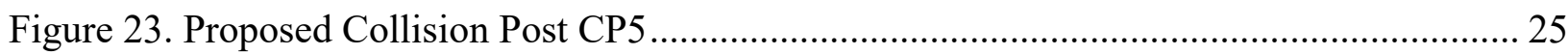

Figure 24. CP5 von Mises Stress Contour Under LC07 …….................................................. 26

Figure 25. CP5 von Mises Stress Contour Under LC10 ........................................................ 27

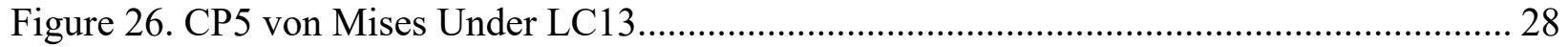

Figure 27. Weight Comparison of Collision Posts ................................................................. 29 


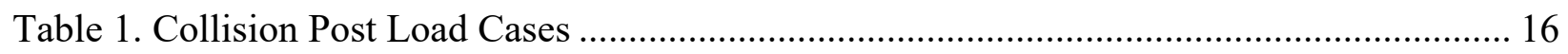

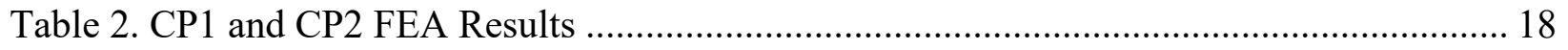

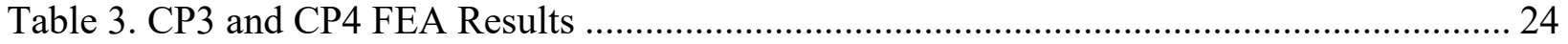

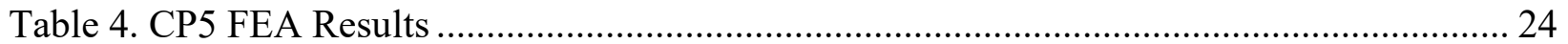




\section{Executive Summary}

The Federal Railroad Administration (FRA) contracted Sharma and Associates, Inc. to estimate the risk of injuries and fatalities under train collisions involving legacy locomotives built prior to the adoption of modern crashworthiness standards. Sharma and Associates, Inc. also investigated the crashworthiness of a sample legacy locomotive by conducting a finite element analysis (FEA) at the Sharma facility in Countryside, IL. According to the study that took place from April 2, 2015, to December 31, 2017, retrofitted collision posts of the sample legacy locomotive are expected to fail under load cases that are required by the crashworthiness standards. Two collision post designs were proposed to meet and exceed the 2001 version of the crashworthiness standards along with the third design that is expected to meet the 2016 version. Further testing of the proposed collision posts was recommended for the validation.

Modern locomotives are built to the crashworthiness standards that are defined in Subpart D of Title 49 Code of Federal Regulations (CFR) Part 229 and the Association of American Railroads' (AAR) S-580 standards. The original S-580 locomotive crashworthiness standard was released by the AAR in 1989 and became effective in 1990. As railroads continued to run longer and heavier trains, the standard has undergone revisions to maintain a level of safety for the locomotive cab occupants. Various levels of revisions to S-580 occurred in 1994, 2001, 2005, 2008, 2014, 2015, and 2016. AAR S-580 provides standards for the anti-climber, collision posts, corner posts, short hood structure, underframe, and truck attachment.

Locomotives that were manufactured before 1990, specifically the narrow-nose locomotives, were not designed to these crashworthiness standards and lack the crew protection in case of train collisions. While narrow-nose locomotives have generally been relegated to either switcher or non-lead locomotive service on several Class I railroads, it is not uncommon to see these units in mainline service, particularly on non-Class I lines. Though the number of these locomotives is decreasing, fleet evolution trends for the next 13 years shows that a significant number of them will remain in service for the foreseeable future. Therefore, there remains a risk of injuries and fatalities for the crew under train collisions. A review of the FRA accident database revealed that between 2000 and 2014, there were 114 head-on freight train collisions, or an average of about eight incidents per year. While most of these collisions did not result in fatalities (likely as a result of their cabs being S-580 compliant), the data revealed the exposure risk of the locomotive crew during such collisions. The consequences of such collisions could be significant for legacy locomotives.

Previous FRA sponsored studies to assess the crashworthiness of the locomotive cab showed that stronger collision posts provide the greatest benefit in terms of compliance with AAR S-580 requirements. 


\section{Introduction}

Modern locomotives are built to the crashworthiness standards that are defined in Subpart D of Title 49 Code of Federal Regulations (CFR) Part 229 and Association of American Railroads (AAR) S-580 standards. These standards include specific requirements for the anti-climber, underframe, collision post, corner post, short hood structure, and truck attachment. Older locomotives, specifically the narrow-nose locomotives, were not designed to these crashworthiness standards. Therefore, these older locomotives afford less crew protection in case of train collisions.

\subsection{Background}

The original S-580 locomotive crashworthiness standard was released by the AAR in 1989 and became effective in August, 1990 [1]. In September 1992, the Congress passed Public Law 102365 , requiring the U.S. Department of Transportation to conduct research and analysis to consider the costs and benefits of several types of crashworthiness improvement features [1]. The Federal Railroad Administration's (FRA) Rail Safety Advisory Committee (RSAC) Locomotive Crashworthiness Working Group (LCWG) was created in 1997 with participation from FRA, AAR, railroads, and labor unions, as well as several other institutions. The AAR crashworthiness standard S-580 was incorporated into U.S. Federal Regulations as CFR $§ 229.205$ and became effective January 1, 2009. The AAR S-580 Standard has evolved over the years and currently the 2016 version is in effect.

AAR S-580 governs the strength, geometry and attachments of the locomotive underframe, anticlimber, collision posts, corner posts, short hood skin and fuel tank. AAR S-580 evolved over time as follows:

- Anti-climber: The anti-climber was required to resist a 200,000-lb. vertical load until 2005. After 2005, anti-climbers were required to have an extent equal to $1 / 3^{\text {rd }}$ the width of the cab. The vertical force requirement was lowered to 100,000 lb. applied over a 12inch band anywhere along the anti-climber perimeter.

- Collision post: 1989, 1994 and 2001 versions of AAR S-580 required a minimum of two collision posts attached to the underframe longitudinal center sills. Each post was required to withstand $500,000 \mathrm{lb}$. at the underframe deck and 200,000 lb. at 30 inches above the deck. The size of the load application area and its angle relative to the longitudinal axis were not specified. In 2005, collision post strength requirements were tightened. For example, each collision post was required to withstand a 750,000-lb. load applied at any angle within \pm 15 from the longitudinal axis of the locomotive at the underframe deck.

- Corner Posts: The 2005 version of S-580 introduced corner post requirements for narrownose locomotives which are still in effect.

- Short Hood Structure: The 1989, 1994 and 2001 versions of AAR S-580 required a short hood skin equivalent to $1 / 2$ inch steel plate with 25,000 psi yield strength. In the 2005 version, the short hood structure was required to withstand a 400,000-lb. longitudinal load that is applied over a specified area at its upper corner. 
- Underframe: S-580 requires an underframe that must withstand a longitudinal load of $1,000,000 \mathrm{lb}$. applied at the inner draft stops without permanent deformation of the body structure.

- Truck Attachment: Since 2005, S-580 has required the truck to locomotive frame attachment to withstand an equivalent ultimate shear value of 250,000 lb. applied in line with the longitudinal centerline of the locomotive.

A summary of the evolution of S-580 is shown in Figure 1 and Figure 2 for the wide nose and narrow-nose locomotives, respectively. In this report, 2001 and $2005 \mathrm{~S}-580$ requirements, as given in Figure 2, were used to evaluate the baseline and modified collision post designs in the legacy narrow-nose locomotive. 2001 collision post requirements are the same with the original version of 1989. Modern crashworthy locomotives' collision posts are designed according 2005 version since collision post requirements have not changed since 2005 .

The legacy locomotives, such as narrow-nose designs that were manufactured before the 1990, have generally been relegated to non-lead locomotive service in Class I railroads. Several short lines have purchased narrow-nose locomotives that were being retired from Class-I service for use as mainline locomotives on their systems. As a result, these locomotives are likely to remain in the North American railroad fleet for the foreseeable future and pose risk to locomotive cab occupants.

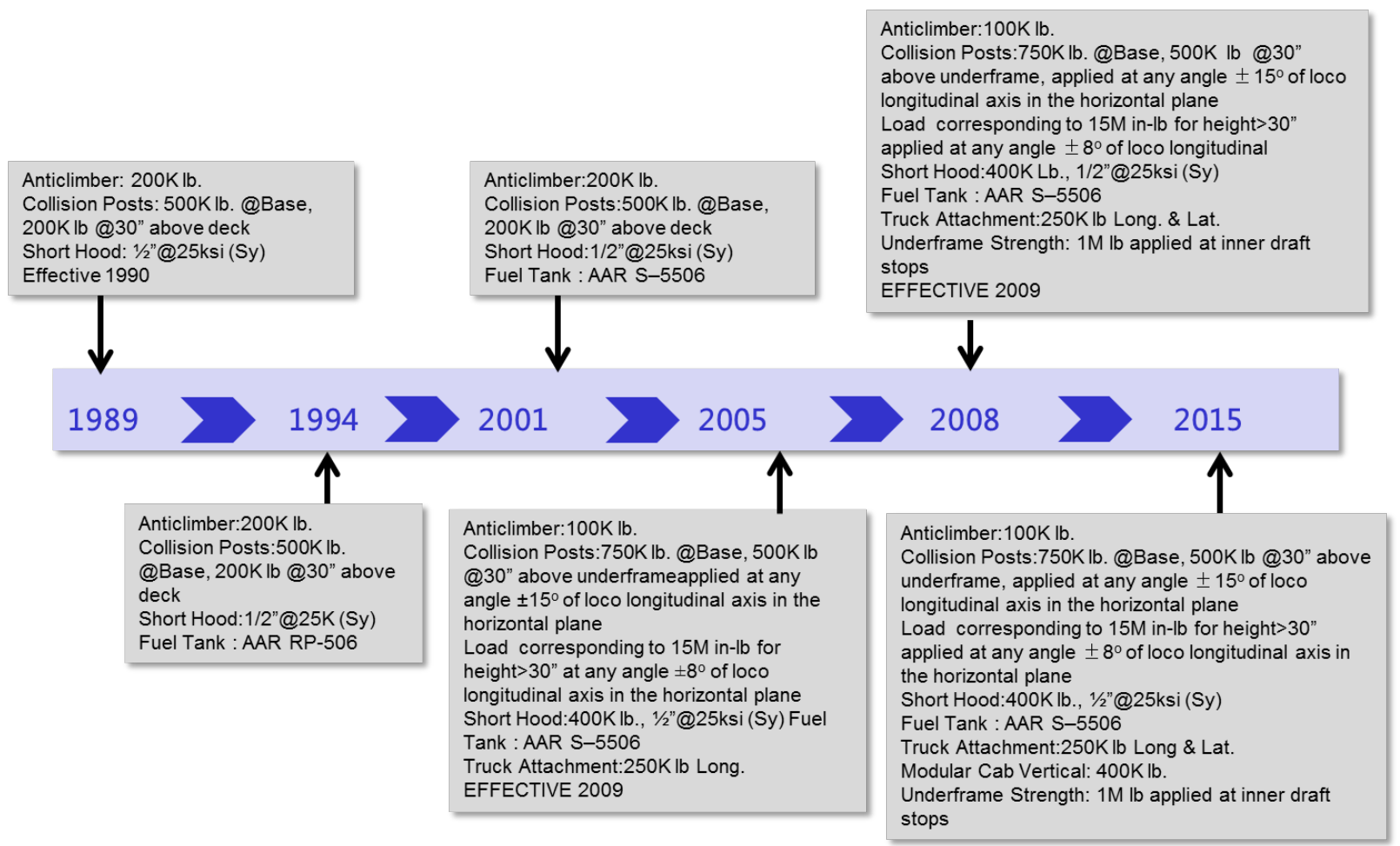

Figure 1. S-580 Evolution - Wide Nose Locomotives 


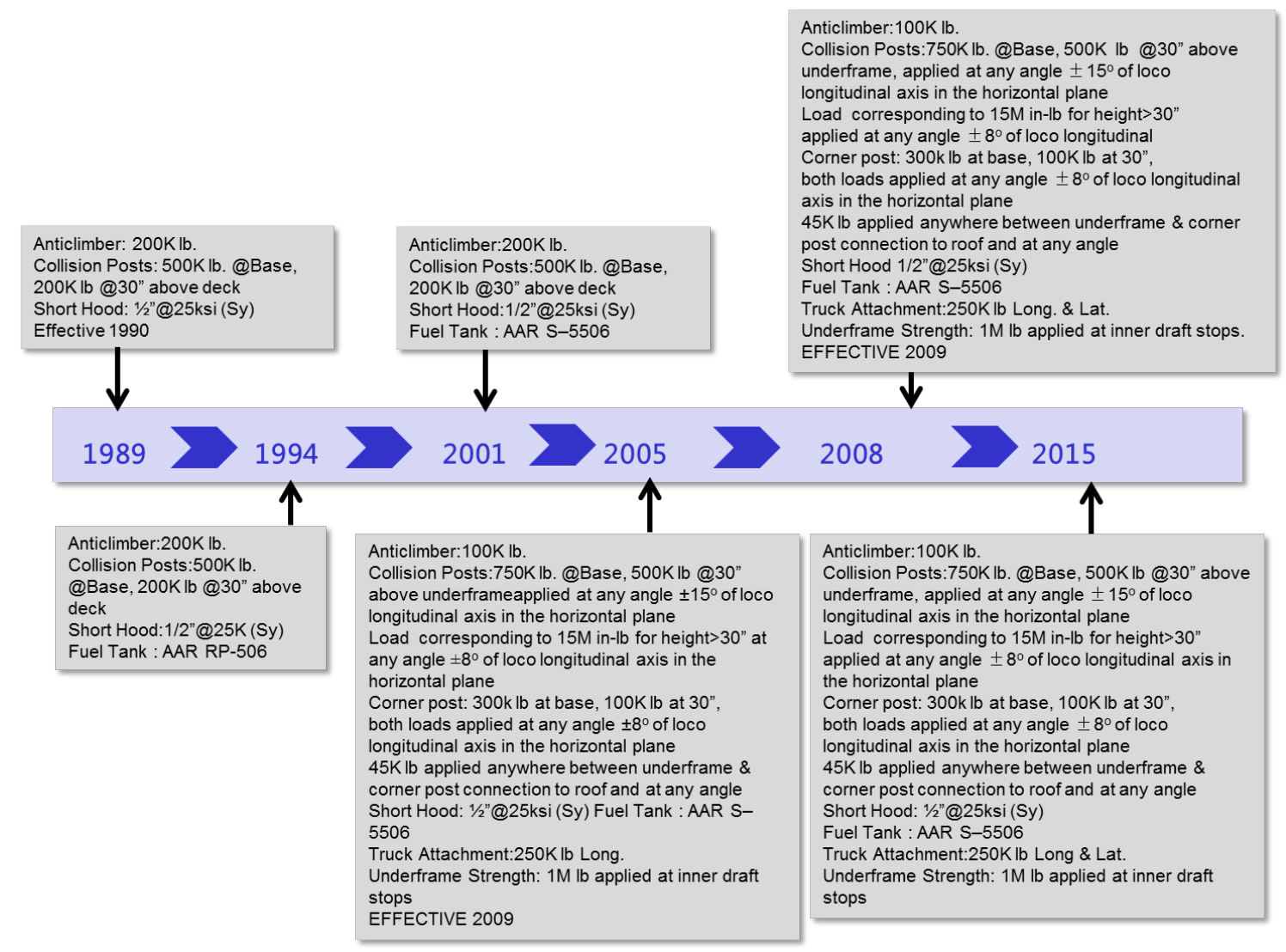

Figure 2. S-580 Evolution of Narrow-Nose Locomotives

\subsection{Objectives}

The following were the objectives of this report:

a) To conduct a risk assessment of the narrow-nose legacy locomotives involved in fatal collisions

b) To evaluate a collision post-crashworthiness of a narrow-nose legacy locomotive that was assembled in the 1960s and retrofitted with collision posts

c) To submit a proposal for alternative collision post designs and material thicknesses to meet and exceed the collision post requirements of AAR S-580 (2001 and 2005 versions)

\subsection{Overall Approach}

A review of the FRA accident database revealed that there were about 114 head-on freight train collisions between 2000 and 2014, or an average of about 8 incidents per year (see Figure 3). While most of these collisions did not result in fatalities (likely as a result of their cabs being S-580 compliant), the data revealed the exposure risk of the locomotive crew during such collisions. FRA developed computer models in order to assess the crashworthiness of the locomotive cab area [2]. An increase in the strength of the collision post was determined to provide benefits in terms of compliance with AAR S-580 requirements [3]. Based on the 
findings from these FRA efforts, this report focuses on the evaluation of retrofit collision post designs to improve the legacy locomotive crashworthiness.

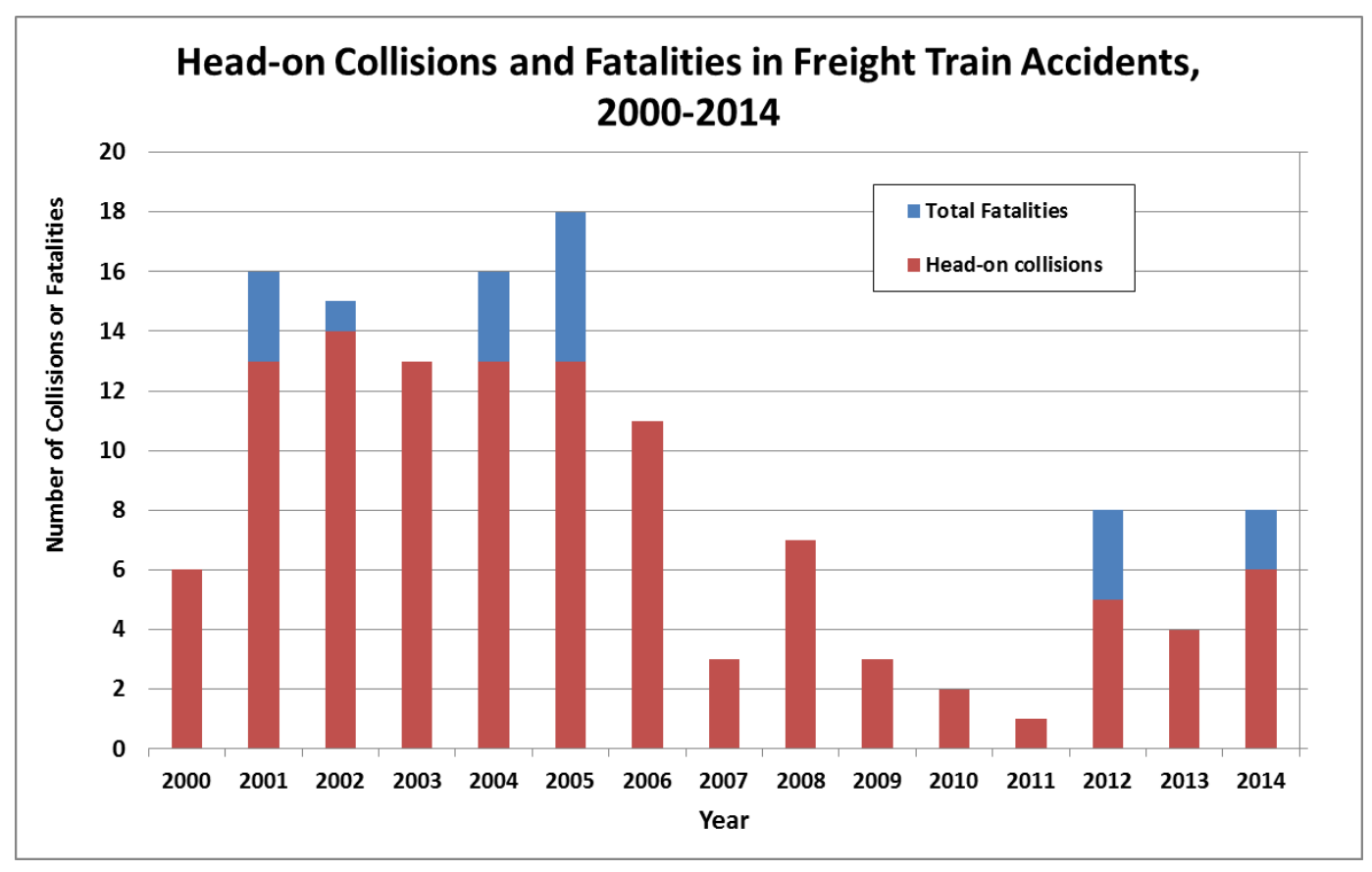

Figure 3. Head-on Collisions and Fatalities, 2000-2014

\subsection{Scope}

This study evaluates the risk exposure associated with the use of legacy locomotives in the US rail network. An investigation was conducted of the crashworthiness performance of a sample legacy locomotive that was manufactured in 1960s and retrofitted in 2001. All necessary measurements were taken. A three-dimensional computer-aided design (CAD) model was created in order to develop the finite element model (FEM). Load cases and boundary conditions were created on the basis of AAR S-580. Three different design options were developed by using the FEM in order to meet and exceed the AAR S-580 2001 and 2016 version. A test plan to evaluate the performance of design proposals is provided at the end of the report.

\subsection{Organization of the Report}

Section 2 of the report shows the risk assessment of injuries and fatalities under train collisions involving legacy locomotives. Section 3 describes the sample legacy locomotive, the FEM, crashworthiness performance of sample retrofit collisions posts. Section 3 also shows the proposed designs to meet and exceed the crashworthiness standards. Section 4 summarizes the work along with providing recommendations for future work. 


\section{Risk Assessment of Legacy Locomotives}

While narrow-nose locomotives have generally been relegated to switcher or non-lead locomotive service, current regulations do not prohibit these older units from being used in the lead position. Several short lines have purchased narrow-nose locomotives that were retired from Class-I service for use as mainline locomotives on their systems. As a result, these locomotives are likely to remain in the North American railroad fleet for the foreseeable future and pose risk to locomotive cab occupants.

\subsection{Fleet Distribution}

Risk of crew injuries and fatalities from legacy locomotives operating in collision situations was estimated based on data collected from the FRA accident database, and the National Transportation Safety Board's (NTSB) accident reports and other train traffic information [4] [5] [6]. The following data were gathered from these reports:

- The number of legacy locomotives in the current fleet including a breakdown between the Class-I railroads and short lines. The locomotives manufactured before 1990 were not built to AAR S-580 crashworthiness standards and are referred to as "legacy" locomotives in this report.

- The number of S-580 compliant locomotives built between 1990 and 2008. These are called "Pre-2009."

- The number of locomotives built between 2009 and 2016 compliant to the latest S-580. These locomotives are identified as "S-580 compliant" or "post S-580" in this report.

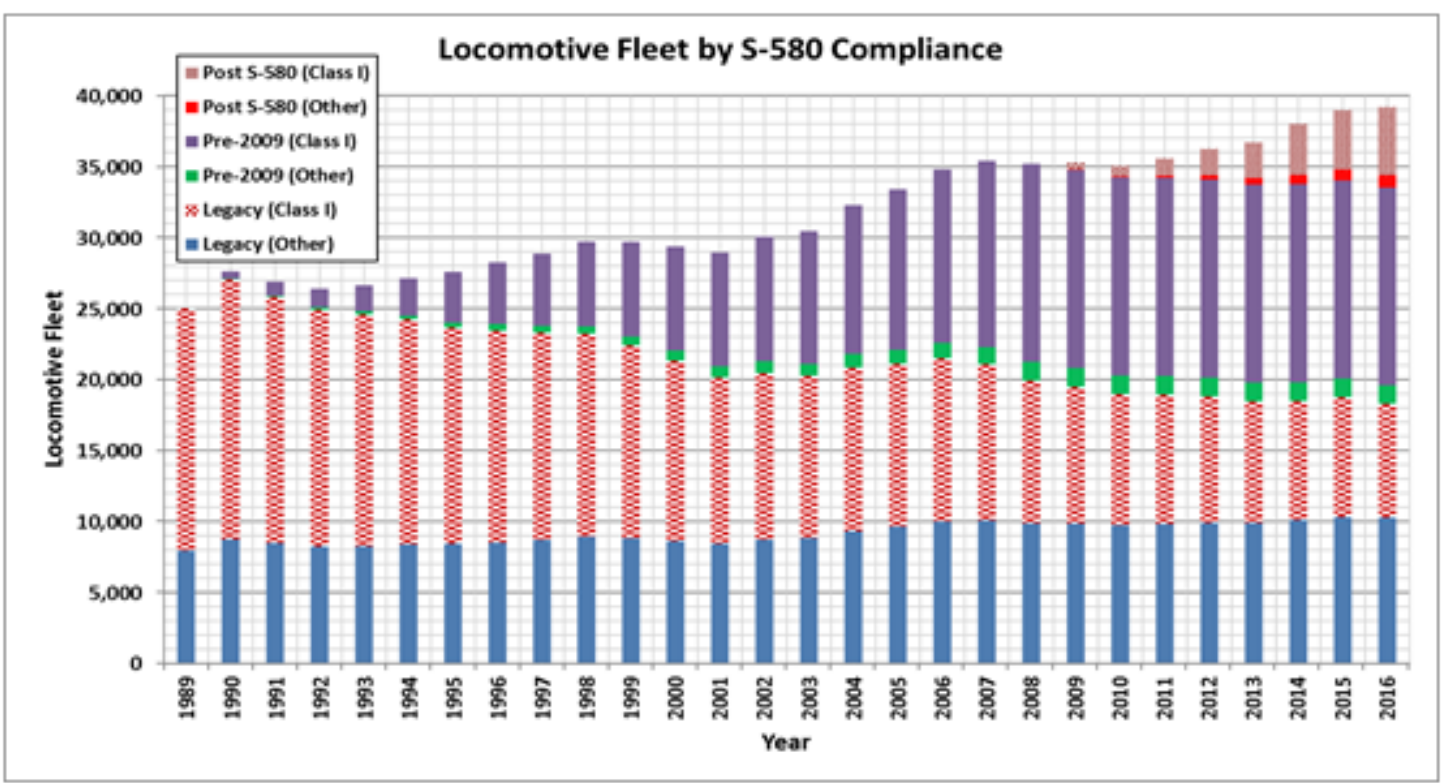

Figure 4. Legacy and S-580 locomotive Fleet in Class-I and Other Railroads 


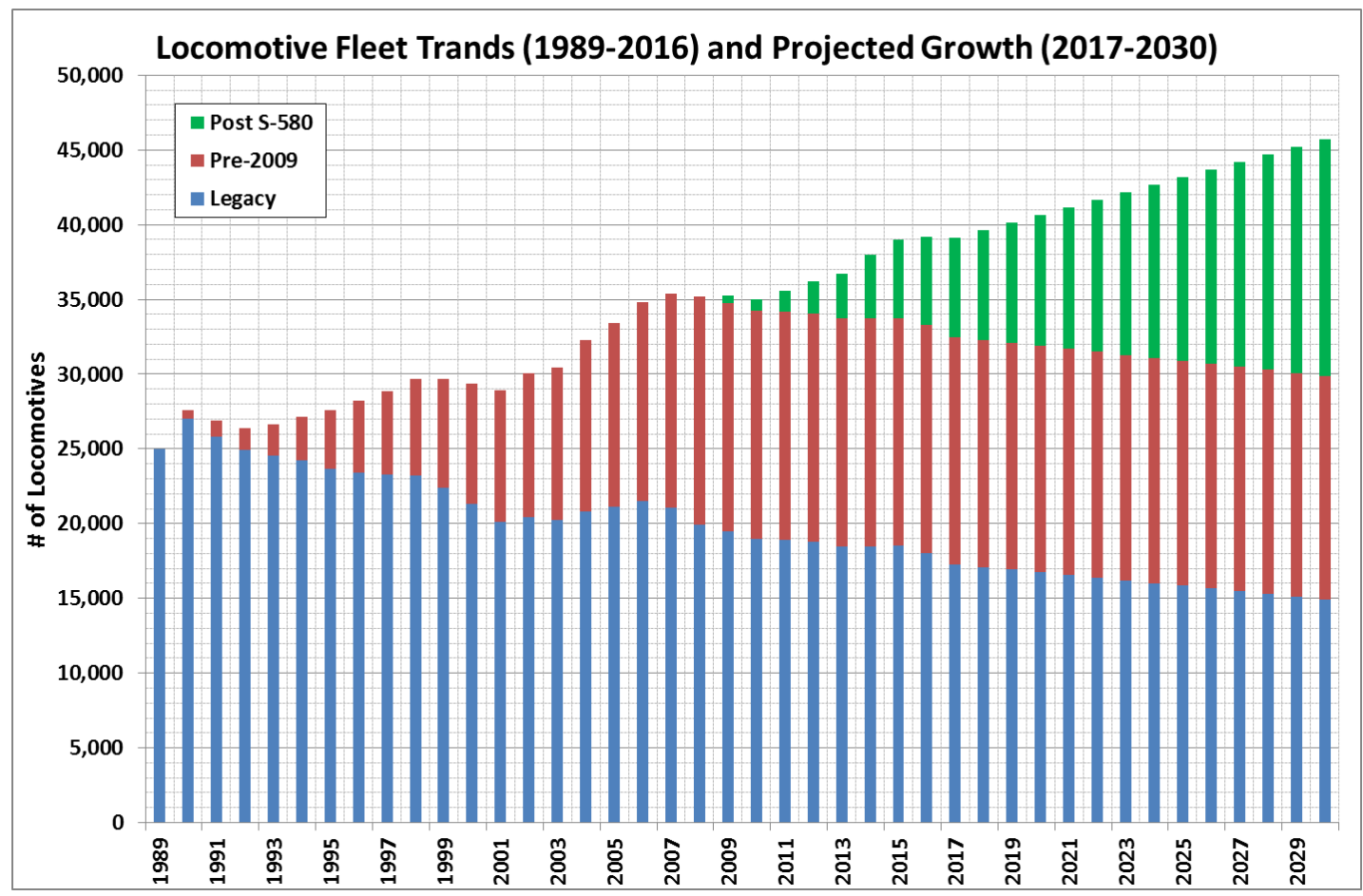

Figure 5. Mix of Legacy and S-580 Locomotives - Past Trend and Projected Growth

Figure 4 shows the locomotive fleet distribution as of 2016, in terms of compliance with S-580 standards for Class-I and other railroads. The non-Class I fleet data estimate for legacy locomotives was based on sample data queries from the UMLER ${ }^{\circledR}$ list [7]. The ratio of ownership of legacy locomotives between Class I and other railroads for the years between 1989 and 2016 was assumed to be the same as the 2014 value. The projected fleet distribution of S-580 compliant, pre-2009 and legacy locomotives for Class-I and other railroads is shown in Figure 5. The estimate for the 2017 to 2030 locomotive fleet is based on a linear regression fit of the fleet growth data from 1989 to 2016.

The following assumptions were made with respect to fleet and traffic estimates:

- Future percent growth estimate of the locomotive fleet is the same as the historic value from 1989 to 2016

- Train miles grow proportionally with the fleet growth

All locomotives built after 2016 are S-580 compliant. The projected fleet distribution in Figure 5 was used to predict the risk to train crews due to non-S-580 compliant locomotives. The risk estimation for the locomotive fleet was performed using the following approach:

- Estimating the number of trains in Class I and other railroads between 1990-2016 based on train-miles data and average number of locomotives per train [8]

- Computing the number of trains with legacy, pre-2009 and post-2009 locomotives in the lead for both Class I and non-Class I railroads

- Determining the number of collisions for 1975-1989, 1990-2008, and 2009-2016 locomotive equipped trains using the FRA database [9] 
- Determine the injury, fatality and collision rates for locomotives built from 1975-1989, 1990-2008, and 2009-2016 [9]

Based on the total locomotive fleet, the number of trains was estimated for 2015-2030. The "Best Case" scenario is defined as trains led by crashworthy locomotives as often as possible for the given year, followed by trains led by pre-2009 locomotives. The "Worst Case" scenario is defined as trains led by legacy locomotives in a given year as often as possible, followed by trains led by pre-2009 locomotives. The best case scenario represents the condition where every attempt is made to use the S-580 compliant, crashworthy locomotives in the lead position, whereas in the worst case scenarios the maximum number of possible trains is led by the legacy locomotives. Once the number of trains led by the S-580 and legacy locomotives is known for a given year, the collision, injury and fatality rates are applied to these trains. Then, cumulative risk for both Class I and other railroads is estimated.

\subsection{Injury and Fatality Rates}

Figure 6 plots the relationship between the number of trains and the number of collisions for Class I and non-Class I railroads on a yearly basis. Number of trains and collisions for Class-I railroads are almost an order of magnitude higher than the non-Class Is.

The numbers of fatalities plotted against the number of collisions involving legacy and pre-2009 S-580 locomotives are given in Figure 7. The numbers of injured persons involving legacy and pre-2009 S-580 locomotives are given in Figure 8. Data for fatalities and injuries involving S-580 compliant locomotives are given in Figure 9.

Estimates for collision, injury and fatality risk were based on the following assumptions:

- The number of train collisions is proportional to the number of trains.

- The chance of any train being in a collision is based on the average collision rate from the historical data.

- Number of trains in collision $=$ Number of trains led by each locomotive type multiplied by collision rate

- Injuries and fatalities are proportional to the number of collisions and are affected by the type of locomotives leading the colliding trains, i.e., legacy, pre-2009 S-580 and S-580 compliant locomotives

Figure 10 shows the projected future fatalities and injuries which range from 47 to 63 and 287 to 315 for the best and worst cases, respectively. 

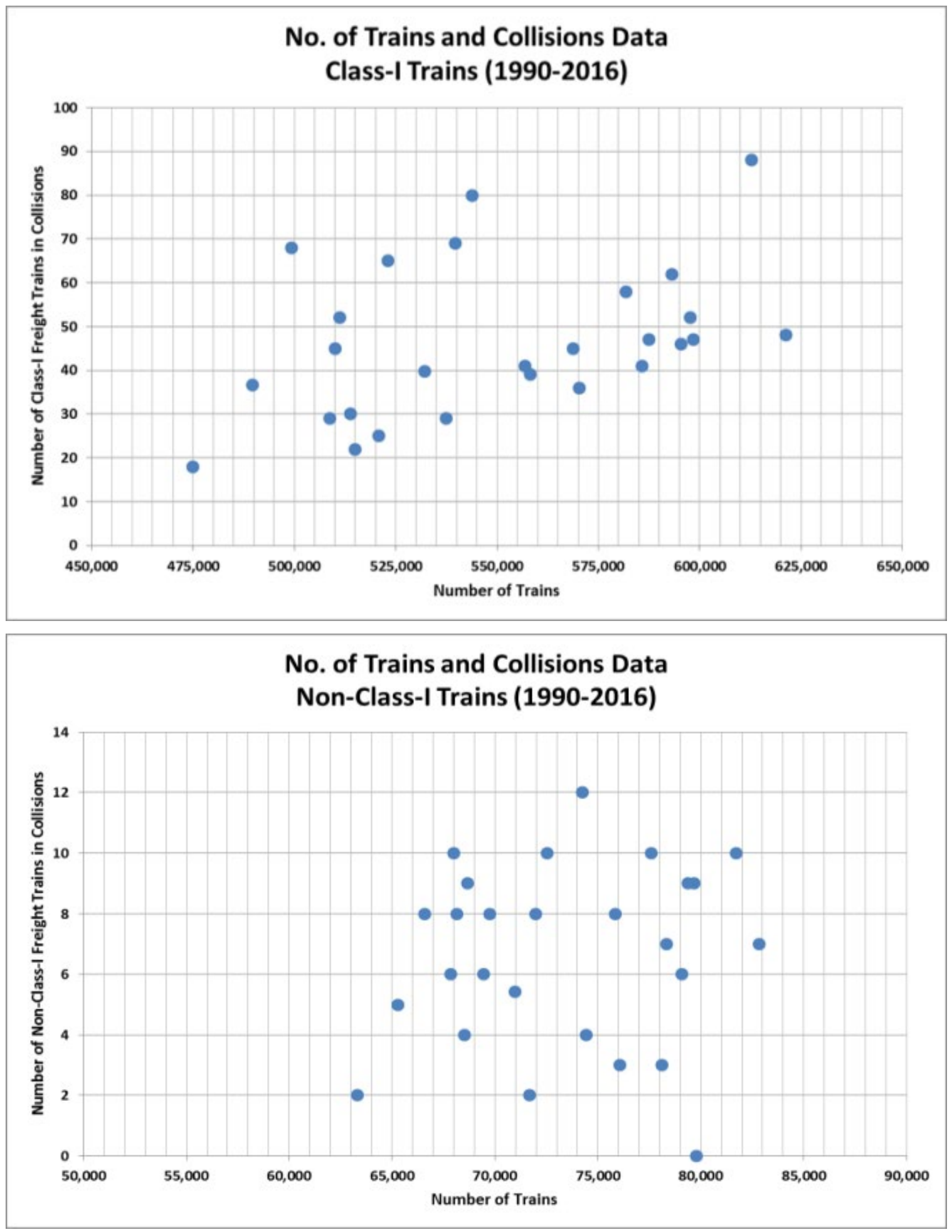

Figure 6. Revenue Trains and Collision Data-1990-2016 Class I and Non-Class-I Trains 

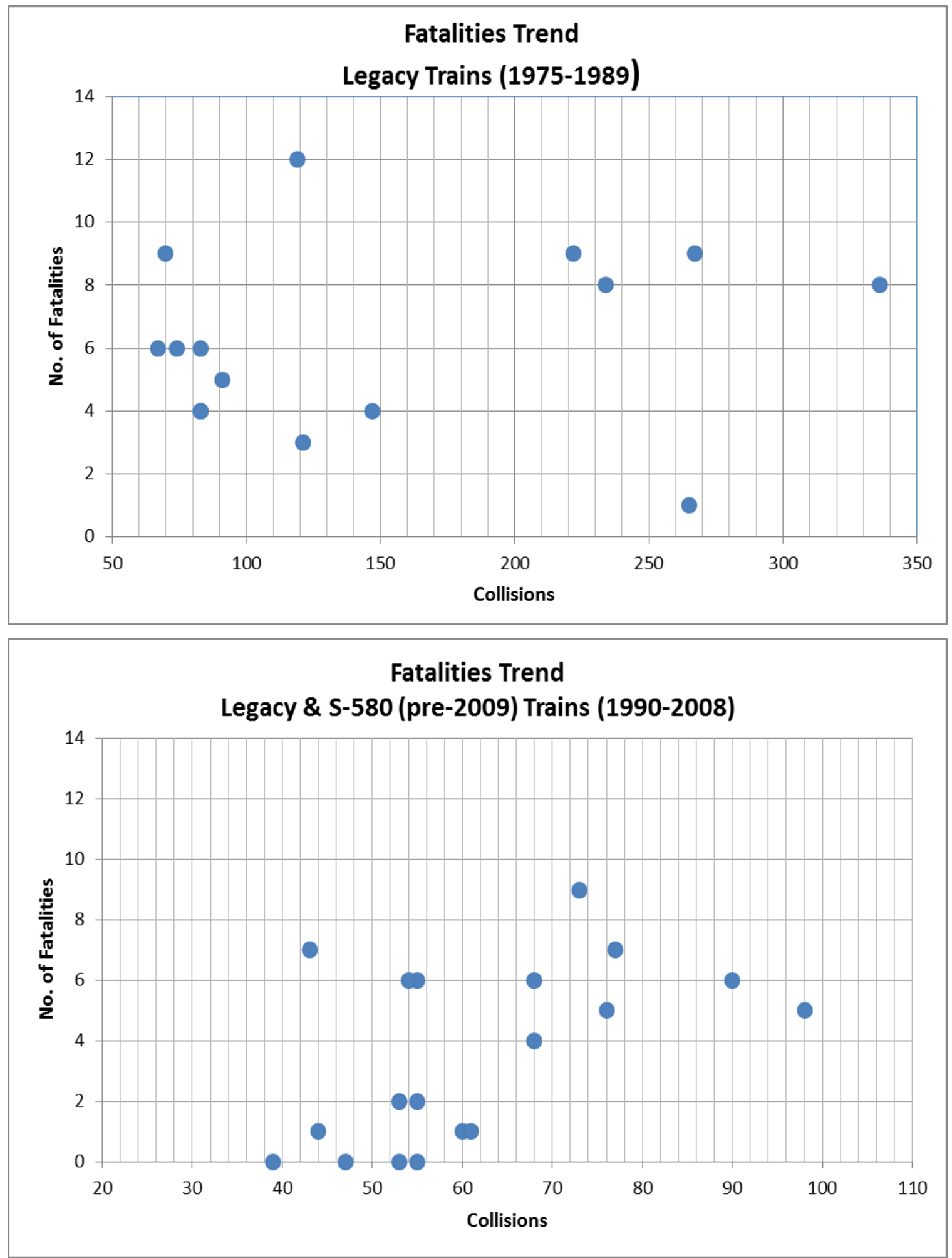

Figure 7. Fatalities Data-Legacy and Pre-2009 S-580 Locomotive Equipped Trains 


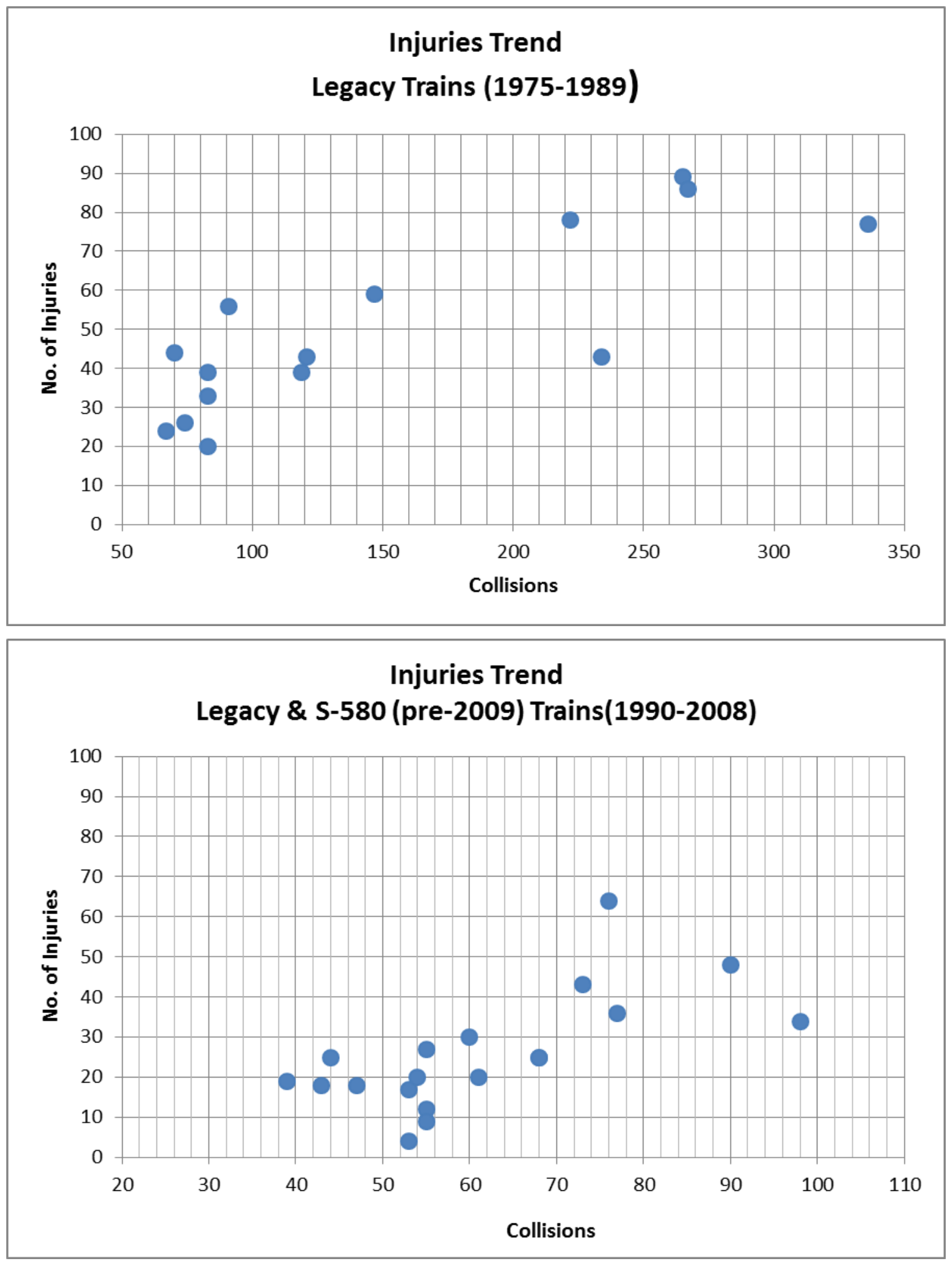

Figure 8. Injuries Data - Legacy and Pre-2009 S-580 Locomotive Equipped Trains 

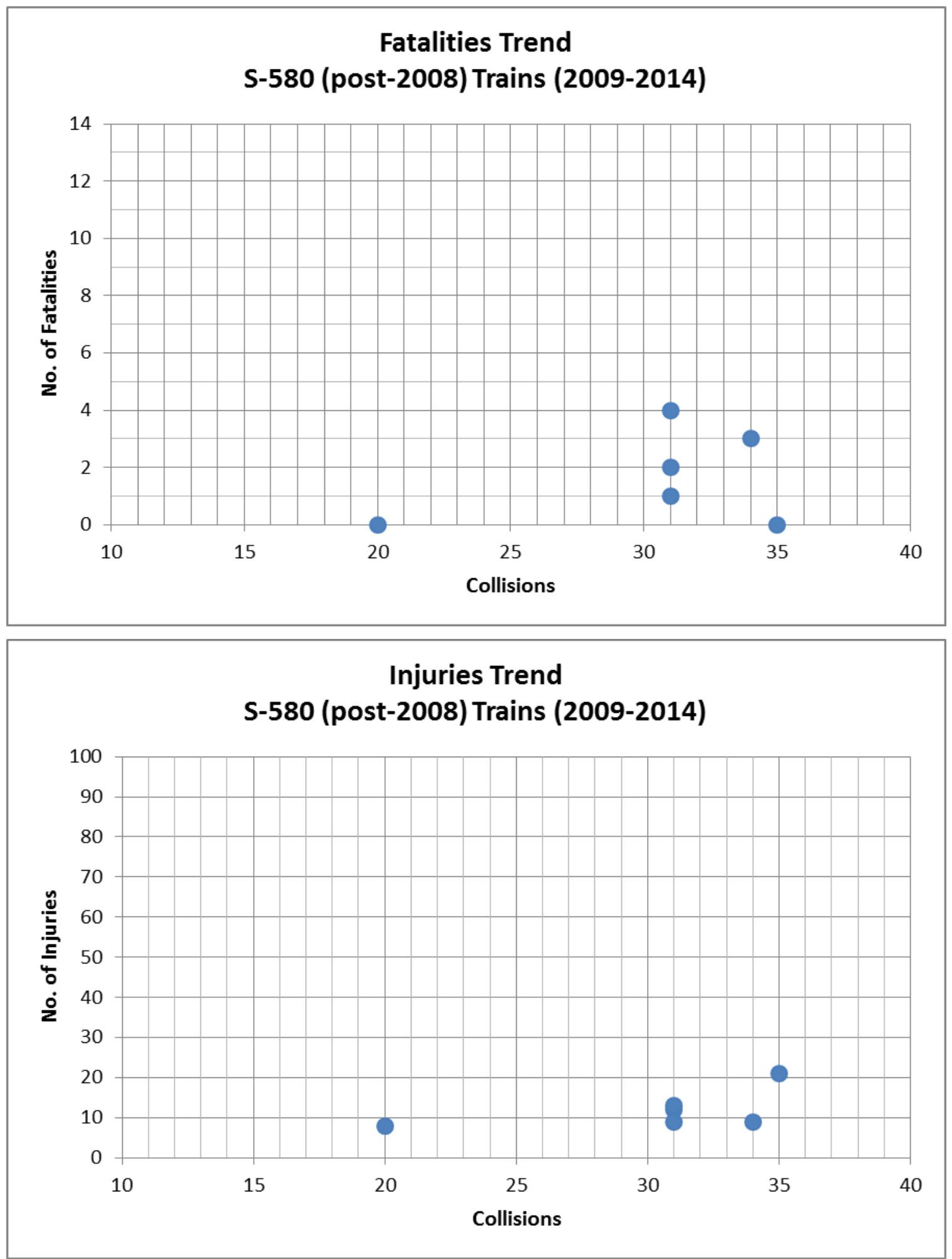

Figure 9. Fatalities and Injuries Data - Post 2008 S-580 Locomotive Equipped Trains 

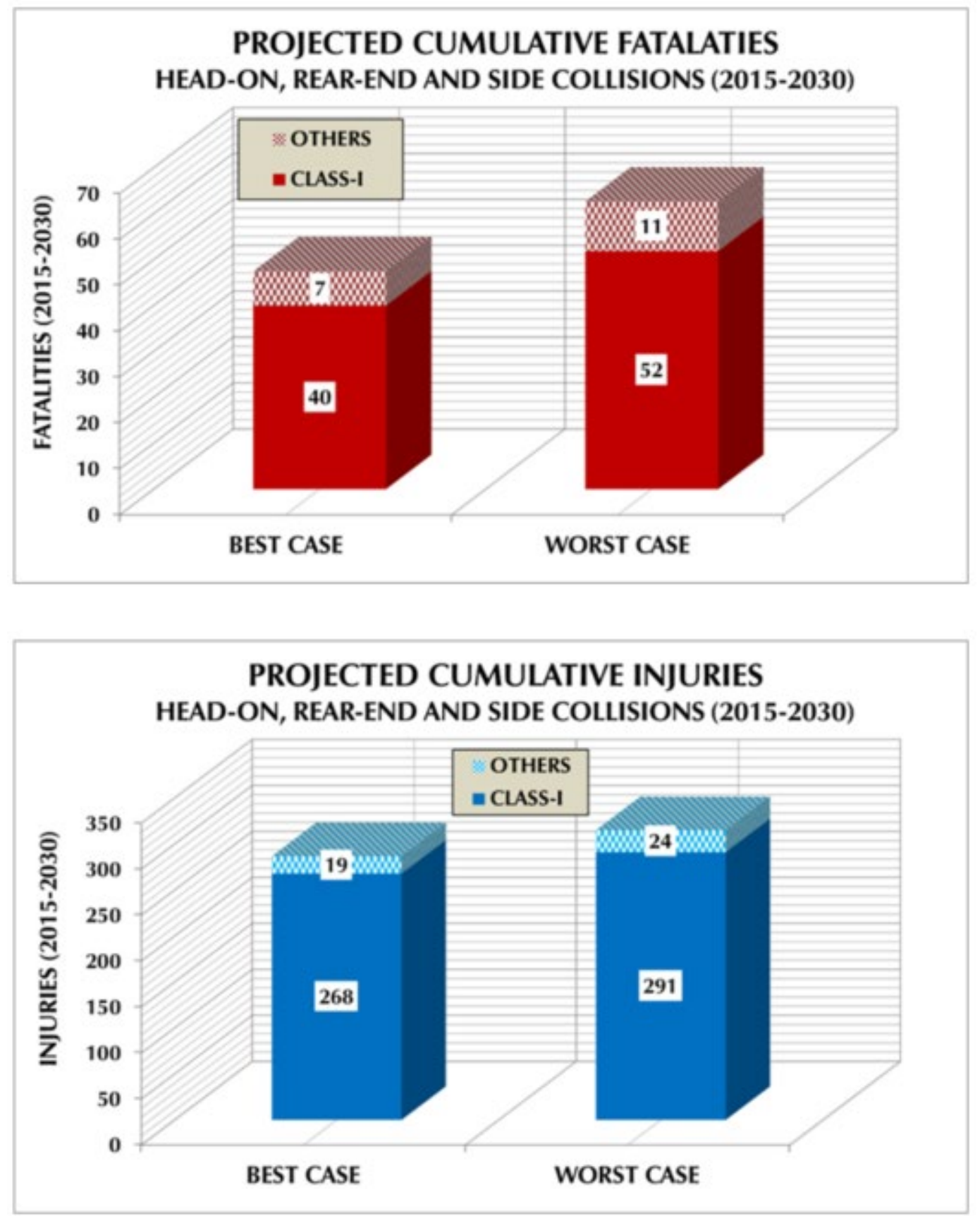

Figure 10. Estimated Fatalities and Injuries for 2017-2030 for Legacy Fleet 


\section{Evaluation of Baseline and Alternative Collision Post Designs}

The structure of the locomotive nose, including the collision posts, was modelled based on physical measurements taken from the locomotive. Figure 11 shows the legacy locomotive used in this study. The front part of this locomotive was modelled in ANSYS ${ }^{\circledR}$ to study its crashworthiness conformance to the 2001 S-580 [10]. Since the deformation of the collision posts and their connected components is of interest, the entire locomotive structure is not modeled. The sub-model of the locomotive structure includes the nose, cab, and 5-ft zone behind the cab for a total length of $20 \mathrm{ft}$. from the anti-climber.

Figure 12 shows the FEM and the constraints applied on the model. The rear surface of the model was constrained in the longitudinal, pitch and yaw directions. The vertical and lateral constraints are implemented at the locomotive truck side-bearer connections. Three-dimensional shell elements, ANSYS Shell 181, are used in the FEM of the locomotive cab. This element is convenient for modeling thin to moderately-thick shell structures. It has six degrees of freedom at each of four nodes and is useful for modeling nonlinear behavior, such as large rotation and strain. Change in the shell thickness is accounted for in the nonlinear analysis. Large deformation nonlinearity is included in the model. Element size is $1 / 2$ " for areas within 10- $\mathrm{ft}$ from the anticlimber. Element size is $2 \mathrm{ft}$. for rest of the structure. The number of elements in CP1 and CP2 are 10,233 and 4,105 respectively. Total number of elements in the FEM is 309,665. The components are connected to each other at mutual nodes.

A572 structural steel is used for the collision post with yield strength of $50 \mathrm{ksi}$ at $0.2 \%$ strain and an ultimate tensile strength of $70 \mathrm{ksi}$. A bilinear stress-strain curve is used with $145 \mathrm{ksi}$ strain hardening (tangent) modulus as a material model [11].

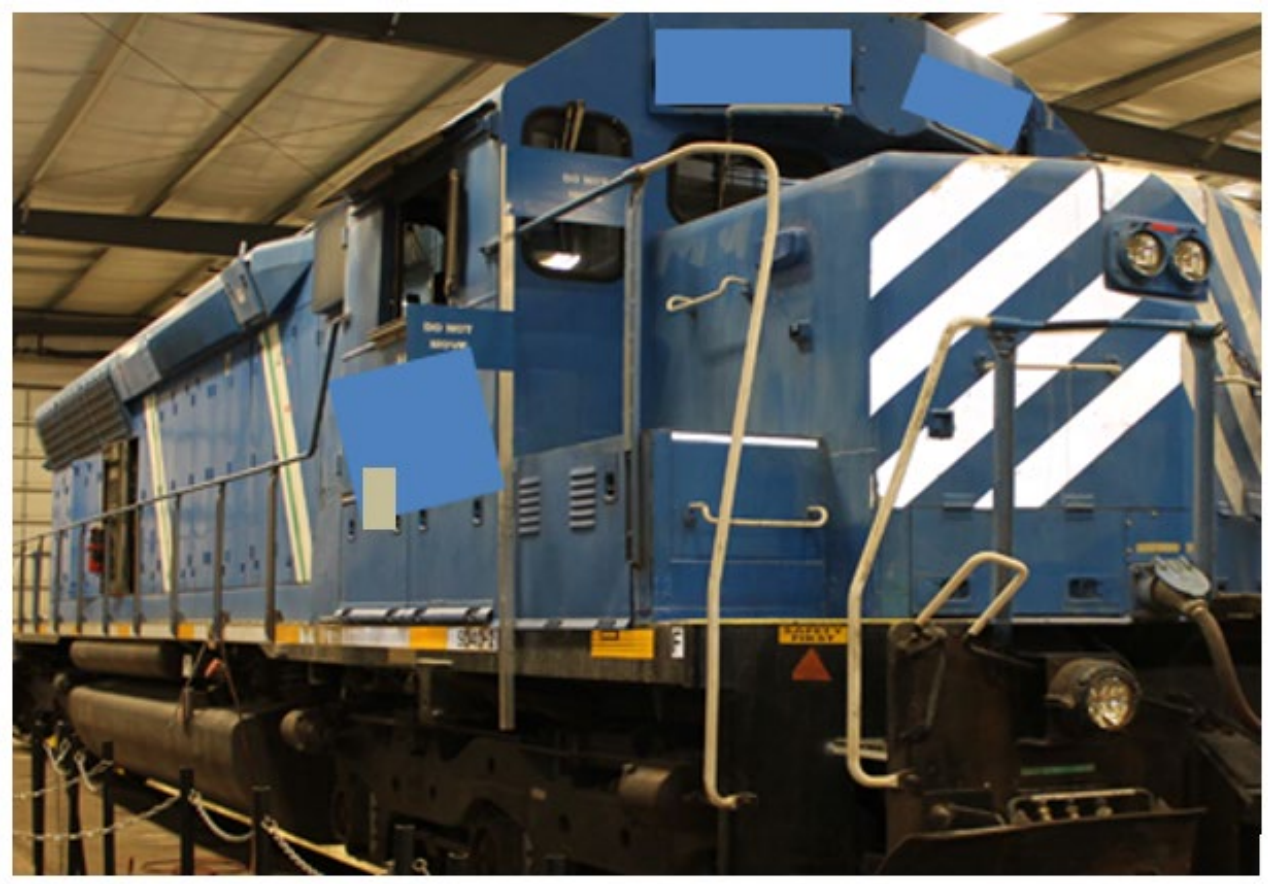

Figure 11. Narrow-Nose Locomotive used for FEA Model 


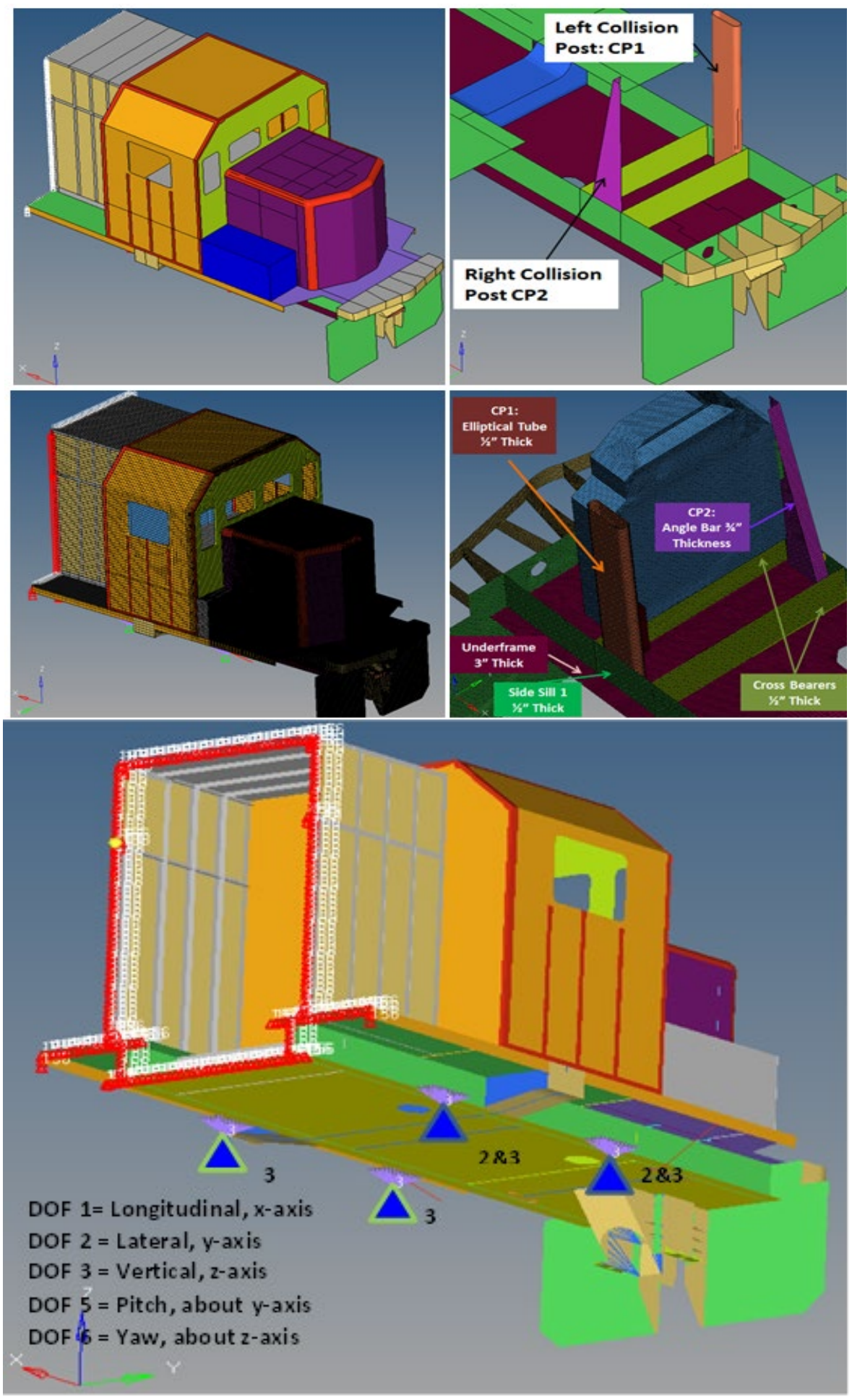

Figure 12. FEA Model and Constraints for Baseline Locomotive Operator Cab

The collision post design requirement in 2001 S-580 stipulates that "a minimum of two collision posts, located on the underframe longitudinal (center sills) shall be designed to withstand a longitudinal force of 200,000 lb. each at $30 \mathrm{ft}$. above the deck and 500,000 lb. each at the underframe deck without exceeding the ultimate strength of the material." 
Table 1 shows each load case (LC), application location, load components, application angle relative to the locomotive longitudinal axis and associated S-580 version. The load cases LC2 and LC5 in the table comply with the 2001 S-580 requirement. The load cases LC1, LC3, LC4 and LC6 were applied at $\mathrm{a} \pm 15^{\circ}$ angle to the locomotive longitudinal axis to simulate other possible train collision scenarios as required by 2005 or later revisions of AAR S-580. Loads are applied over an area that is 10 percent of the height of the collision post vertically and equal to the width of the post laterally. LC07, LC08 and LC09 simulate 750 kips applied at the underframe level at 15 degrees, 0 degrees and -15 degrees, respectively. LC10, LC11 and LC12 simulate 500 kips applied at $30 \mathrm{ft}$. above the underframe at 15 degrees, 0 degrees and $2-15$ degrees, respectively. LC13 simulates load application at a height of $54 \mathrm{ft}$. from the underframe to simulate a moment of 15 million in-lb. The applied loads were increased in the $2005 \mathrm{~S}-580$ version in comparison to the 2001 level. The collision post load levels that were increased in the 2005 S-580 standard remained unchanged as of the 2016 revision.

Table 1. Collision Post Load Cases

AAR S-580 Standard*

\begin{tabular}{|c|c|c|c|c|}
\hline $\begin{array}{c}\text { Load } \\
\text { Case } \\
\text { ID }\end{array}$ & Load Location & $\begin{array}{c}\text { Net Force } \\
\text { (kips) }\end{array}$ & $\begin{array}{l}\text { Angle } \\
\text { (Deg) }\end{array}$ & Comment \\
\hline LCO2 & Underframe Level & 500 & 0 & \multirow{2}{*}{ AAR S-580 2001} \\
\hline LCO5 & $\begin{array}{c}\text { 30" above Deck } \\
\text { (44"from Underframe) }\end{array}$ & 200 & 0 & \\
\hline LCO1 & Underframe Level & 500 & 15 & \multirow{11}{*}{$\begin{array}{c}\text { AAR S-580 } 2005 \\
\text { \& Forward }\end{array}$} \\
\hline LCO3 & Underframe Level & 500 & -15 & \\
\hline LCO4 & $\begin{array}{c}\text { 30" above Deck } \\
\text { (44"from Underframe) }\end{array}$ & 200 & 15 & \\
\hline LCO6 & $\begin{array}{c}\text { 30" above Deck } \\
\text { (44"from Underframe) }\end{array}$ & 200 & -15 & \\
\hline LCO7 & Underframe Level & 750 & 15 & \\
\hline LCO8 & Underframe Level & 750 & 0 & \\
\hline LCO9 & Underframe Level & 750 & -15 & \\
\hline LC10 & $\begin{array}{l}30 \text { in. above the } \\
\text { Underframe }\end{array}$ & 500 & 15 & \\
\hline LC11 & $\begin{array}{l}30 \text { in. above the } \\
\text { Underframe }\end{array}$ & 500 & 0 & \\
\hline LC12 & $\begin{array}{l}30 \text { in. above the } \\
\text { Underframe }\end{array}$ & 500 & -15 & \\
\hline LC13 & $\begin{array}{l}40 " \text { above the Deck (54" } \\
\text { from Underframe) }\end{array}$ & 278 & 8 & \\
\hline
\end{tabular}

*Allowable stress is material tensile strength of $70 \mathrm{ksi}$

\subsection{Baseline Collision Post Crashworthiness Evaluation}

The geometry of the left and right collision posts was different for the baseline locomotive. This is possibly due to the available space on the left and right side of the sand box in the nose. The left collision post had an elliptical tube cross section and is identified in this report as CP1. The 
right collision post was an angle, identified in this report as CP2. The collision posts are shown in Figure 13.

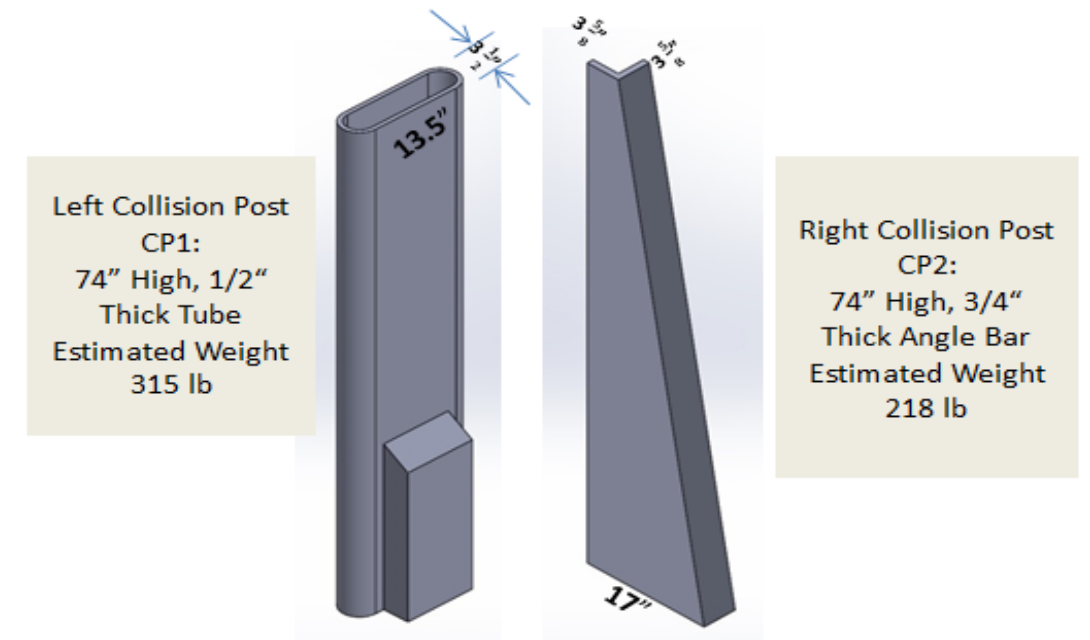

Figure 13. Baseline Collision Post Designs

Figure 14 shows the LC01 stress contour plot for the current design of the left collision post (CP1). CP1 failed at $100 \mathrm{Kips,}$ which was only 20 percent of the required load. The stress contour for the right collision post (CP2) for the same loading situation is shown in Figure 15. The baseline collision post plots for the remaining load cases (LC02 to LC06 for CP1 and CP2) are given in Appendix A. The FEA results for CP1 and CP2 are summarized in Table 2. CP1 and CP2 did not meet the collision post requirement in the $2001 \mathrm{~S}-580$ standard.

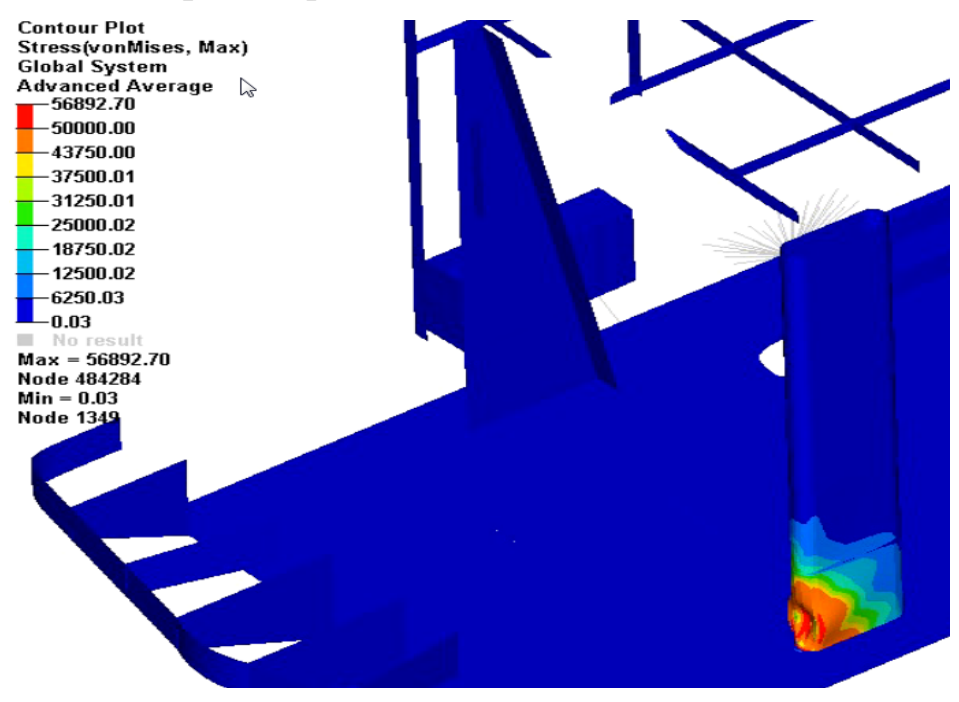

Figure 14. Baseline CP1 Stress Contour for LC01 


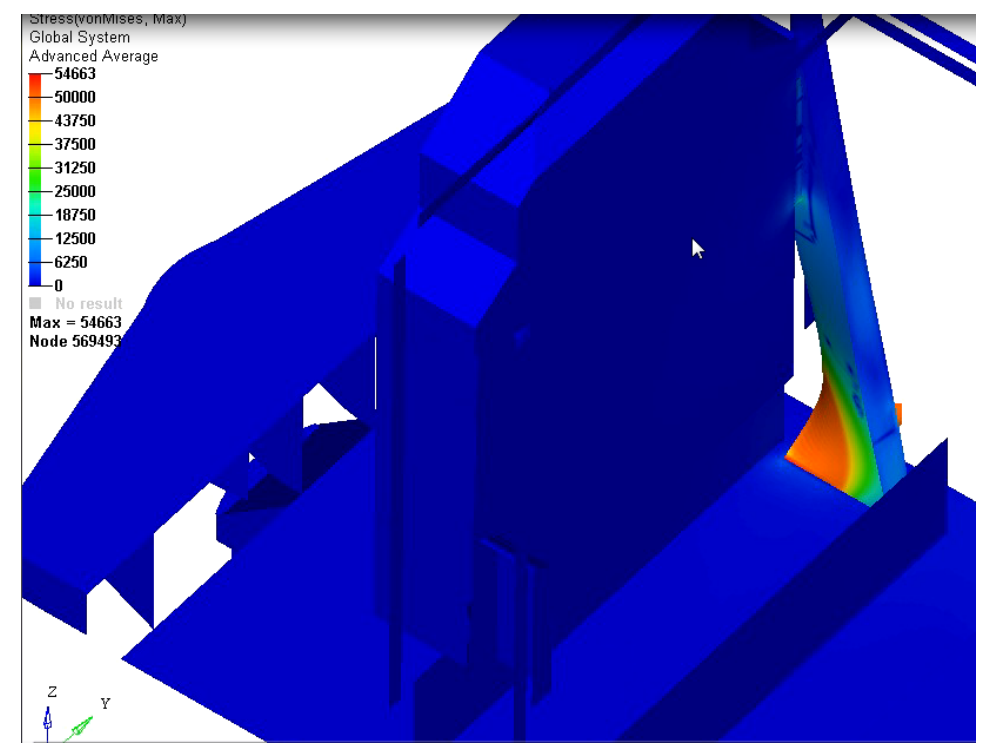

Figure 15. Baseline CP2 Stress Contour for LC01

Table 2. CP1 and CP2 FEA Results

\begin{tabular}{|c|c|c|c|c|}
\hline & Load Case ID & $\begin{array}{c}\text { Applied Load } \\
\text { (kips) }\end{array}$ & Angle (Deg) & Load Capacity \\
\hline \multirow{6}{*}{ 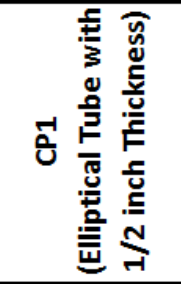 } & LCO1 & 500 & 15 & $20 \%$ \\
\hline & $\mathrm{LCO} 2$ & 500 & 0 & $83 \%$ \\
\hline & $\mathrm{LCO} 3$ & 500 & -15 & $22 \%$ \\
\hline & LCO4 & 200 & 15 & $65 \%$ \\
\hline & LC05 & 200 & 0 & $100 \%$ \\
\hline & LCO6 & 200 & -15 & $65 \%$ \\
\hline \multirow{6}{*}{ 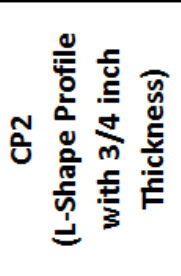 } & $\mathrm{LCO} 1$ & 500 & 15 & $35 \%$ \\
\hline & $\mathrm{LCO} 2$ & 500 & 0 & $36 \%$ \\
\hline & $\mathrm{LCO} 3$ & 500 & -15 & $36 \%$ \\
\hline & LCO4 & 200 & 15 & $90 \%$ \\
\hline & LCO5 & 200 & 0 & $85 \%$ \\
\hline & LCO6 & 200 & -15 & $81 \%$ \\
\hline
\end{tabular}

\subsection{Evaluation of the Proposed Collision Post Designs to Meet 2001 Version of AAR S-580 (CP3 and CP4)}

In order to improve the crashworthiness of the legacy locomotives, alternative collision post designs, CP3 and CP4, are proposed. CP3, which is shown in Figure 16, provides an advantage when there is a limited available space along lateral axis in the front nose. It also requires less installation labor due to its simple design. CP4, shown in Figure 17, is an I-Beam version of CP3, but with a thinner web. CP3 and CP4 have $2 \frac{1}{2}$ and 1 inch thick web plates, respectively. CP4 has a 6-inch wide and $1 \frac{1}{2}$ inch thick flange welded to the web plate. The flange that is thinner than 1.5 inch warps about the vertical axis. It results in local failure under 500-kips load case. The left and right collision posts are joined by two rectangular plates in the lateral direction. The CP4 design has also thinner lateral web plates (1/2 inch vs. 1 inch). Fabrication of 
$\mathrm{CP} 4$ is more laborious due to the extra welds. The lateral steel plates provide resistance for the two collision posts when the loads are applied at an angle. The length of the base is determined from the available space between cross bearers on the underframe sill. The thicknesses were determined by iterations after several simulations. Both designs meet and exceed the S-580 2001 version collision post requirements.

Figure 18 and Figure 19 show the stress contour on the tapered steel plate (CP3) and I-Beam designs for the LC01 load case, respectively. Both posts withstood 500-kip load applied at the underframe level at a 15 degree angle. The stress contour plots for the remaining load cases from LC02 to LC06 for the CP3 and CP4 posts are given in Appendix B and Appendix C. Both designs passed all the relevant collision post load cases based on the $2001 \mathrm{~S}-580$ standard.

Both CP3 and CP4 designs pass the $2001 \mathrm{~S}-580$ requirements. For all load cases, the maximum deflection of the CP4 design is lower than the CP3 configuration. The worst case is LC04 in which 200 kips of load is applied at a height of $30 \mathrm{ft}$. above the deck at an angle of 15 degrees. For this load case, the maximum deflection is $3.3 \mathrm{ft}$. for CP3 and $1.9 \mathrm{f.t}$ for CP4. Refer to the deflection plots in Figure 20 for CP3 and Figure 21 for CP4. The plot in Figure 22 shows the load vs. deflection curve for both CP3 and CP4 collision posts for the worst load case LC04. It is seen that the stiffness for CP4 is greater than CP3. Therefore, the maximum CP4 deflections are also lower than the maximum CP3 deflections for the other load cases. The results for the load cases are summarized in Table 3.

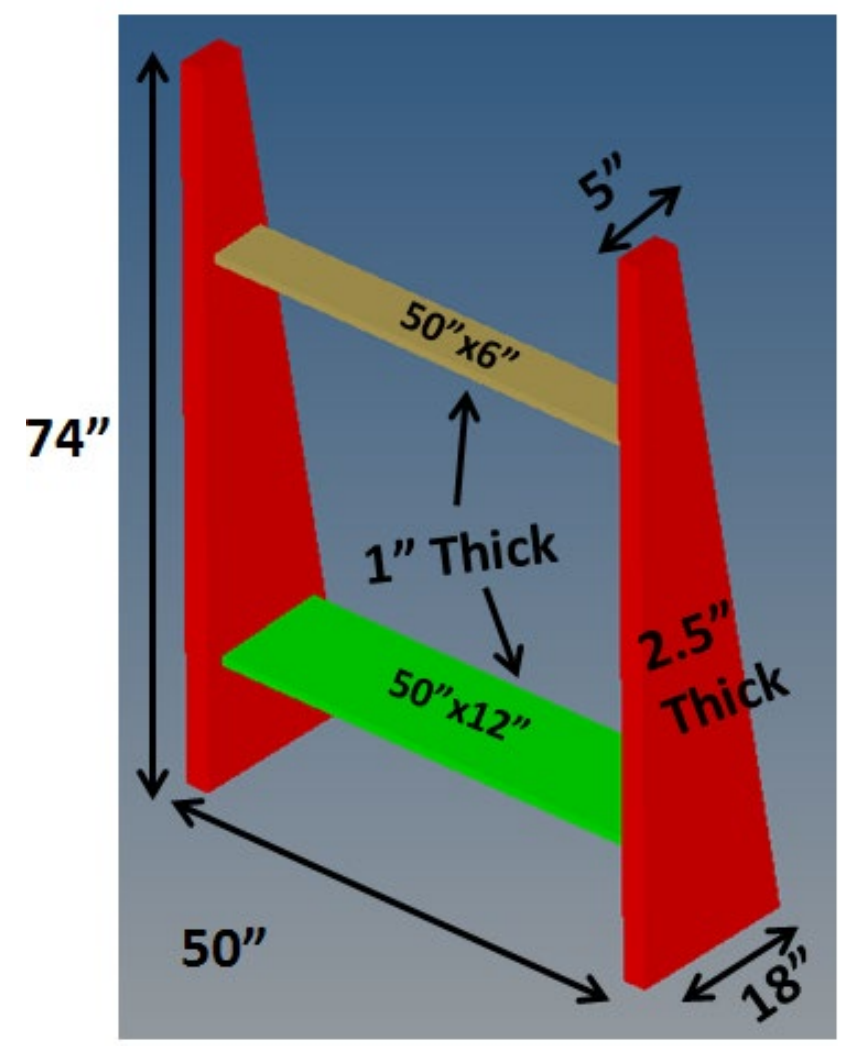

Figure 16. Collision Post CP3 (Tapered Steel Plate) 


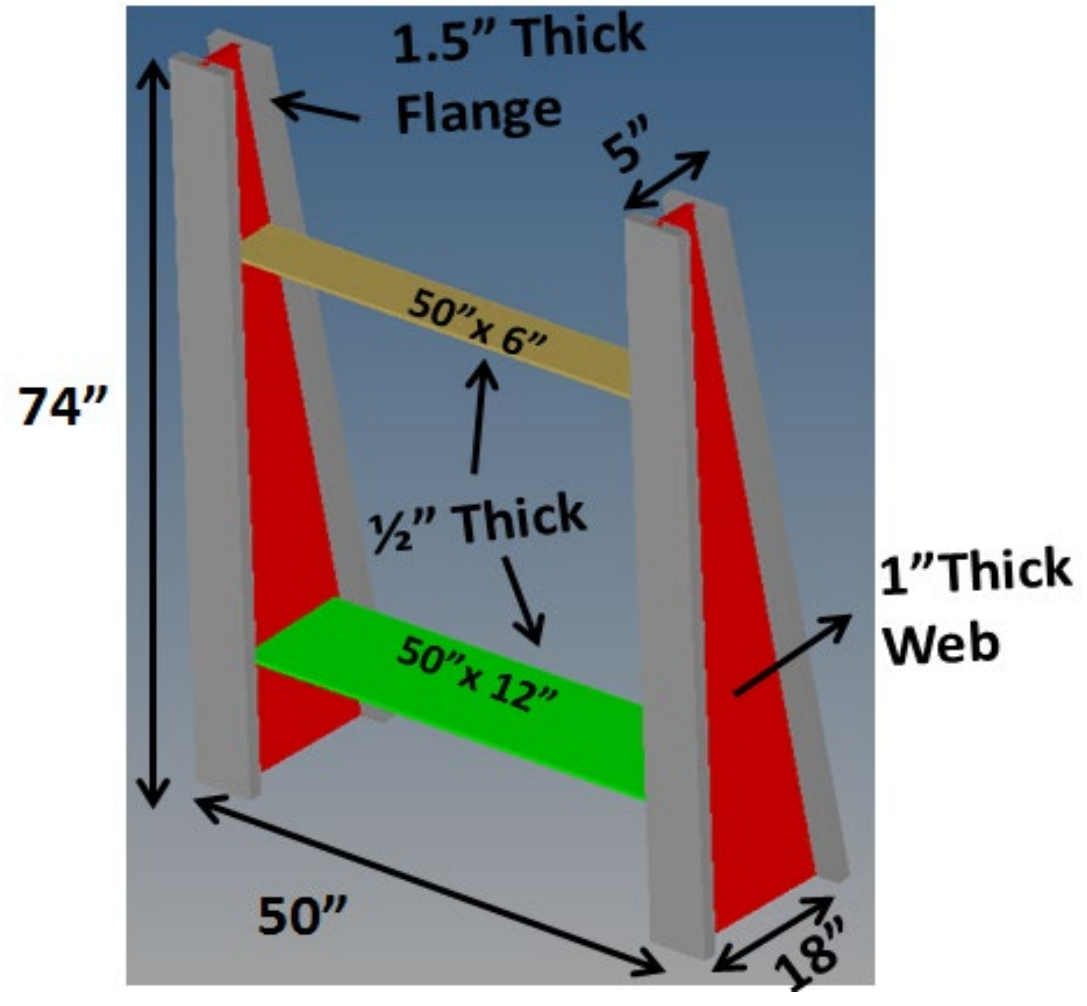

Figure 17. Collision Post CP4 (Tapered I Beam) 


\section{Contour Plot}

Stress (vonMises, Max)

Global System

Advanced Average

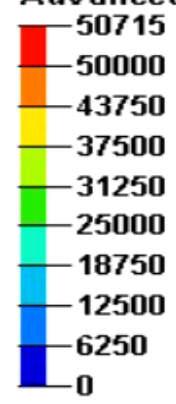

$\mathbf{M a x}=\mathbf{5 0 7 1 5}$

Node 732515

$\operatorname{Min}=0$

Node 732771

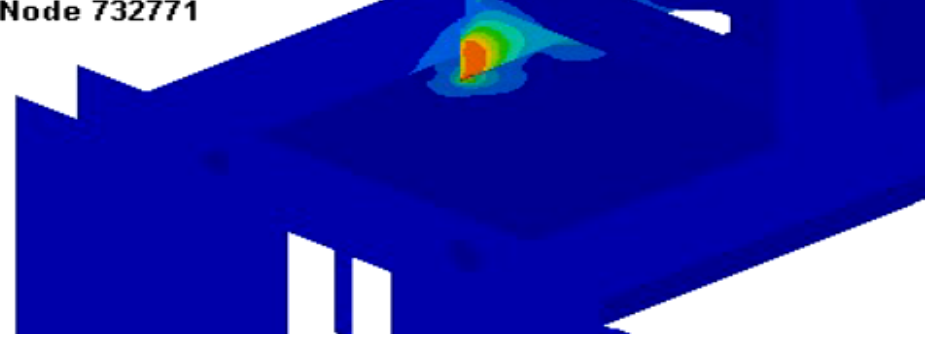

Figure 18. CP3 Stress Contour for LC01

\section{Contour Plot}

Stress(vonMises, Max)

Global System

Advanced Average

51407
-50000
-43750
-37500
-31250
-25000
-18750
-12500
-6250
0

Max $=\mathbf{5 1 4 0 7}$

Node 727442

Min $=0$

Node 1351

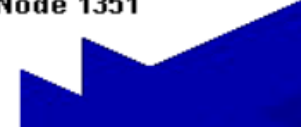

Figure 19. CP4 Stress Contour for LC01 


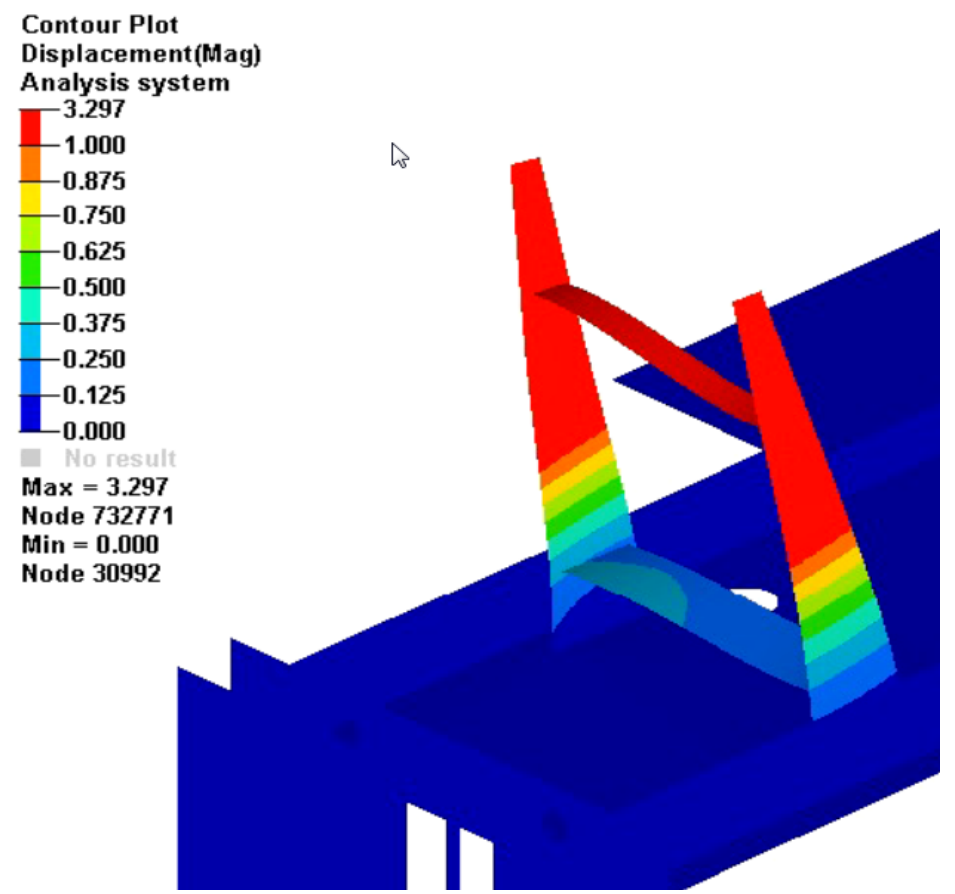

Figure 20. CP3 Displacement Plot for LC04 (5X Magnification)

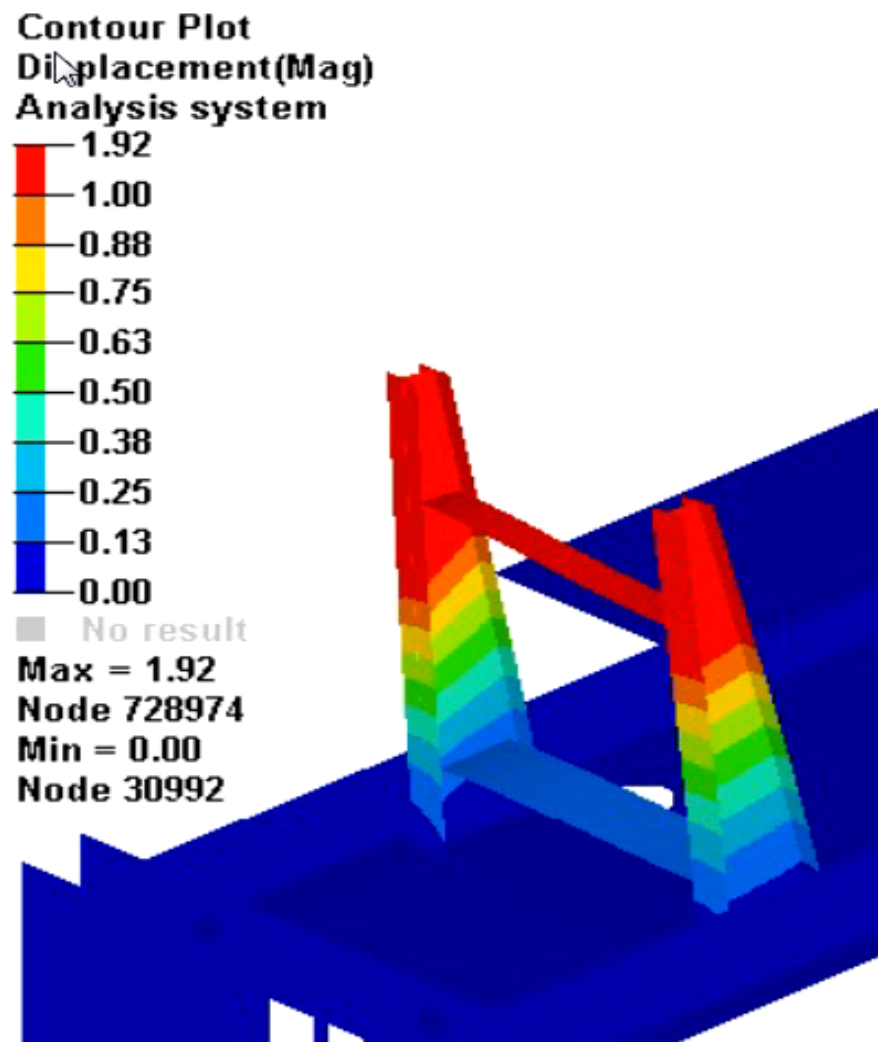

Figure 21. CP4 Displacement Plot for LC04 (5X Magnification) 


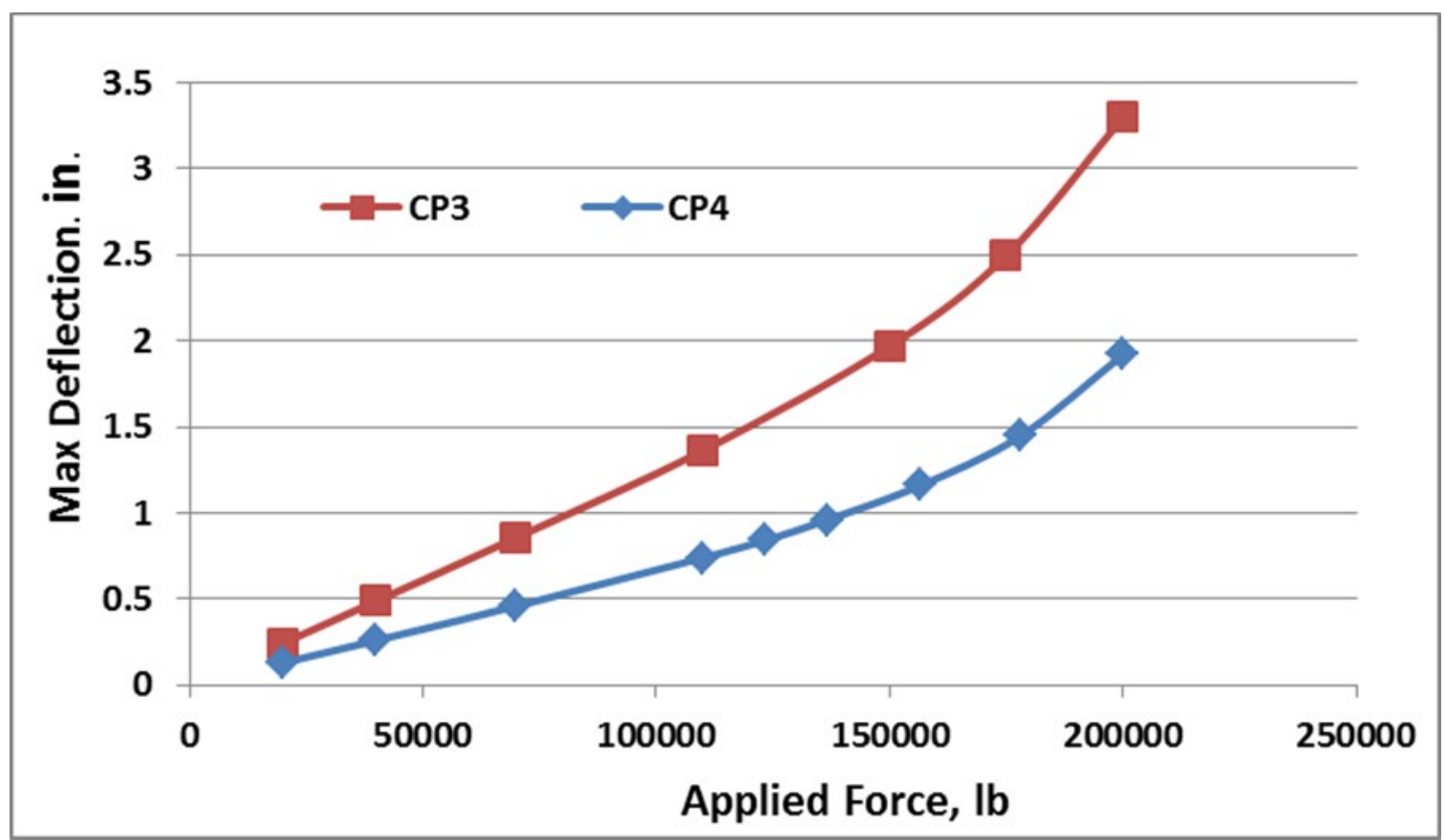

Figure 22. Stiffness Comparison of Collision Posts for Load Case LC04 
Table 3. CP3 and CP4 FEA Results

\begin{tabular}{|c|c|c|c|c|c|}
\hline & Load Case ID & $\begin{array}{l}\text { Applied Load } \\
\text { (kips) }\end{array}$ & Angle (Deg) & $\begin{array}{c}\text { Max von Mises } \\
\text { Stress (ksi) }\end{array}$ & $\begin{array}{c}\text { Max } \\
\text { Deflection(in) }\end{array}$ \\
\hline \multirow{6}{*}{ 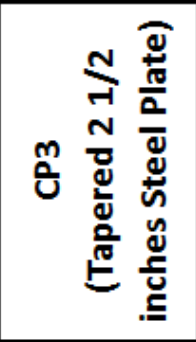 } & LCO1 & 500 & 15 & 50.7 & 0.13 \\
\hline & $\mathrm{LCO} 2$ & 500 & 0 & 50.2 & 0.09 \\
\hline & $\mathrm{LCO} 3$ & 500 & -15 & 50.6 & 0.11 \\
\hline & $\mathrm{LCO4}$ & 200 & 15 & 52.6 & 3.3 \\
\hline & LCO5 & 200 & 0 & 52.6 & 1.1 \\
\hline & LCO6 & 200 & -15 & 52.3 & 3.1 \\
\hline \multirow{6}{*}{ 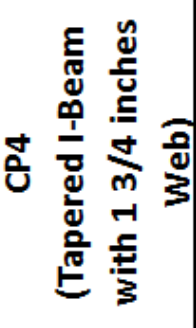 } & LCO1 & 500 & 15 & 51.4 & 0.1 \\
\hline & $\mathrm{LCO} 2$ & 500 & 0 & 50.8 & 0.07 \\
\hline & LCO3 & 500 & -15 & 51.4 & 0.09 \\
\hline & $\mathrm{LCO4}$ & 200 & 15 & 53 & 1.9 \\
\hline & LCO5 & 200 & 0 & 50.9 & 0.7 \\
\hline & LC06 & 200 & -15 & 52.9 & 1.8 \\
\hline
\end{tabular}

\subsection{Evaluation of the Proposed Collision Post Design to Meet 2016 Version of AAR S-580 (CP5)}

3. Collision post requirements were tightened significantly in 2005 and are still current in 2016. To meet current collision post strength requirements, the web thickness of the tapered I-Beam design (CP4) is increased from 1 inch to $1 \frac{3}{4}$ inches. This configuration, CP5, is shown in Figure 23. The FEA model estimates that CP5 does not fail under any of the load cases provided in Table 1. Figure 24, Figure 25, and Figure 26 show the stress contours under LC7, LC10 and LC13. These are more challenging load cases that resulted in failure of the first four collision post designs. Table 4 summarizes the maximum stress and deflection of CP5 under load cases 1 to 13. The remainder of the stress contour plots is provided in Appendix E.

Table 4. CP5 FEA Results

\begin{tabular}{|c|c|c|c|c|}
\cline { 2 - 6 } \multicolumn{1}{c|}{ Load Case ID } & $\begin{array}{c}\text { Applied Load } \\
\text { (kips) }\end{array}$ & $\begin{array}{c}\text { Angle } \\
\text { (Deg) }\end{array}$ & $\begin{array}{c}\text { Max von Mises } \\
\text { Stress (ksi) }\end{array}$ & $\begin{array}{c}\text { Max } \\
\text { Deflection(in) }\end{array}$ \\
\hline \multirow{4}{*}{ LC01 } & 500 & 15 & 51 & 0.10 \\
\hline LC02 & 500 & 0 & 51 & 0.06 \\
\hline LC03 & 500 & -15 & 51 & 0.08 \\
\hline LC04 & 200 & 15 & 52 & 1.37 \\
\hline LC05 & 200 & 0 & 51 & 0.65 \\
\hline LC06 & 200 & -15 & 52 & 1.34 \\
\hline LC07 & 750 & 15 & 52 & 0.16 \\
\hline LC08 & 750 & 0 & 51 & 0.10 \\
\hline LC09 & 750 & -15 & 54 & 0.13 \\
\hline LC10 & 500 & 15 & 56 & 2.12 \\
\hline LC11 & 500 & 0 & 53 & 1.05 \\
\hline LC12 & 500 & -15 & 57 & 1.98 \\
\hline LC13 & 278 & 8 & 52 & 2.14 \\
\hline
\end{tabular}




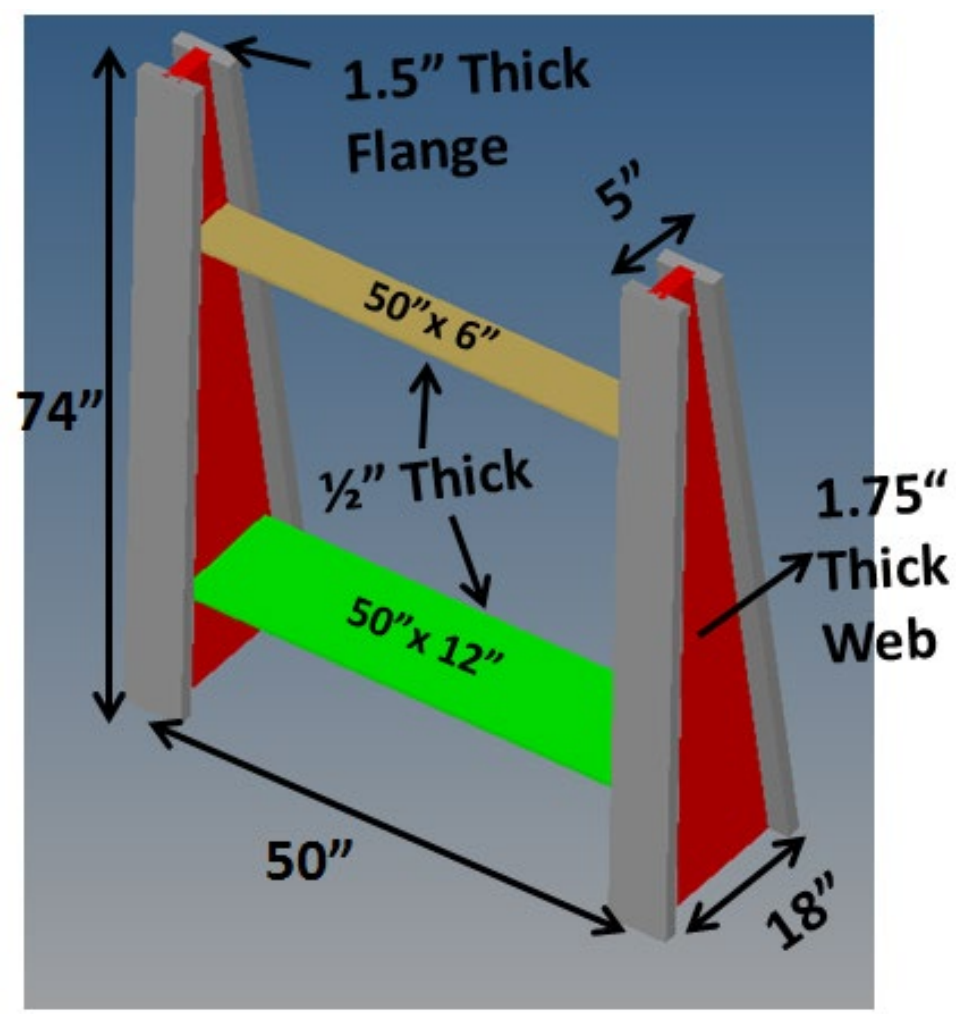

Figure 23. Proposed Collision Post CP5 


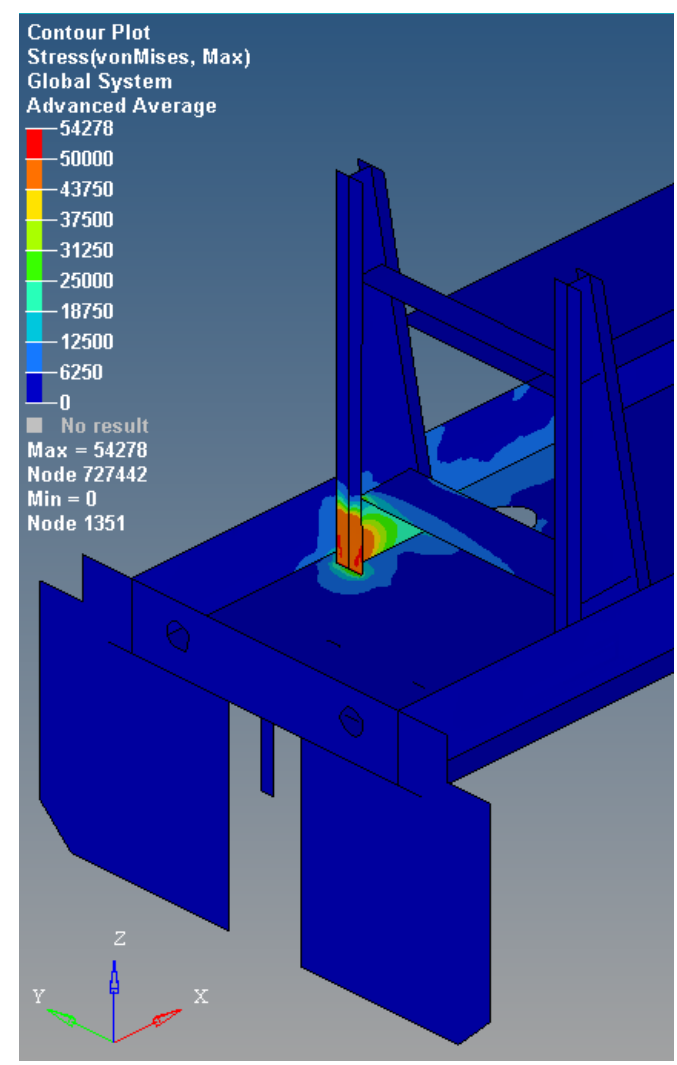

Figure 24. CP5 von Mises Stress Contour Under LC07 


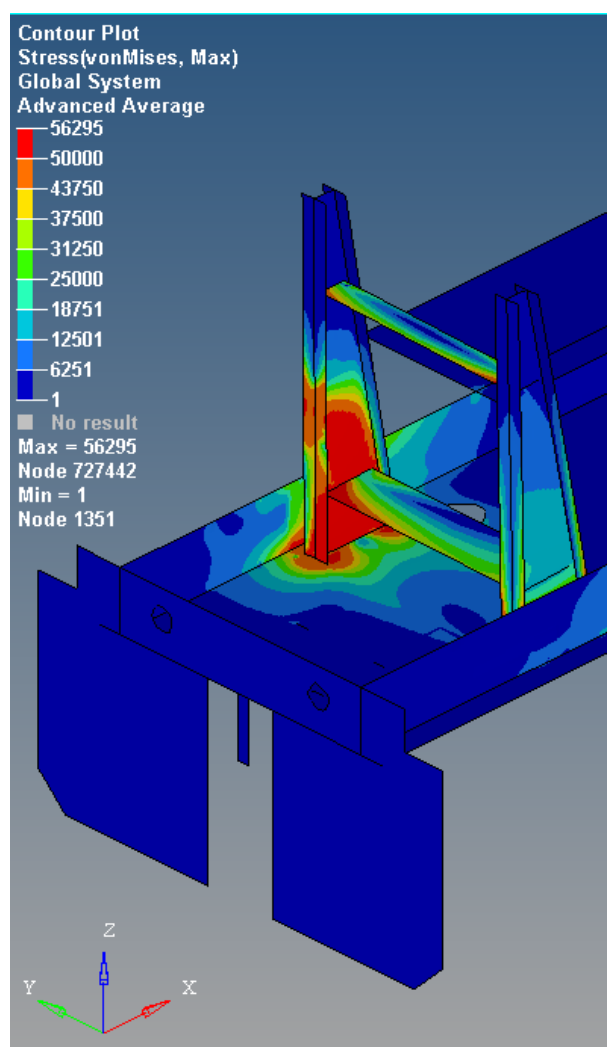

Figure 25. CP5 von Mises Stress Contour Under LC10 


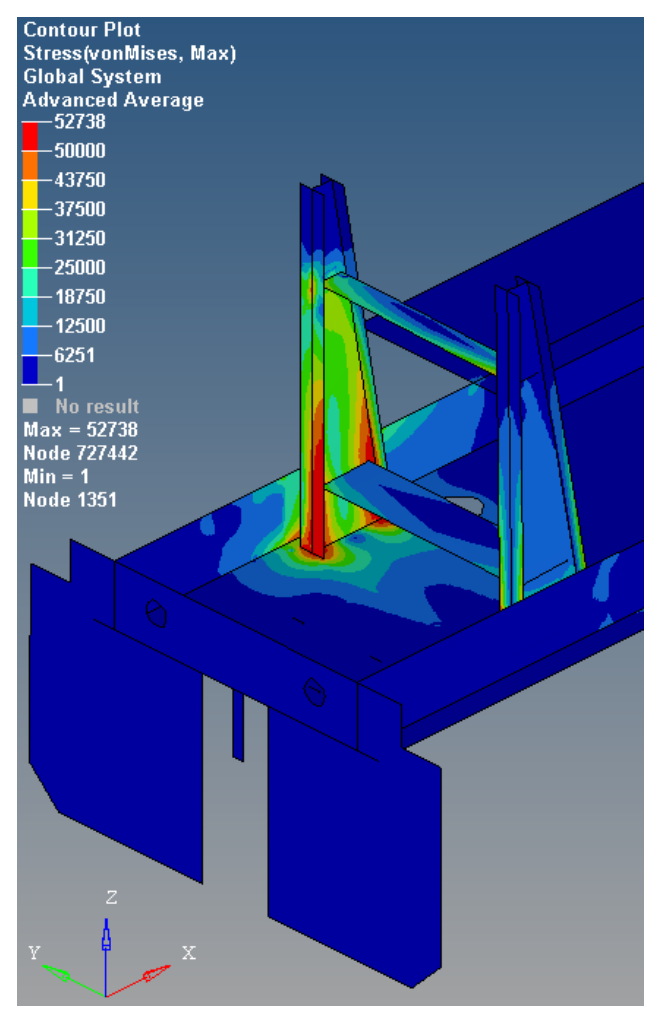

Figure 26. CP5 von Mises Under LC13

\subsection{Weight Impact of Collision Post Design Alternatives}

Figure 27 compares the weight of all posts studied here. The results of the analyses suggest that that the CP3, CP4 and CP5 designs are the best candidates for improving crashworthiness and mitigating risk to cab occupants in the event of a collision. While these designs represent the largest weight increases, it must be acknowledged that sufficient additional structure is required in order to sustain the requisite loads with some safety margin and overcome the performance limitations of the two lighter-weight designs (CP1 and CP2). The additional weight of the proposed retrofits is modest compared to the weight of a ready-to-run locomotive. 


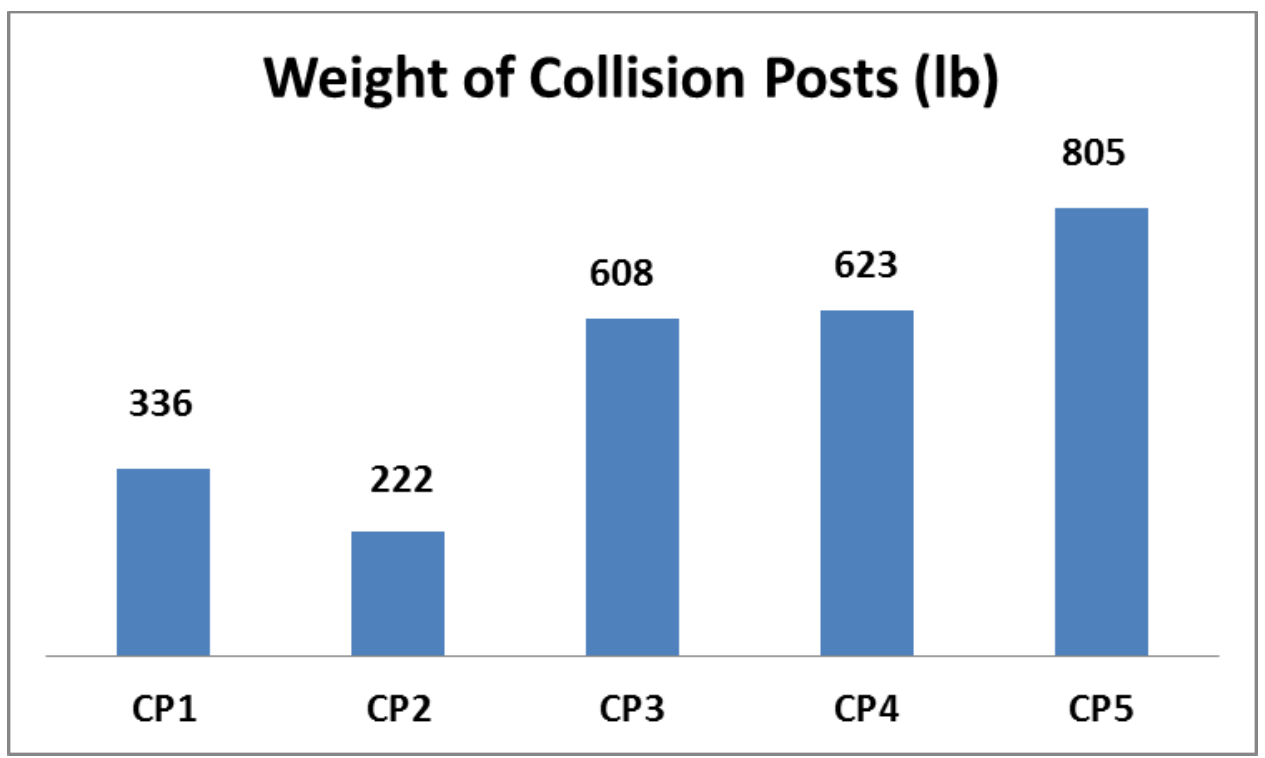

Figure 27. Weight Comparison of Collision Posts 


\section{Conclusion}

Based on the measurements taken from a sample retrofitted narrow-nose locomotive, collision posts were modeled in ANSYS ${ }^{\circledR}$ under AAR S-580 load requirements. The FEM predicted that for the measured posts, CP1 fails under LC02 and CP2 fails under LC02 and LC05. Since the posts failed to withstand these load cases, the baseline retrofitted legacy locomotive did not meet the AARS-580 2001 requirements.

Based on the stress gradients, CP1 showed very high localized stresses under 500-kip load cases and failed due to insufficient steel thickness. There is a possibility that CP1, which is an elliptical steel tube, may meet S-580 2001 or 2005 versions at thicker profile. However, it may be costly or not be possible to fabricate elliptical tube with thickness more than half a foot within the available room in the nose.

CP2 failed to withstand LC02 and LC05 (500 kips and 200-kips longitudinal loads) due to the asymmetric profile geometry (L-profile) and thickness selection. In addition, LC02 and LC05 loads were applied at $\pm 15^{\circ}$. That is the partial requirement of AAR S-580 2005 and later revisions. Both posts lacked the lateral stiffness to withstand lateral component of these load cases (LC01, LC03, LC04, and LC06) as well. Failure modes of CP1 and CP2 under LC01 through LC06 were studied in detail. By using common structural steel profiles, CP3, CP4 and CP5 were designed on the basis of several FEA by optimizing thicknesses, considering the ease of installation, and available room in the nose.

Proposed post designs, CP3 and CP4, are predicted to meet and exceed AAR S-580 2001 version by withstanding load cases 1 through 6 . This is accomplished by welding these only to the underframe sill. CP3 has a relatively thick web (2 1/2 ft.), but it is expected to be advantageous in terms of lower labor cost and fitting into narrow spaces in the case of a retrofit. On the other hand, CP4 performs slightly better in terms of deforming less than CP3. However, it requires extra welding and $31 / 2$ inches additional lateral space. Neither design has any adverse impact on the functionalities of the locomotive.

The FEA model predicts that the CP5 design passes all the load cases required to comply with the latest AAR S-580 collision post requirements. This design is similar to CP4 except for the thicker web. Based on the analysis, it is evident that retrofitting the legacy locomotives with any one of the proposed collision post designs (CP3, CP4 or CP5) will help to improve the locomotive crashworthiness and mitigate the risks for crew injuries and fatalities from the operation of legacy locomotives. The choice of the specific design will depend on the available space in the nose area and risk management philosophy of the railroad operators.

In the next phase of the project, a validation of the proposed collision post designs CP4 and CP5 is recommended with the following steps:

- Identify a legacy locomotive similar to that used for the baseline FEA model

- Remove existing collision posts, if any

- Make two prototype collision posts of CP4 and CP5 designs

- Strain gage CP4 and CP5 at FEA identified high stress locations

- Retrofit the test locomotive with the two prototype CP4 collision posts 
- Apply load as per LC5 and record strains

- Remove CP4 collision posts and retrofit with the CP5 collision posts

- Record strains for the LC5 load case

- If the collision posts pass the LC5 requirement, test the CP5 limit load as per LC11

- Validate FEA results for CP4 and CP5 


\section{References}

1. Federal Railroad Administration, “Improving Railroad Safety and Rail Passenger Technology through Targeted Research and Demonstrations 1992-1997," Technical Report, DOT/FRA/ORD-99/02, August 1999: Washington, DC.

2. Maryville, R. A., Stringfellow, R. G., Rancatore, R. J., and Hosmer, T. P., "Locomotive Crashworthiness Research Volume 5: Cab Car Crashworthiness Report, Technical Report DOT/FRA/ORD-95/08.5, Federal Railroad Administration, March 1996.

3. Federal Railroad Administration, "Locomotive Crashworthiness Research: Executive Summary," Technical Report, DOT/FRA/ORD-95/08, July 1995: Washington, DC.

4. Bureau of Transportation Statistics, “Table 1-32: Class-I Railroad Locomotive Fleet by Year Built (Locomotive Units)," May 2017: United States Department of Transportation.

5. Progressive Railroading, "Rail car and locomotive statistics: Fleet Stats 2015," July 2015: Trade Press Media Group.

6. Association of American Railroads, Railroad Facts 2011 Edition, n.d.

7. RailInc, “The UMLER System," n.d.

8. Bureau of Transportation Statistics, “Table 1-35: U.S. Vehicle-Miles (Millions), May 2017: United States Department of Transportation.

9. Federal Railroad Administration, “Accident Data as reported by Railroads," Rail Equipment Accidents (6180.54) and Highway Rail Accidents (6180.57), n.d: Office of Safety Analysis.

10. ANSYS $^{\circledR}$ Mechanical Enterprise, Release 16.2.

11. Federal Railroad Administration, Maryville, R. A., Stringfellow, R. G., Rancatore, R. J., and Hosmer, T. P., "Locomotive Crashworthiness Research Volume 1: Model Development and Validation," Technical Report, DOT/FRA/ORD-95/08.1, July 1995: Washington, DC. 
Appendix A. CP1 FEA Results

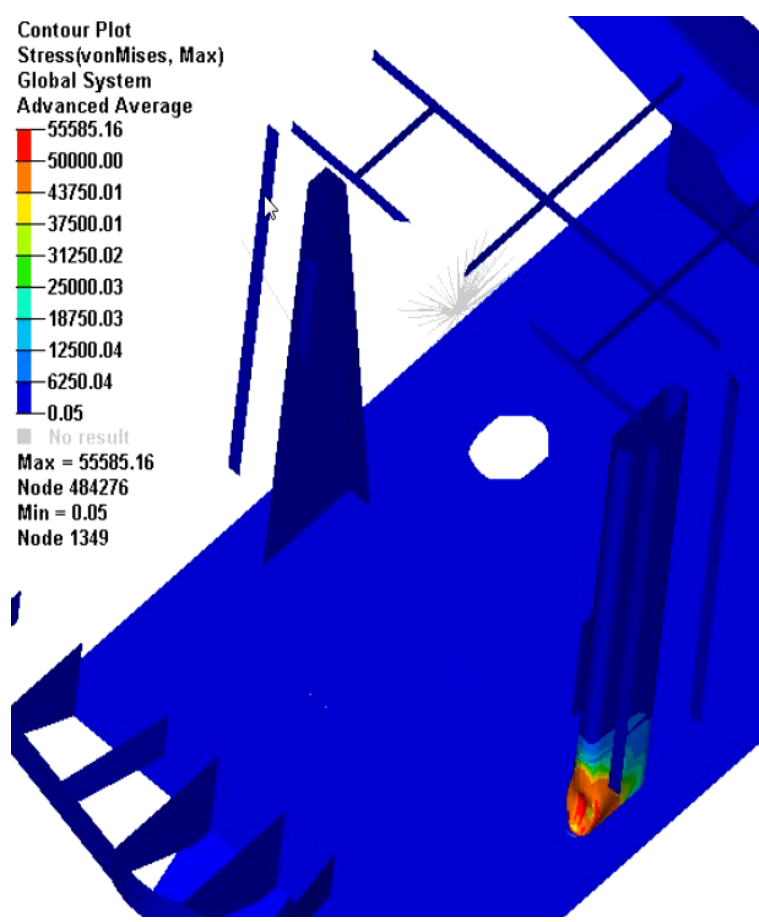

Note: Applied Load 500 kips, $0^{\circ}$ at underframe level CP1 failed at 415 kips $(83 \%$ of specified load)

Figure A-1. CP1 Stress Contour for LC02

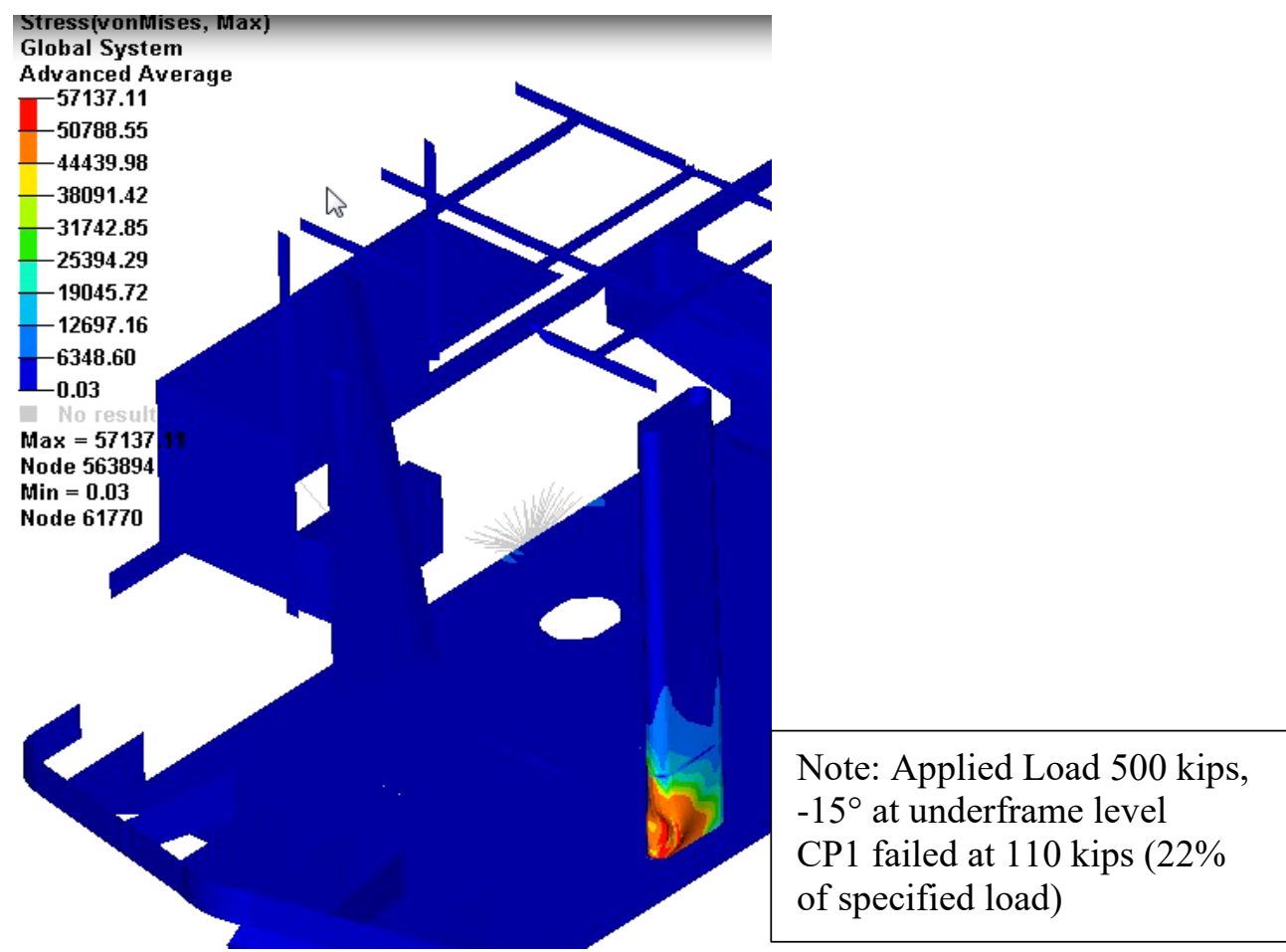

Figure A-2. CPI Stress Contour for LC03 


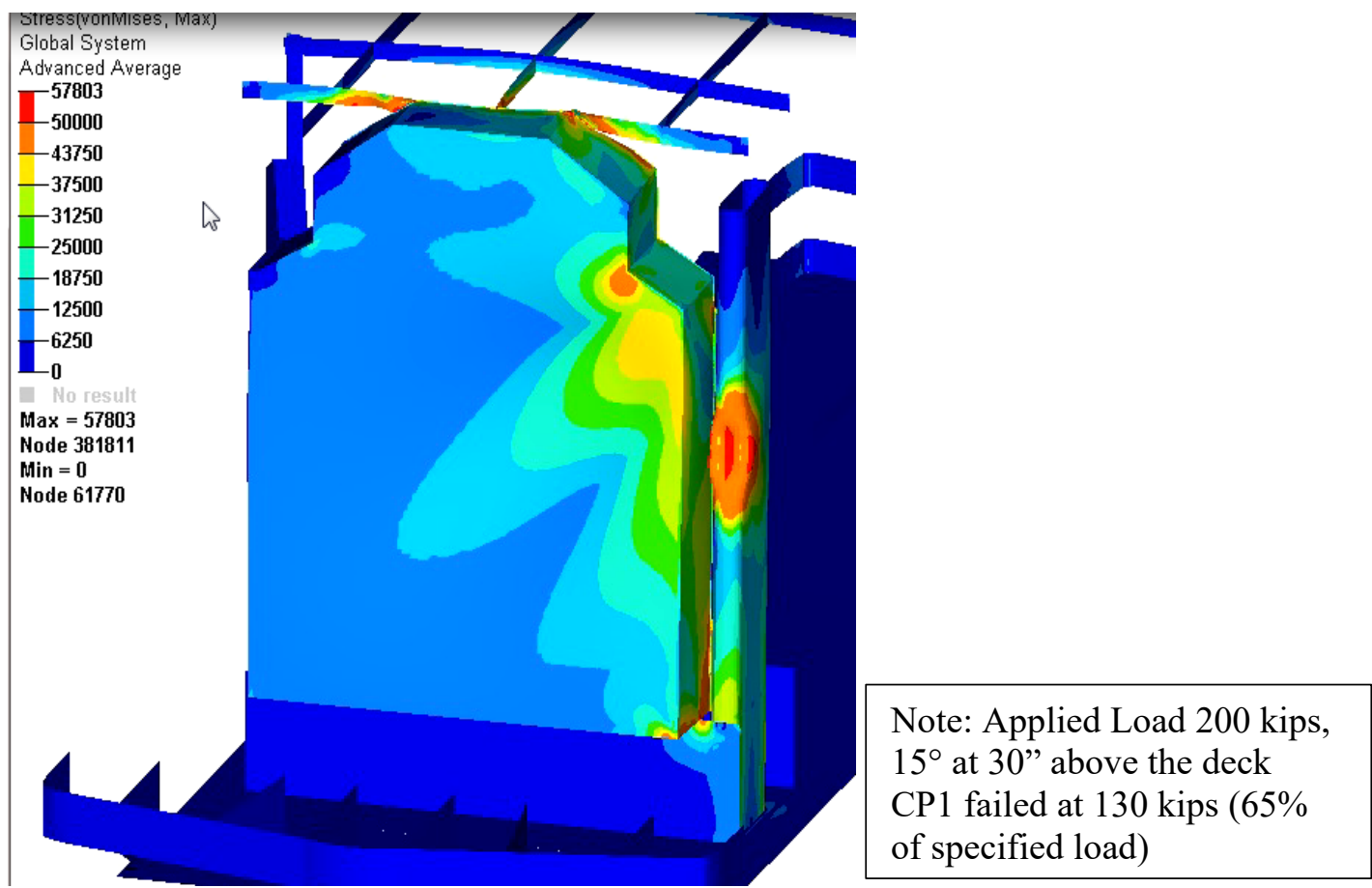

Figure A-3. CP1 Stress Contour for LC04 


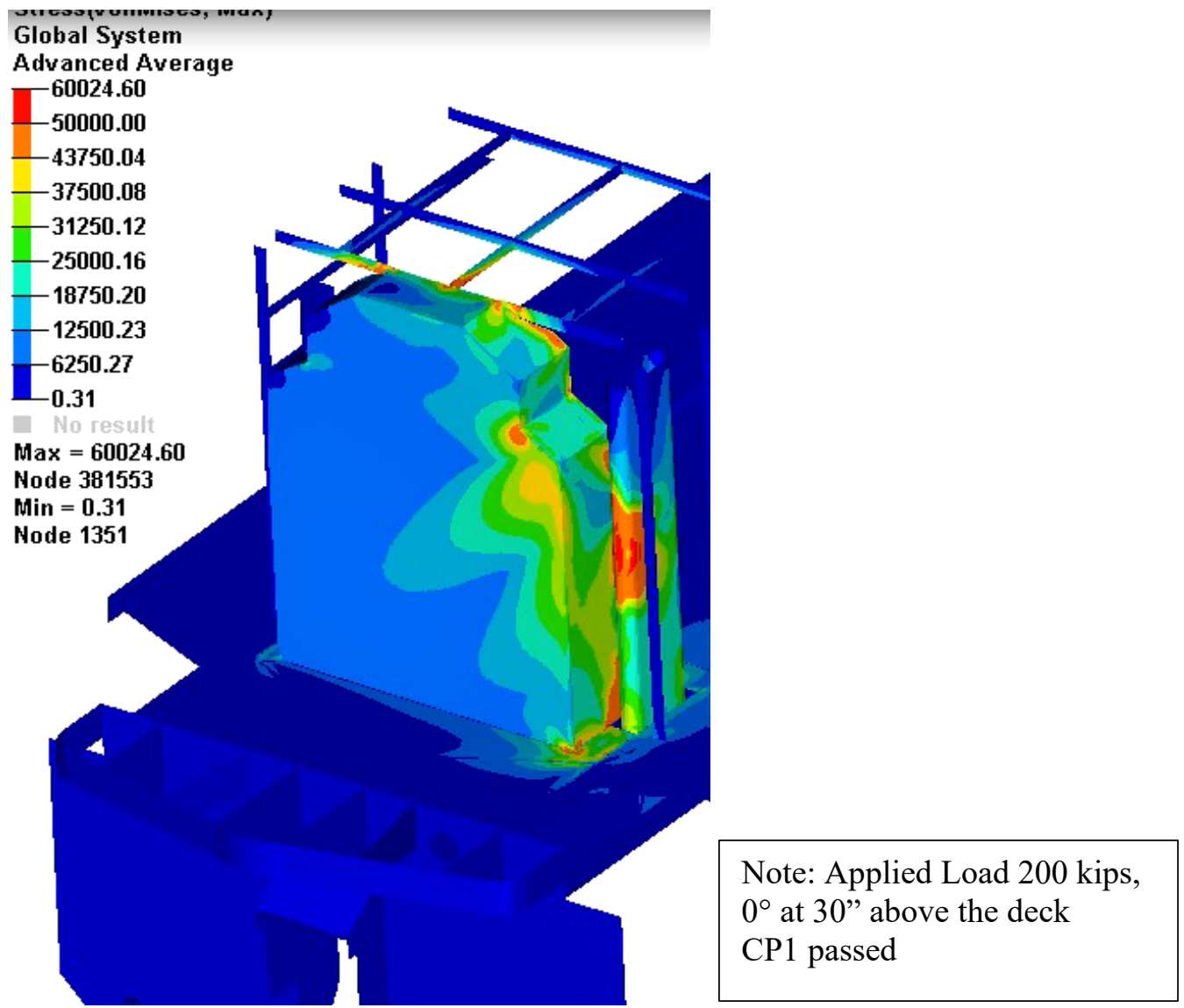

Figure A-4. CP1 Stress Contour for LC05

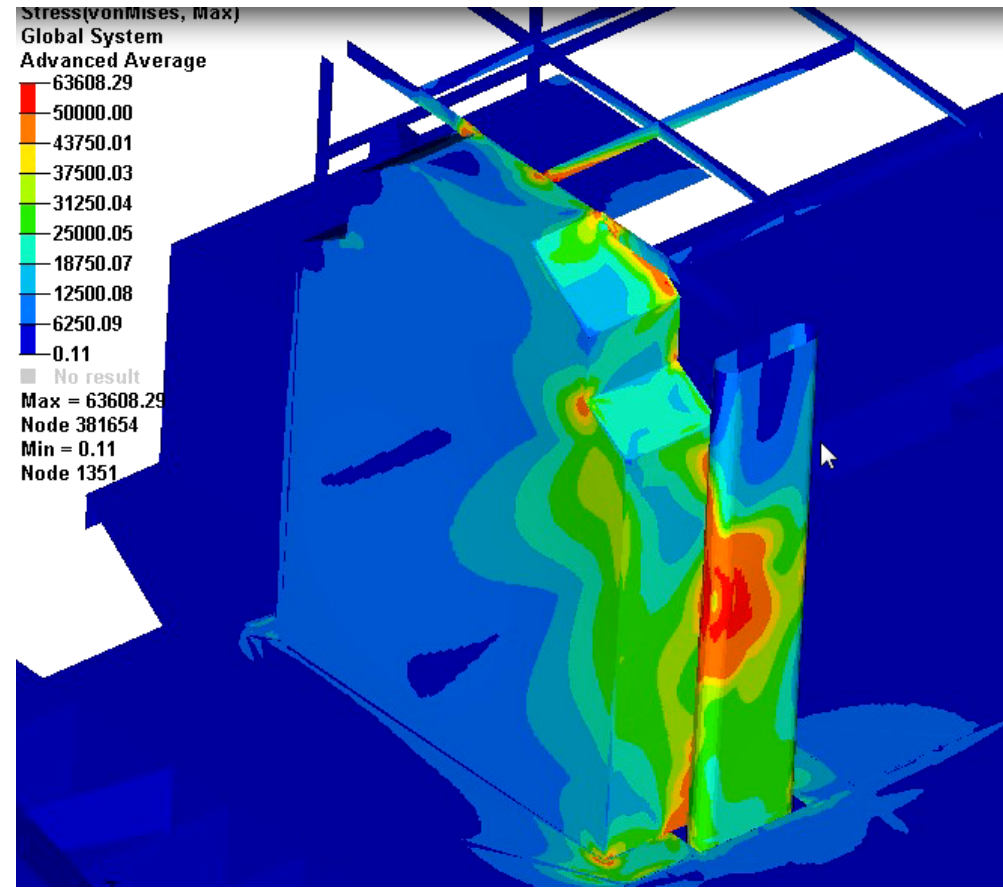

Note: Applied Load 200 kips, $-15^{\circ}$ at $30 "$ above the deck CP1 failed at 130 kips $(65 \%$ of specified load)

Figure A-5. CP1 Stress Contour for LC06 


\section{Appendix B. CP2 FEA Results}

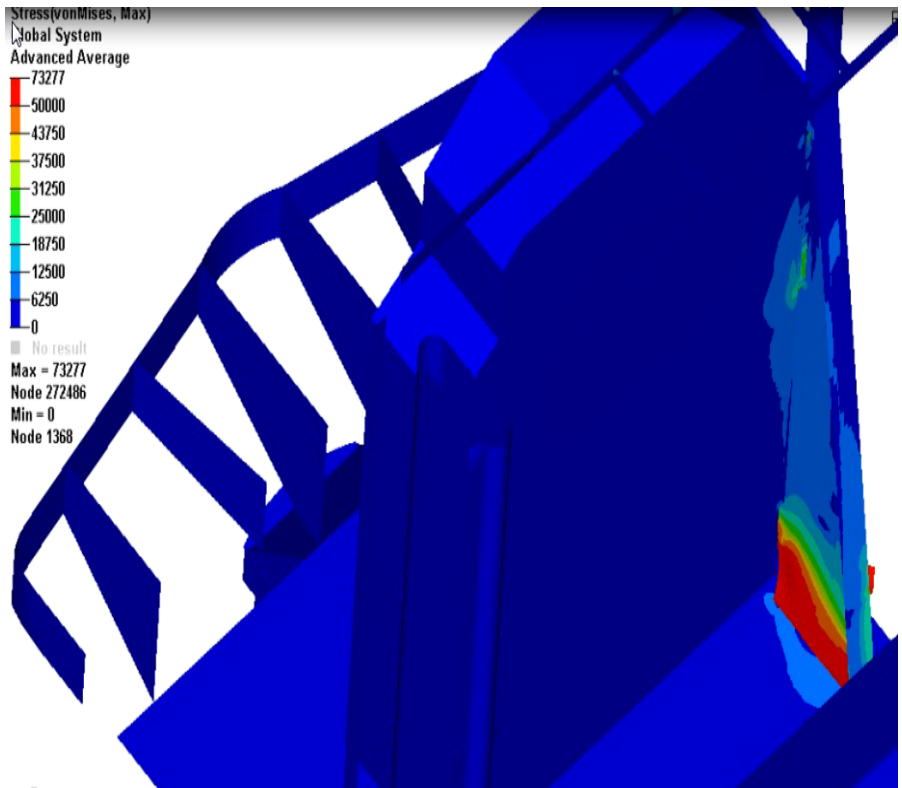

Note: Applied Load 500 kips, $0^{\circ}$ at underframe

CP2 failed at 180 kips (36\% of specified load)

Figure B-1. CP2 Stress Contour for LC02

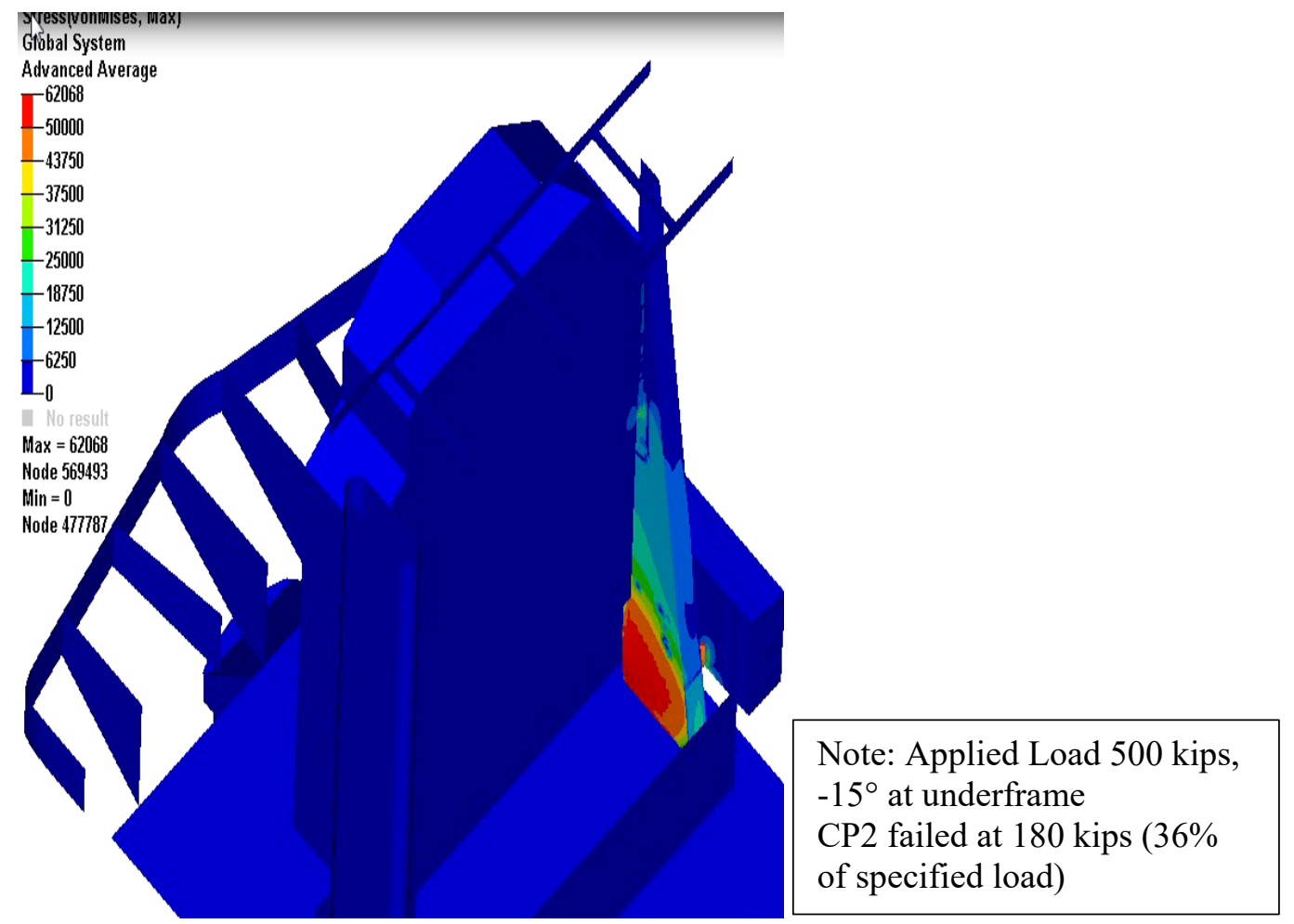

Figure B-2. CP2 Stress Contour for LC03 


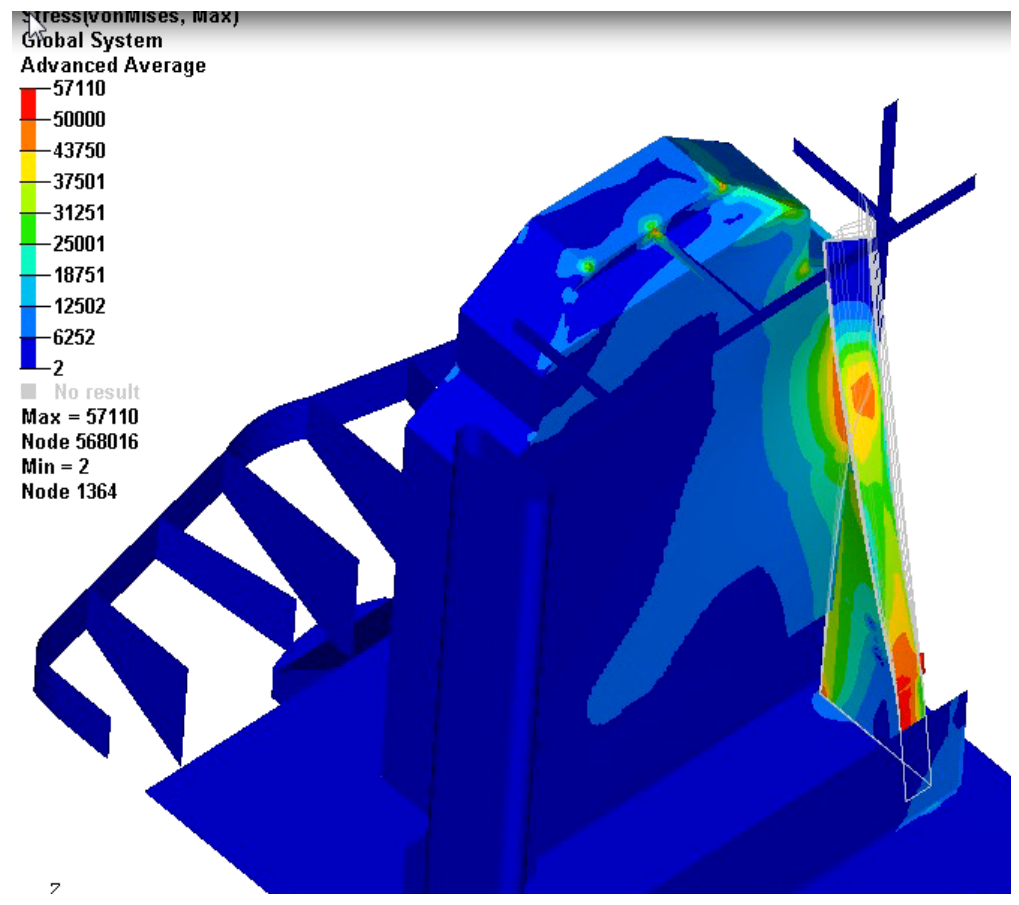

Note: Applied Load 200 kips, $15^{\circ}$ at $30^{\prime \prime}$ above the deck CP2 failed at 180 kips $(90 \%$ of specified load)

Figure B-3. CP2 Stress Contour for LC04

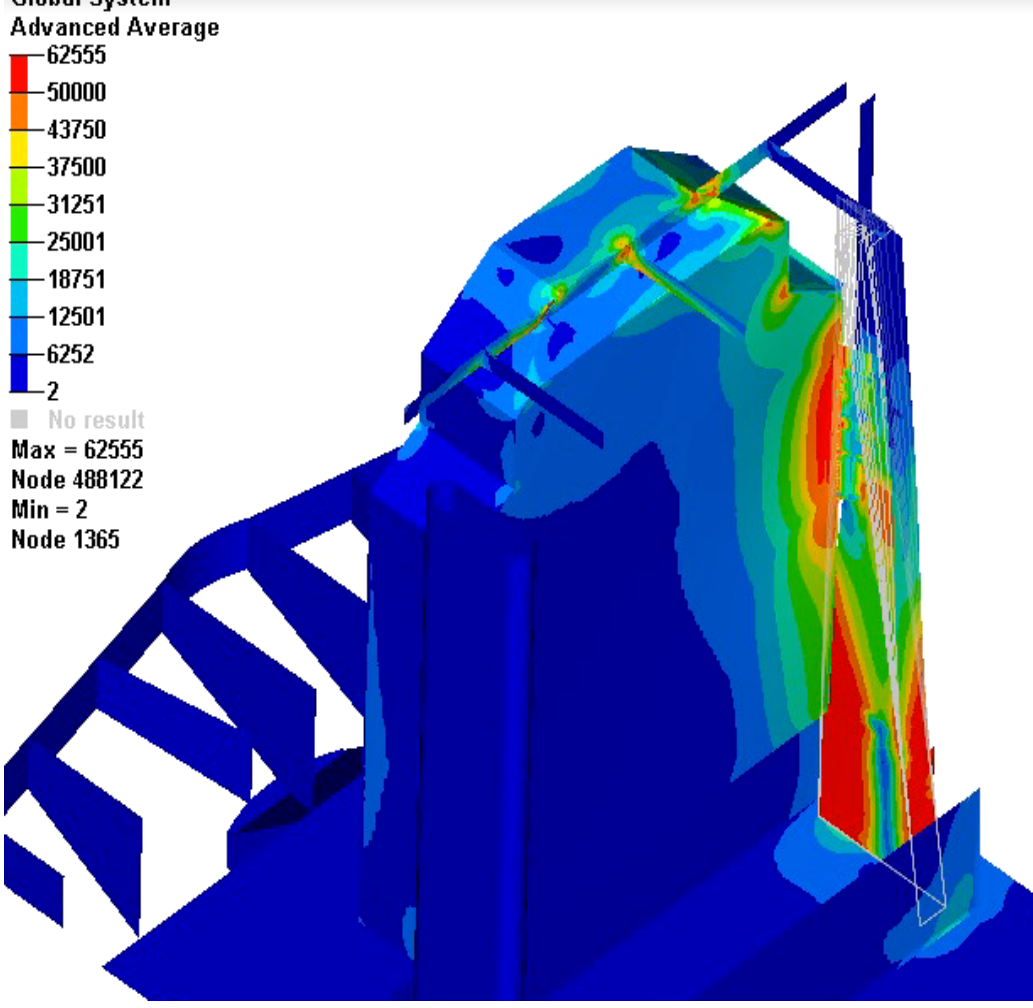

Note: Applied Load 200 kips, $0^{\circ}$ at $30 "$ above the deck CP2 failed at 180 kips $(85 \%$ of specified load)

Figure B-4. CP2 Stress Contour for LC05 


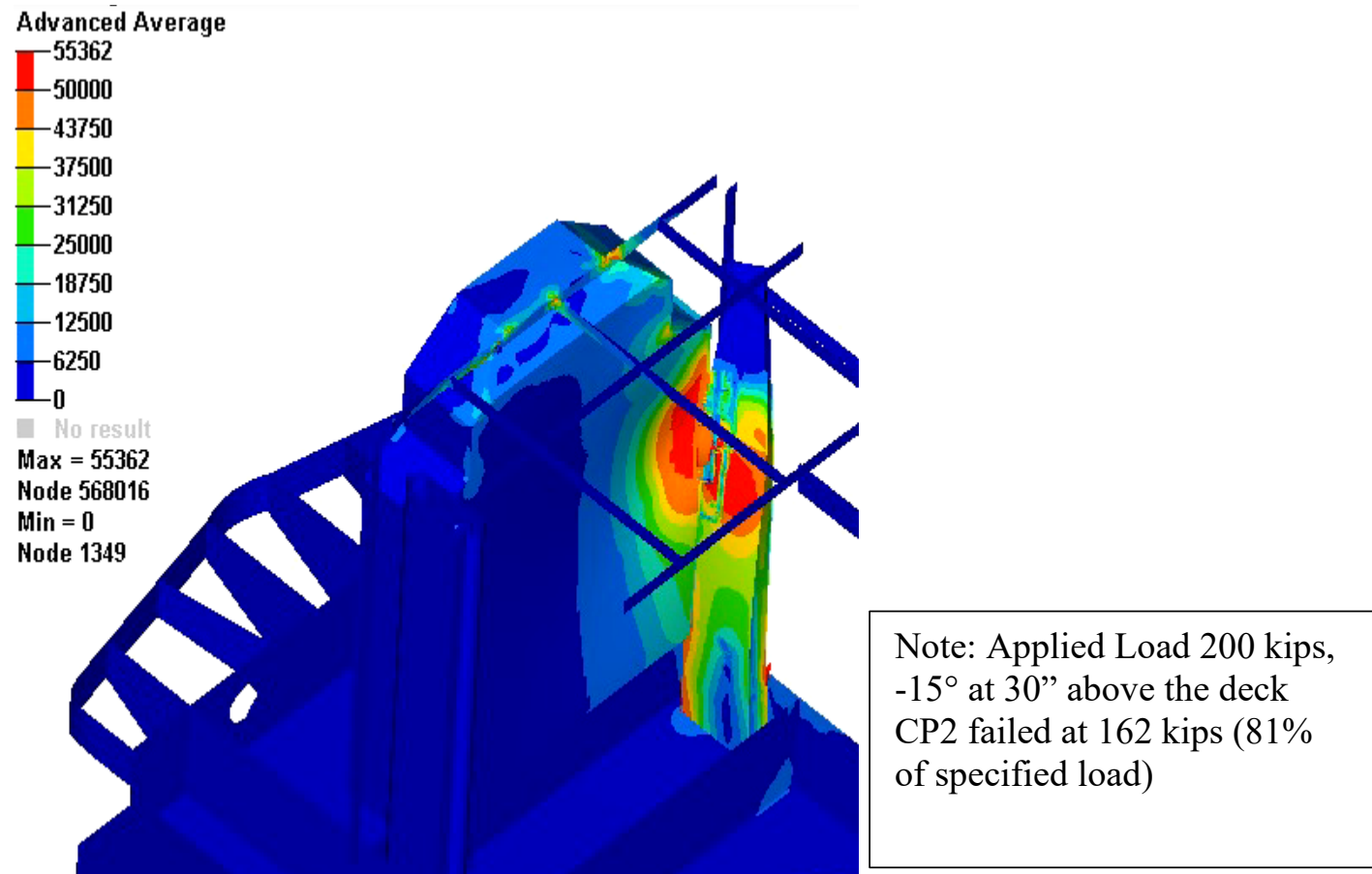

Figure B-5. CP2 Stress Contour for LC06 


\section{Appendix C. CP3 FEA Results}

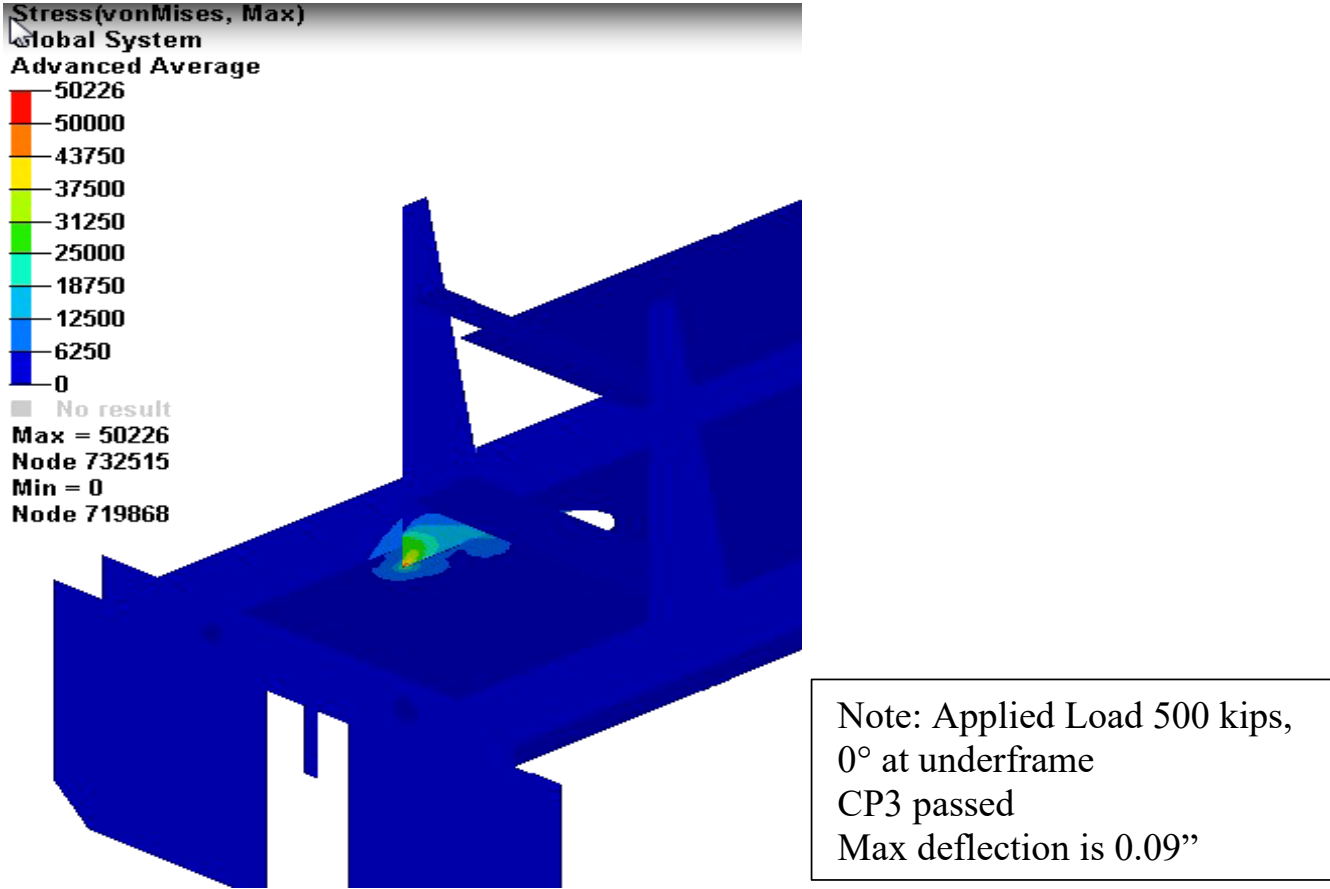

Figure C-1. CP3 Stress Contour for LC02

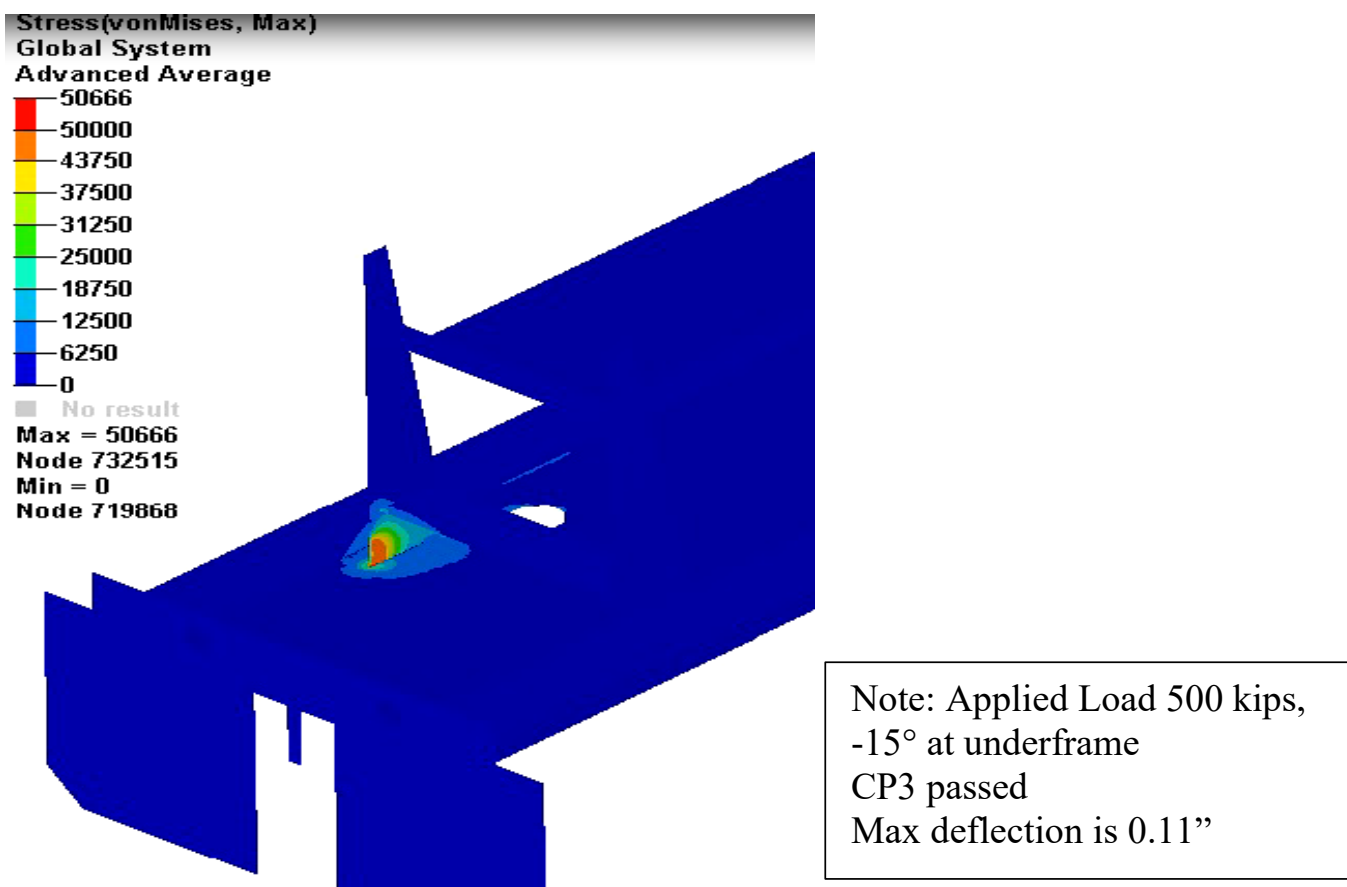

Figure C-2.CP3 Stress Contour for LC03 


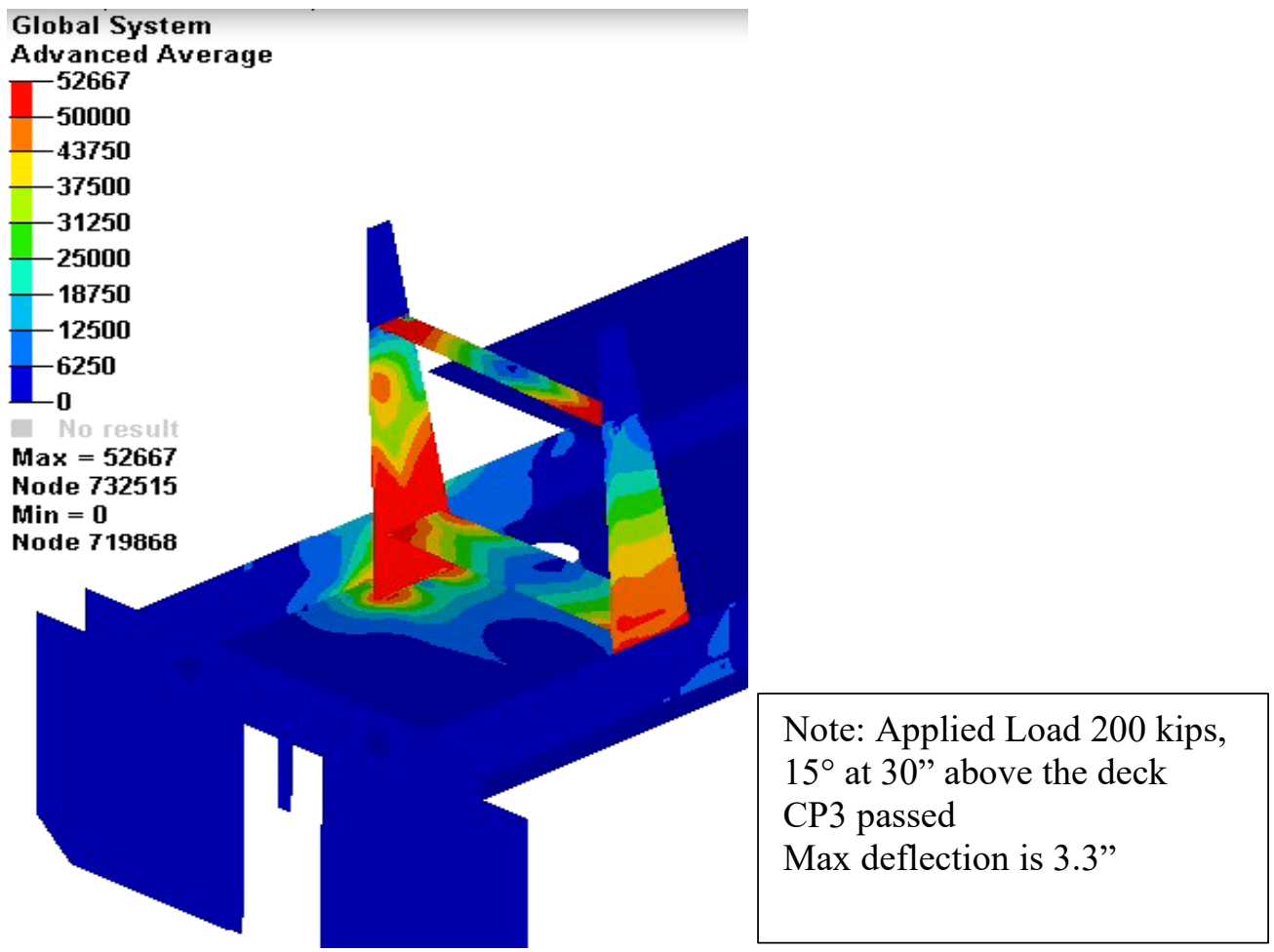

Figure C-3. CP3 Stress Contour for LC04

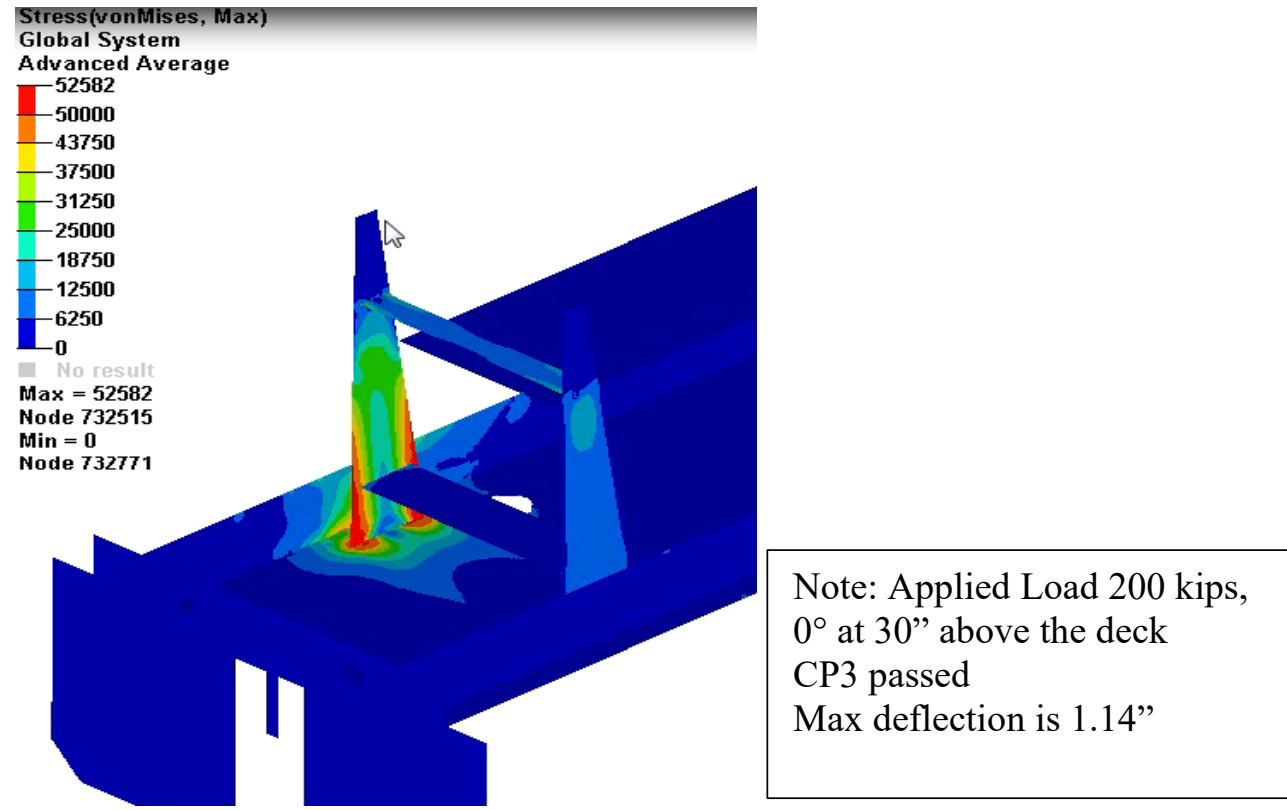

Figure C-4. CP3 Stress Contour for LC05 


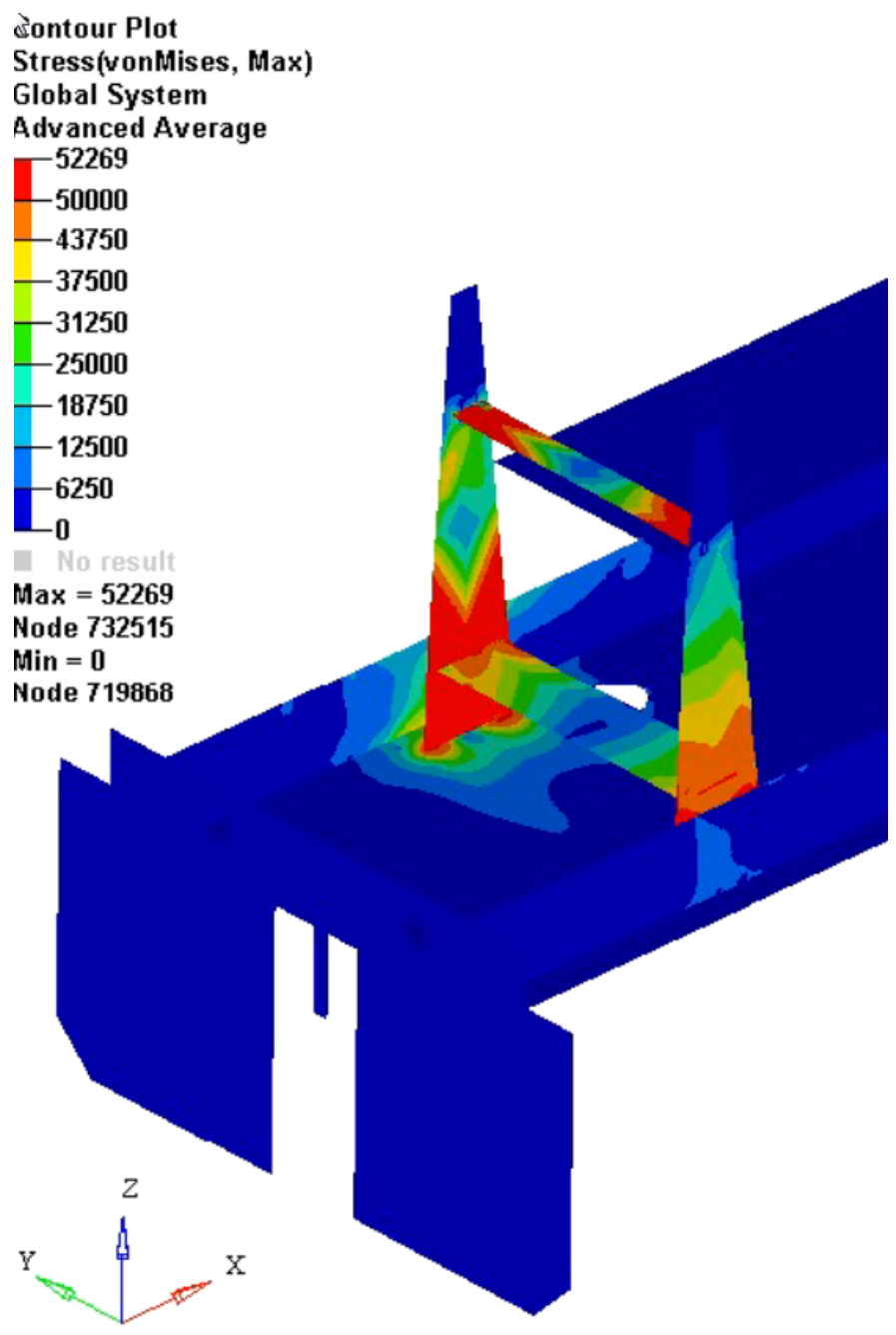

Note: Applied Load 200 kips, $-15^{\circ}$ at $30^{\prime \prime}$ above the deck $\mathrm{CP} 3$ passed Max deflection is 3.12"

Figure C-5. CP3 Stress Contour for LC06 


\section{Appendix D. CP4 FEA Results}

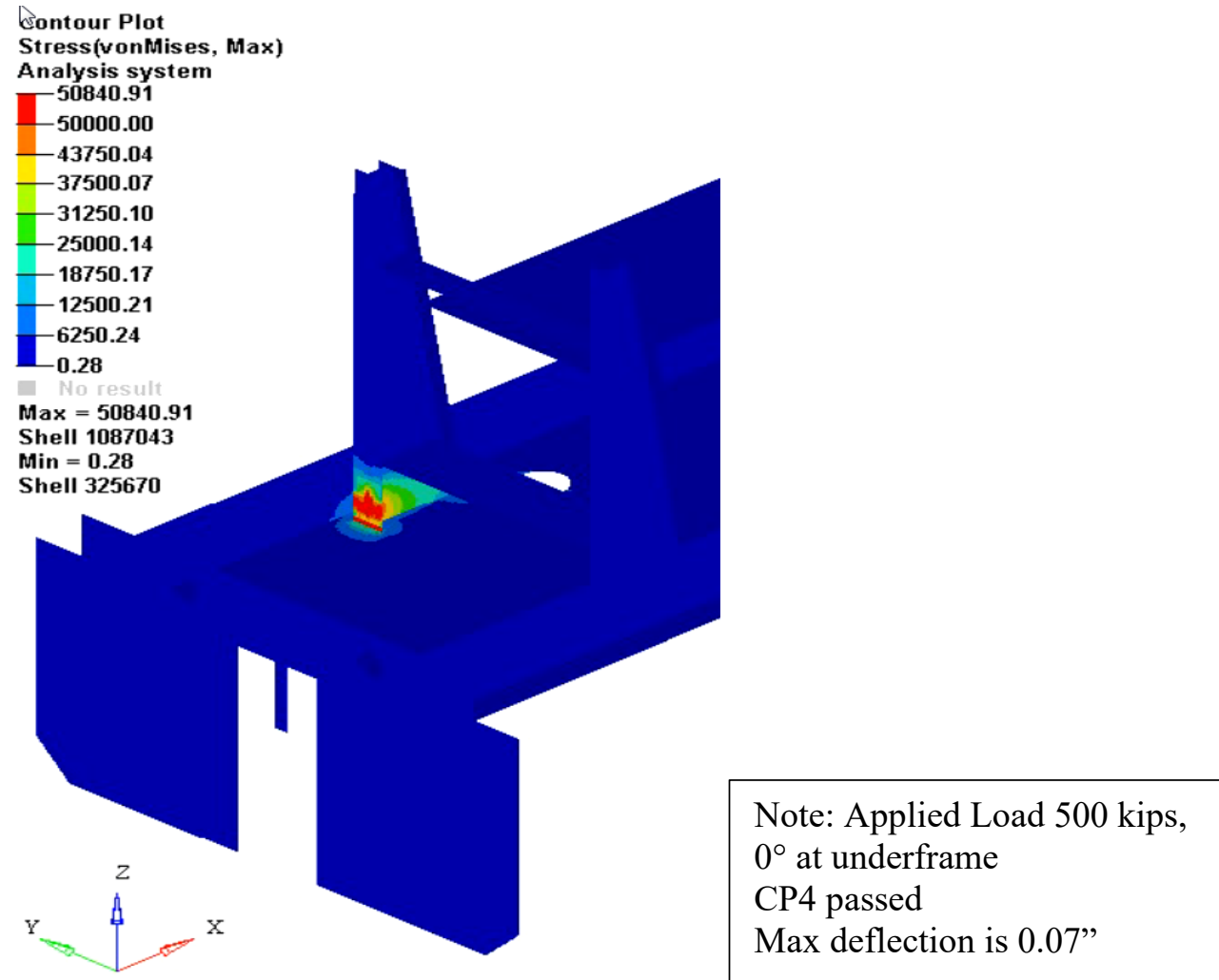

Figure D-1. CP4 Stress Contour for LC02 


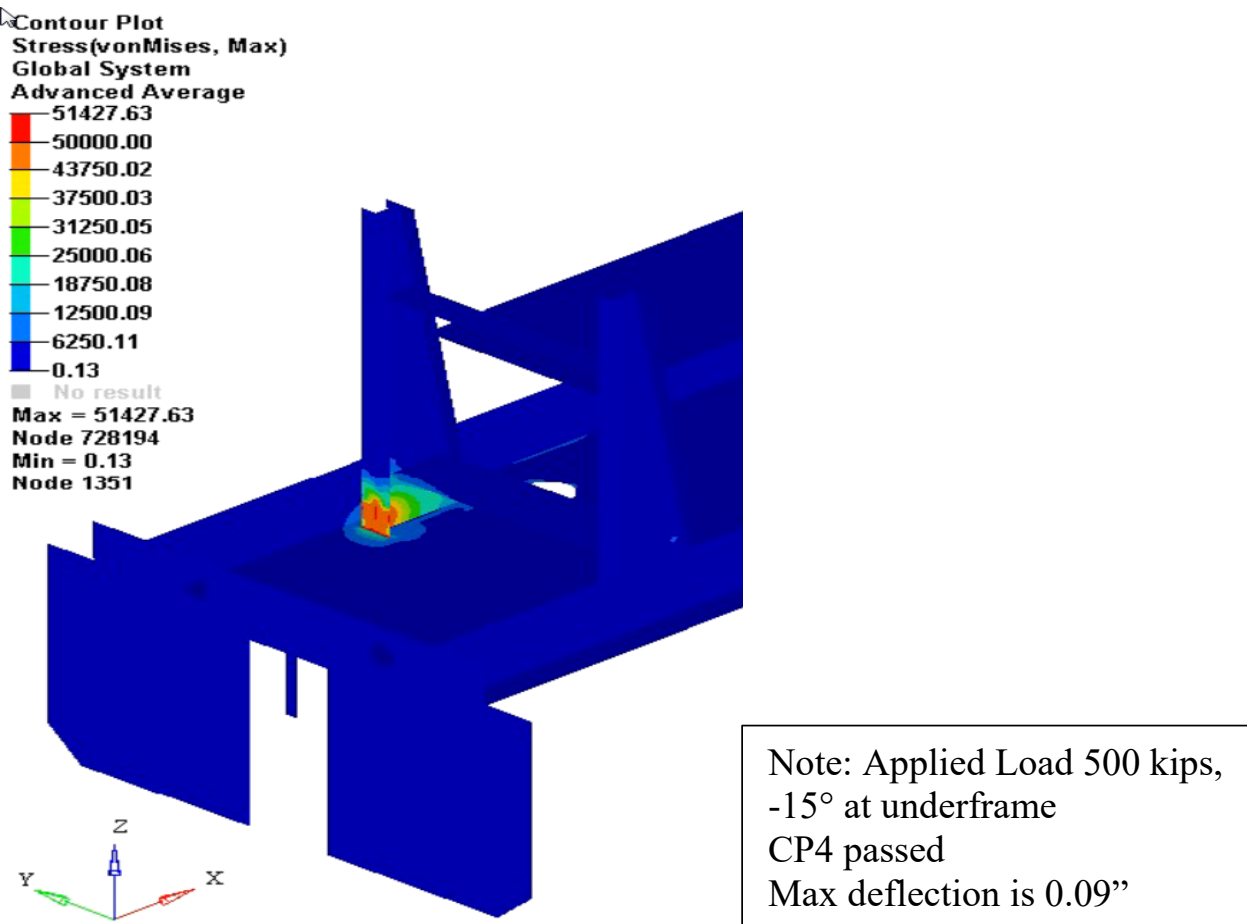

Figure D-2. CP4 Stress Contour for LC03

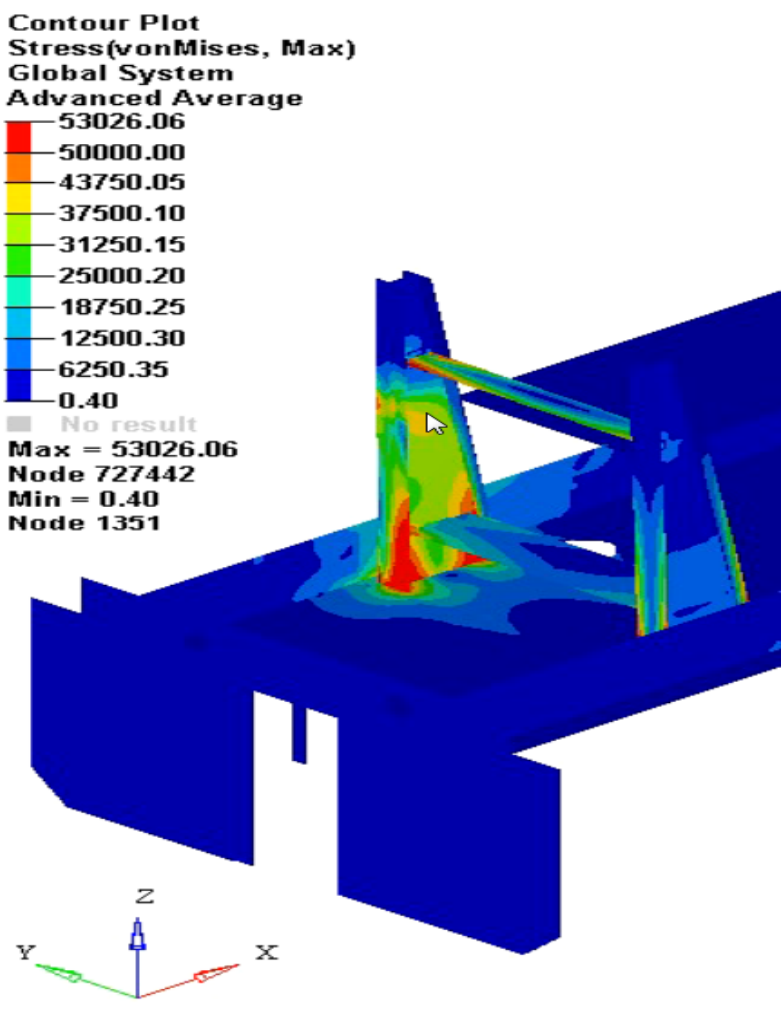

Note: Applied Load 200 kips, $15^{\circ}$ at $30^{\prime \prime}$ above the deck $\mathrm{CP} 4$ passed Max deflection is 1.92"

Figure D-3. CP4 Stress Contour for LC04 


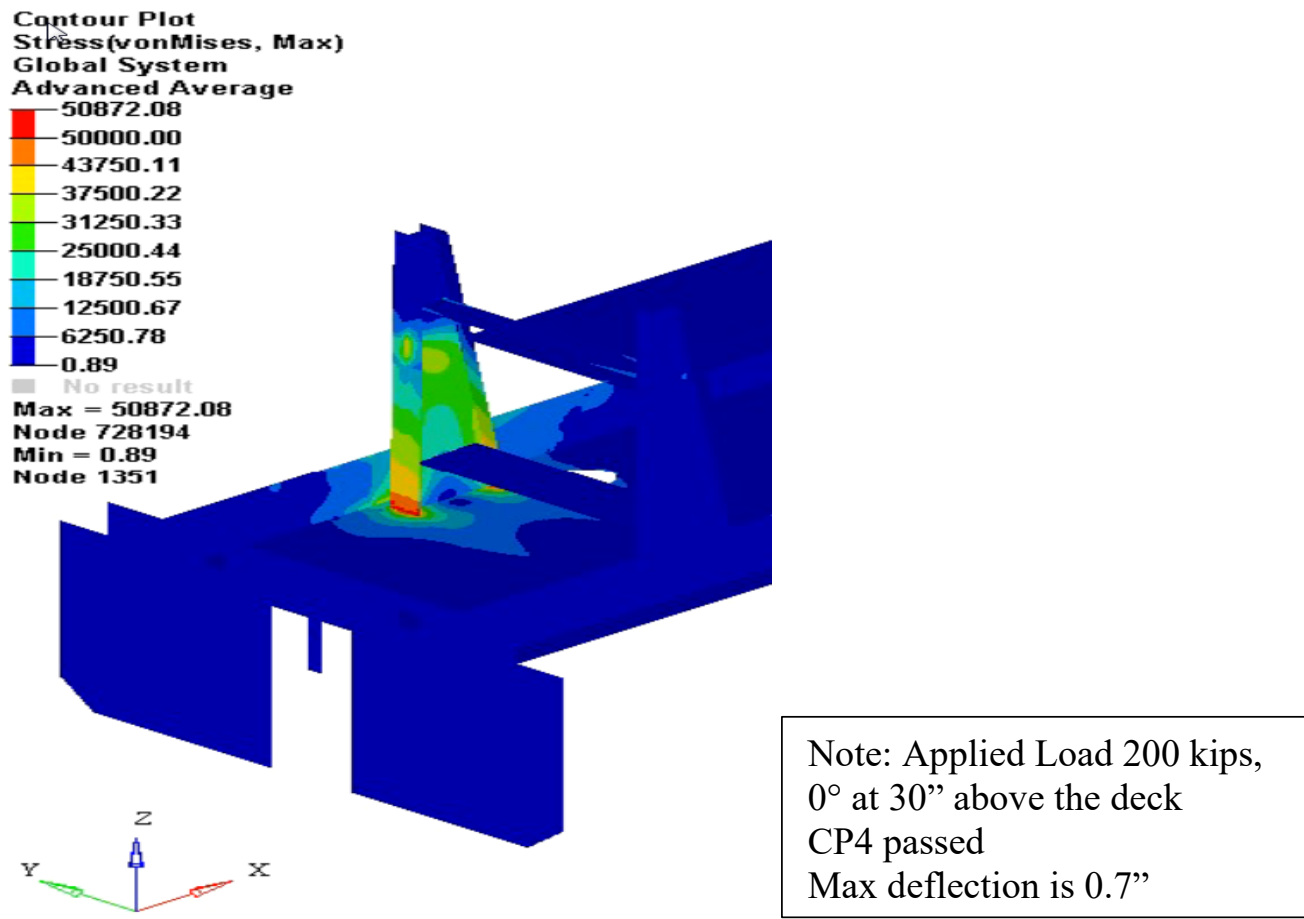

Figure D-4. CP4 Stress Contour for LC05

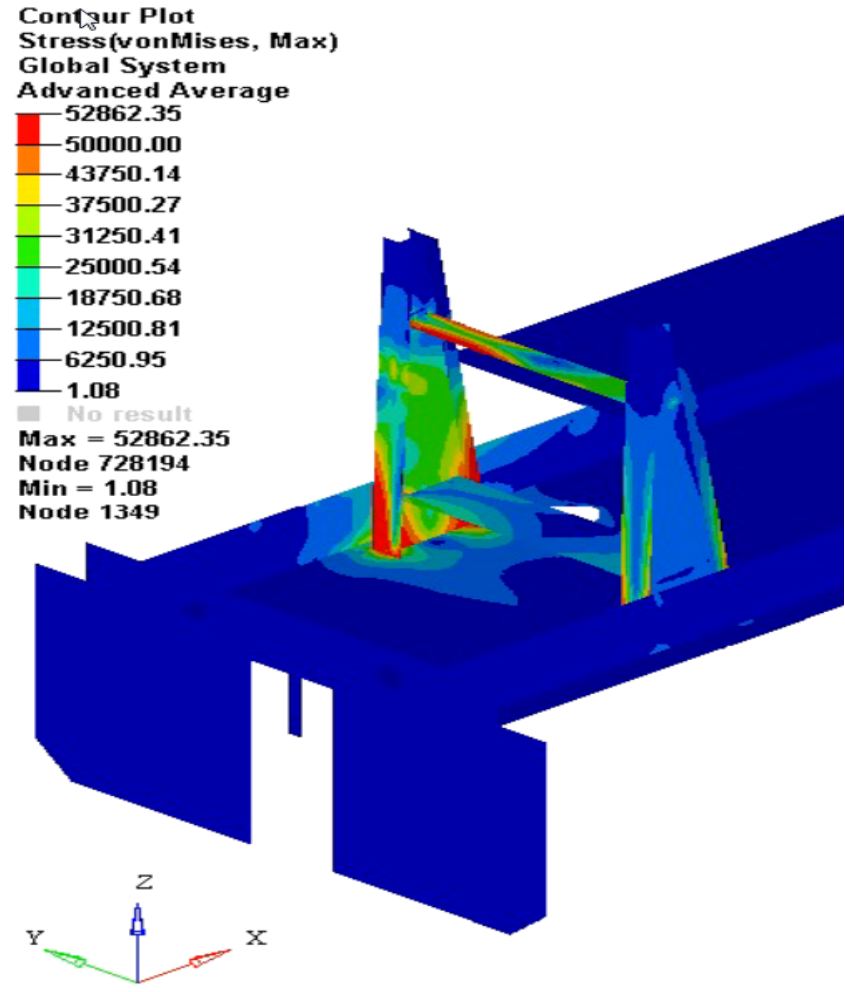

Figure D-5. CP4 Stress Contour for LC06
Note: Applied Load 200 kips, $-15^{\circ}$ at $30^{\prime \prime}$ above the deck CP4 passed Max deflection is 1.83 " 


\section{Appendix E.}

\section{CP5 FEA Results}

Contour Plot

Stress(vonMises, Max)

Global System

Advanced Average

50844

$-50000$

$-43750$

$-37500$

$-31250$

$-25000$

$-18750$

$-12500$

$-6250$

- 0

$\operatorname{Max}=\mathbf{5 0 8 4 4}$

Node 727442

Min = 0

Node 1351

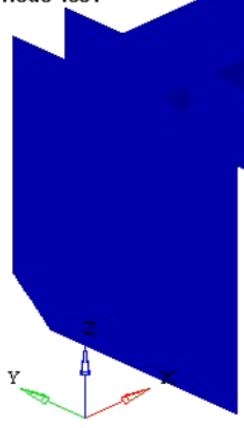

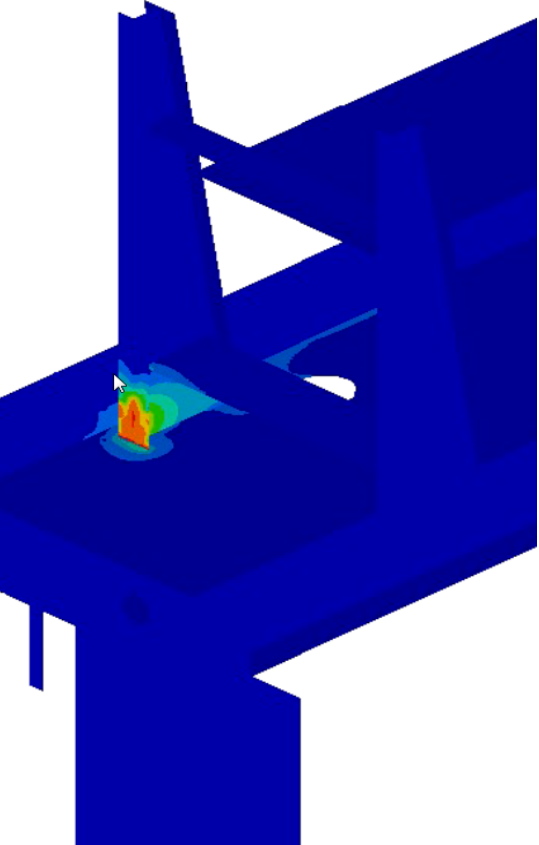

Note: Applied Load 500 kips, $15^{\circ}$ at underframe

CP5 passed

Max deflection is 0.09 "

Figure E-1. CP5 Stress Contour for LC1 


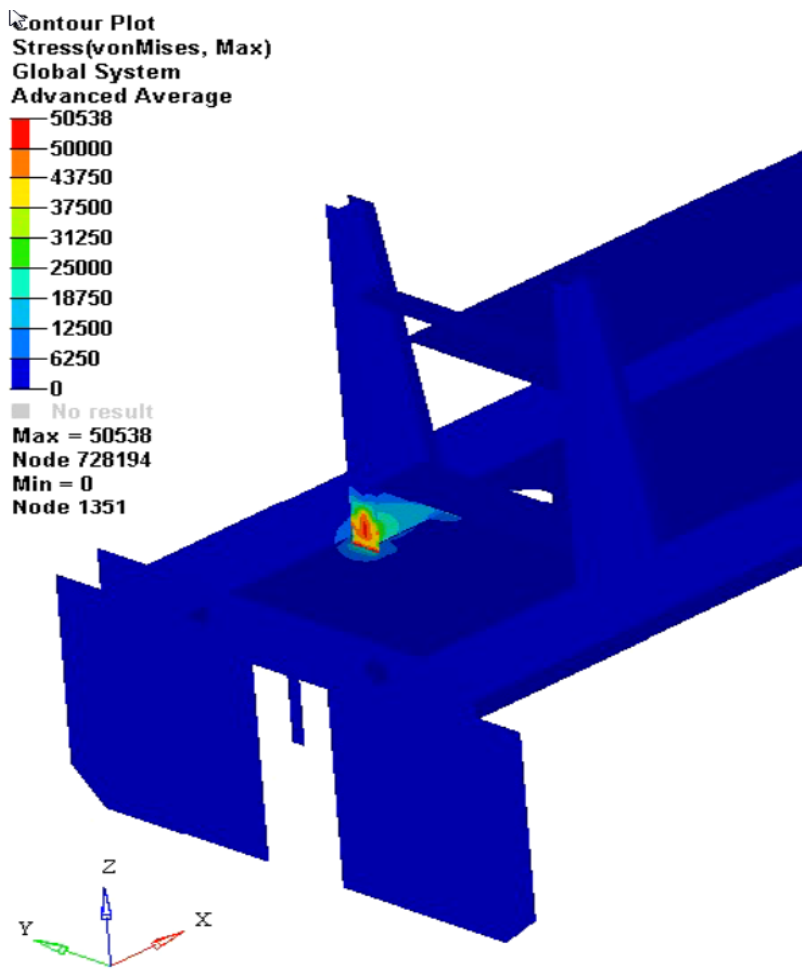

Stress(vonMises, Max)

Alval System

Note: Applied Load 500 kips, $0^{\circ}$ at underframe

CP5 passed

Max deflection is 0.06 "

Figure E-2. CP5 Stress Contour for LC2

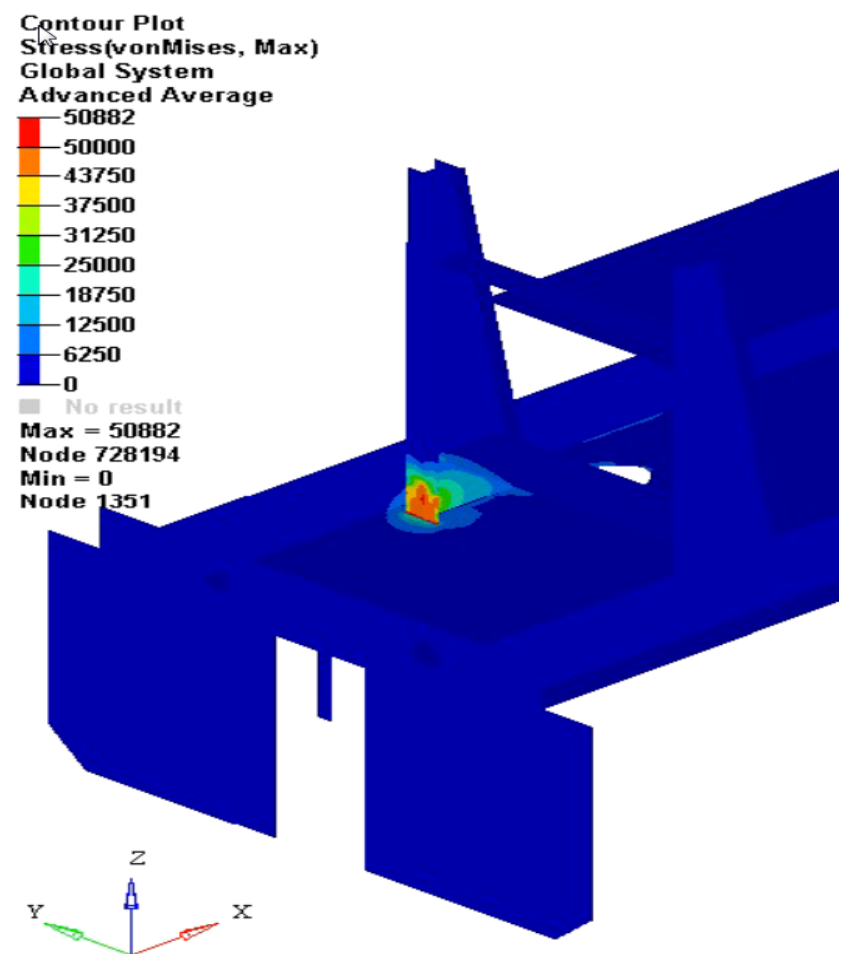

Figure E-3. CP5 Stress Contour for LC3
Note: Applied Load 500 kips, $-15^{\circ}$ at underframe CP5 passed Max deflection is 0.08 " 


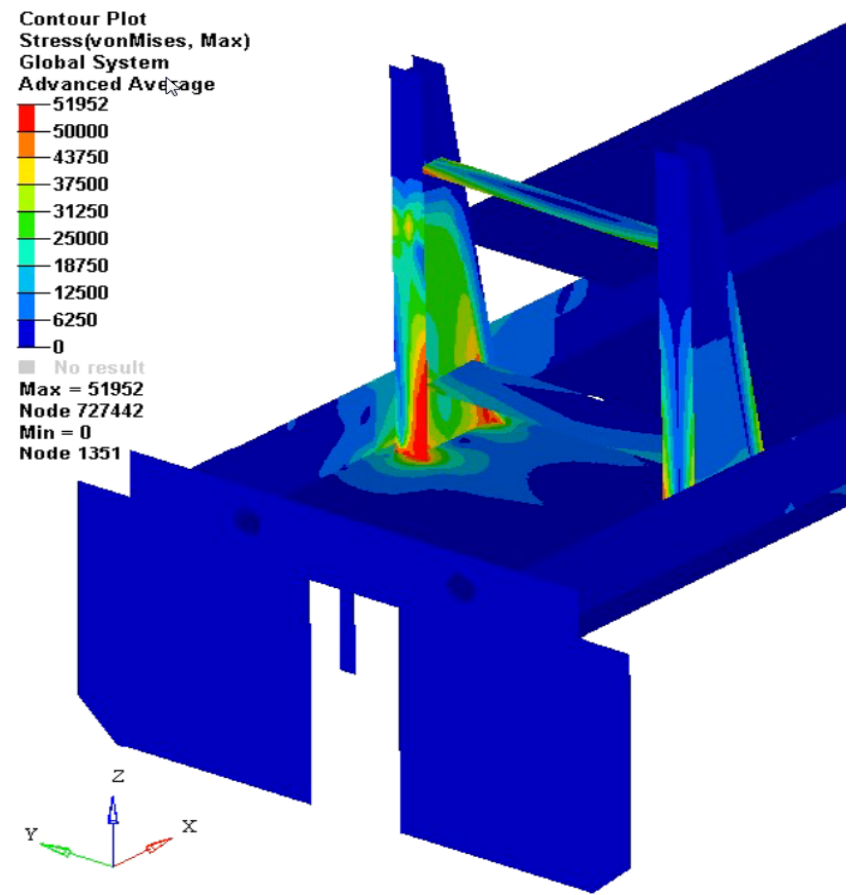

Stress(vonMis

Global System

Advanced Avéage

Figure E-4. CP5 Stress Contour for LC4

Contour Plot

Stress(vonMises, Max)

Global System

Advanced Average

$-50792$

-50000

$-43750$

$-37500$

$-31250$

$-25000$

$-18750$

$-12500$

$-6250$

$-\mathbf{0}$

$\operatorname{Max}=50792$

Max 728792

Node 72819

$\operatorname{Min}=0$

Node 1351
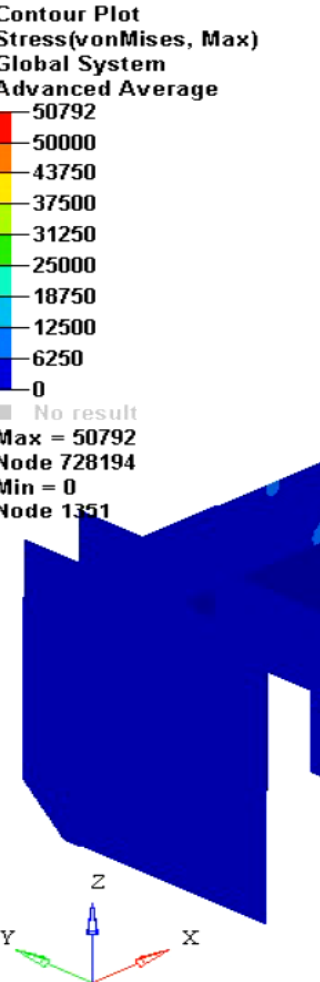

Note: Applied Load 200 kips, $15^{\circ}$ at $30^{\prime \prime}$ above the deck CP5 passed

Max deflection is 1.37 " 


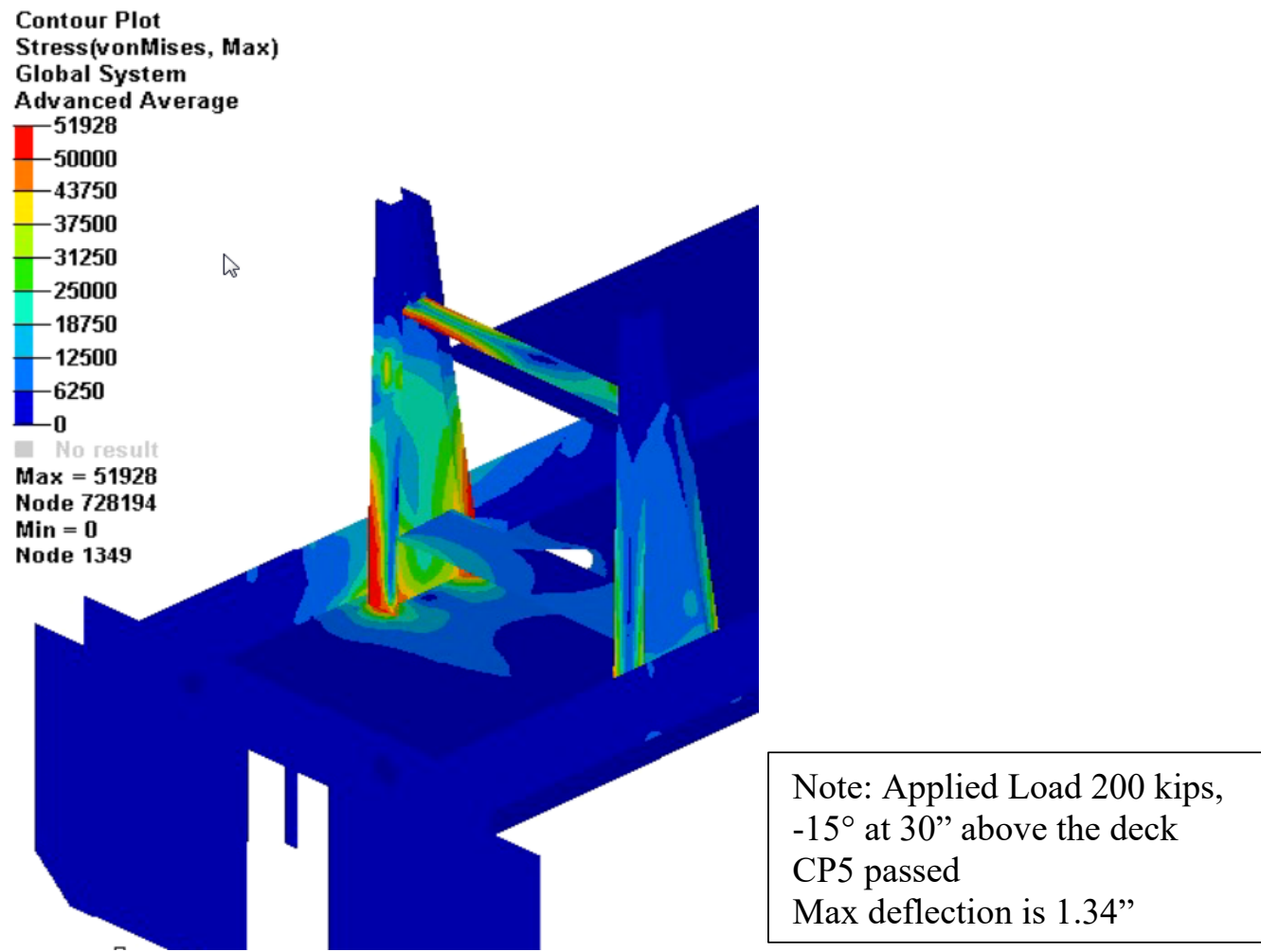

Figure E-6. CP5 Stress Contour for LC6

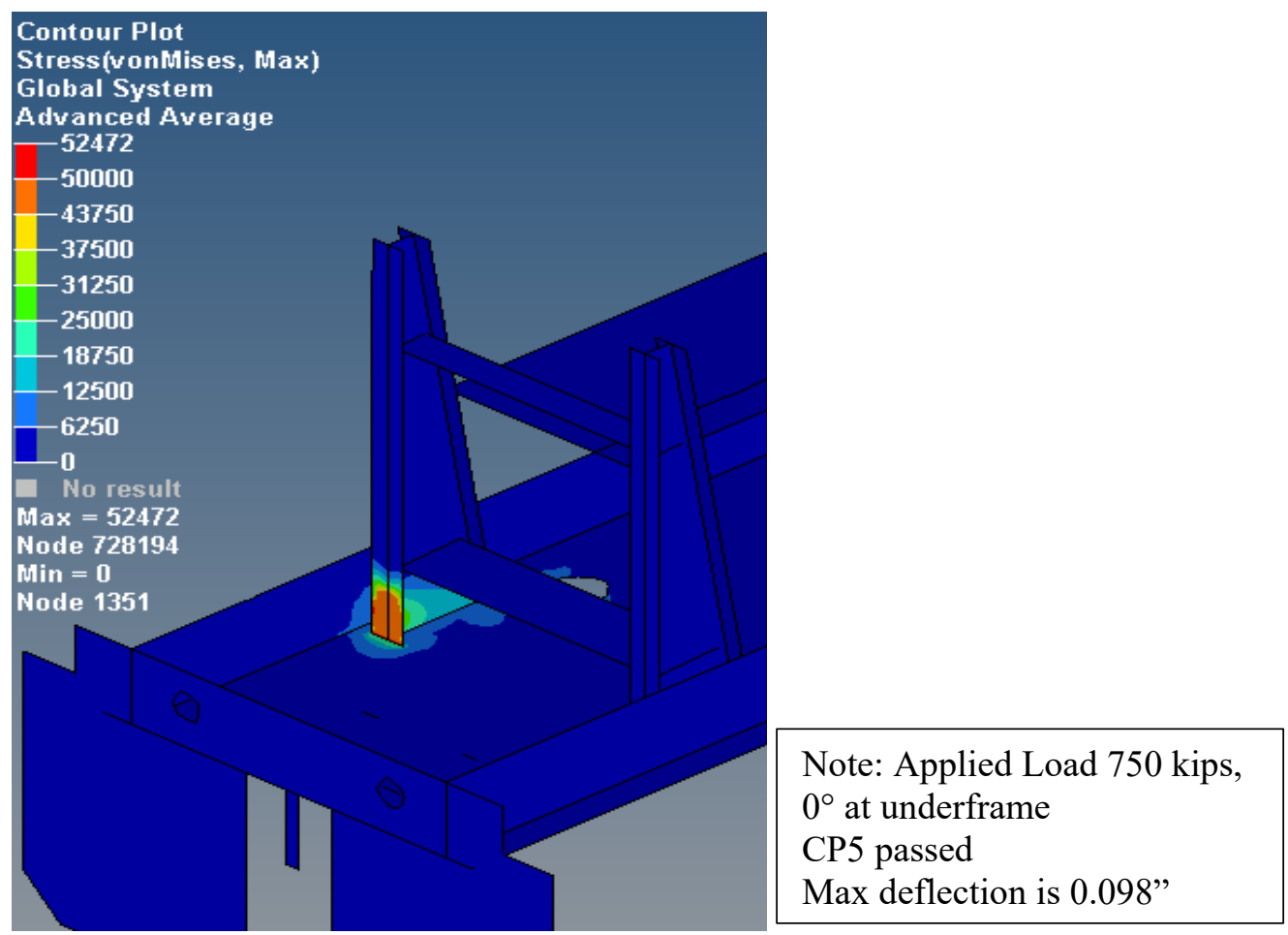

Figure E-7. CP5 Stress Contour for LC8 


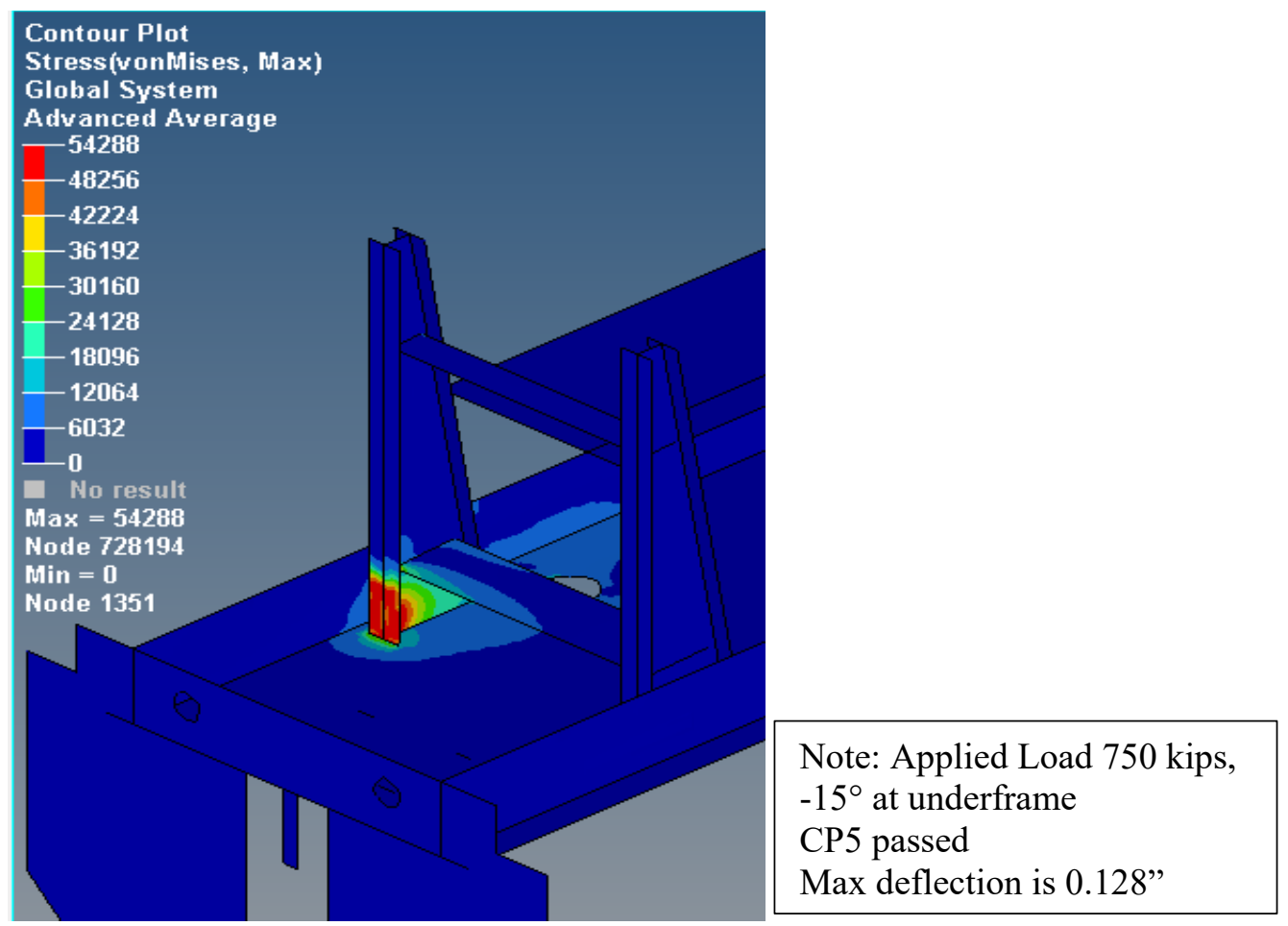

Figure E-8. CP5 Stress Contour for LC9

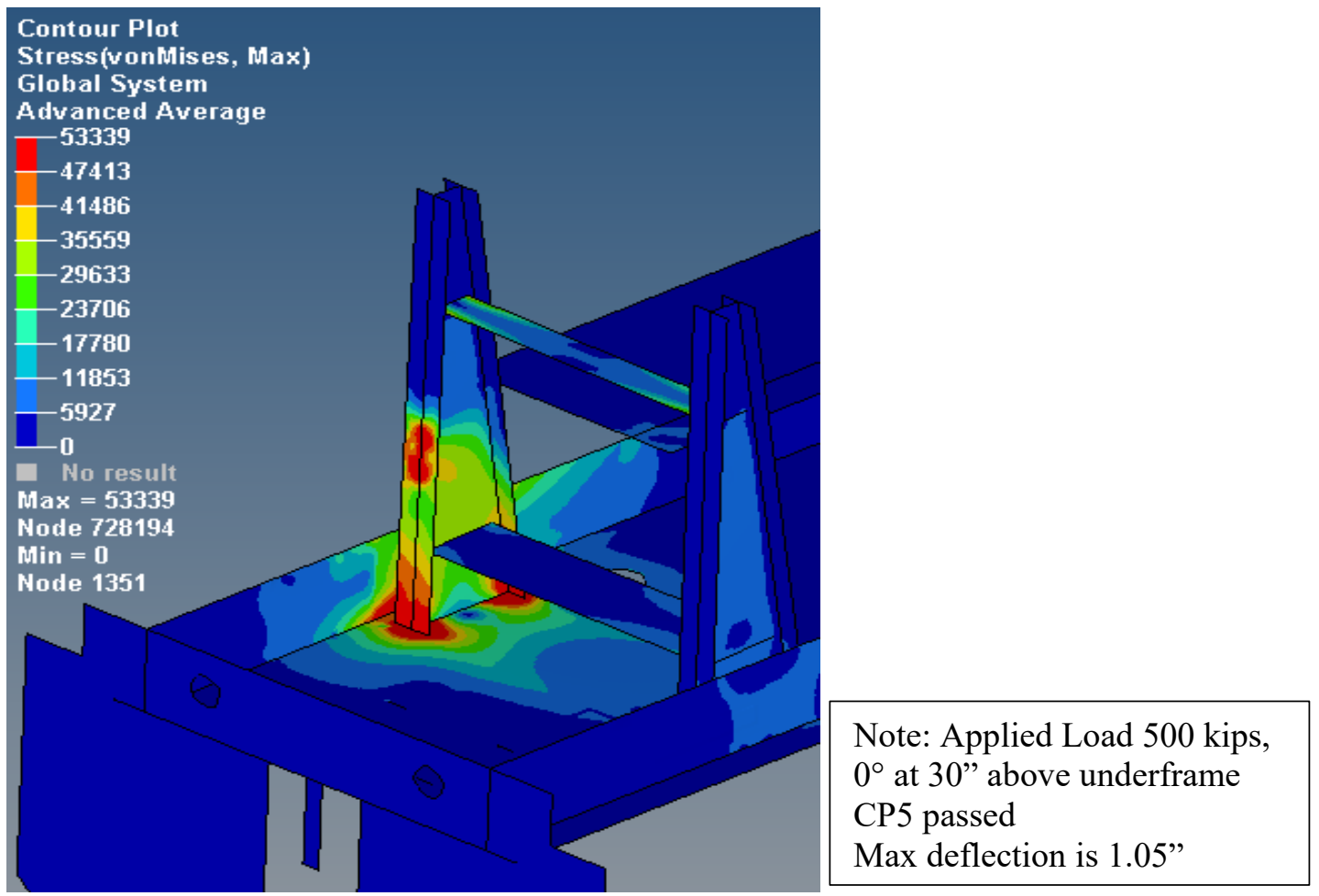

Figure E-9. CP5 Stress Contour for L11 


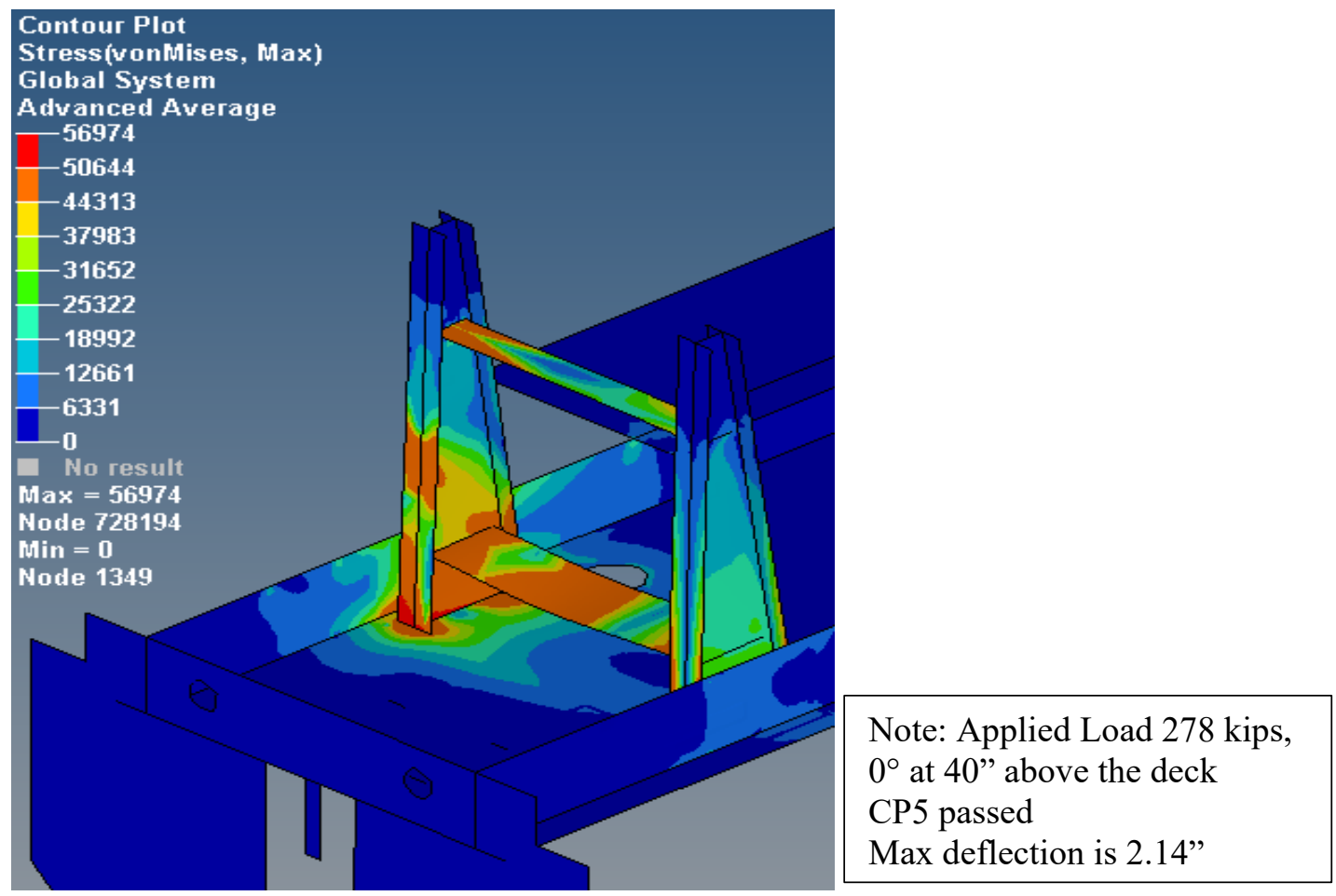

Figure E-10. CP5 Stress Contour for L13 


\section{Abbreviations and Acronyms}

\section{ACRONYMS EXPLANATIONS}

\begin{tabular}{ll}
\hline AAR & Association of American Railroads \\
CFR & Code of Federal Regulations \\
CAD & Computer-Aided Design \\
FRA & Federal Railroad Administration \\
FEA & Finite Element Analysis \\
FEM & Finite Element Method \\
LC & Load Case \\
LCWG & Locomotive Crashworthiness Working Group \\
NTSB & National Transportation Safety Board \\
RSAC & Rail Safety Advisory Committee
\end{tabular}

